Universidad de Lima

Facultad de Comunicación

Carrera de Comunicación

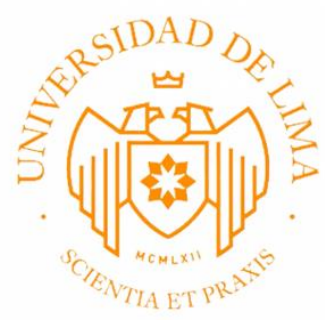

\title{
EXPLORACIÓN DE LAS \\ POTENCIALIDADES DEL RELATO DE CORTA DURACIÓN EN LA SERIE WEB "ROMANCES DE 20 CENTAVOS"
}

Trabajo de Suficiencia Profesional para optar el

Título Profesional de Licenciado en Comunicación

Ana Paula Pareja Mendiola

20140988

\section{Asesor}

Percy Subauste Villanueva

Lima- Perú

Febrero del 2020 


\section{EXPLORACIÓN DE LAS POTENCIALIDADES DEL RELATO DE CORTA DURACIÓN EN LA SERIE WEB "ROMANCES DE 20 CENTAVOS"}




\section{TABLA DE CONTENIDO}

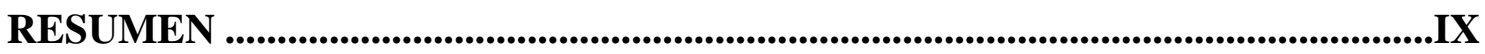

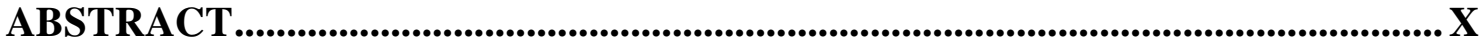

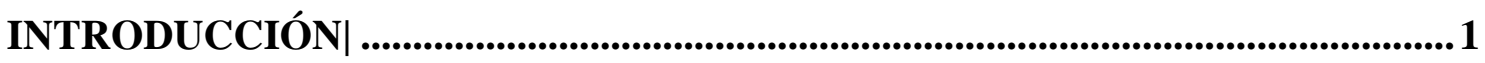

CAPÍTULO 1: ANTECEDENTES DEL TRABAJO ..............................................2

1.1 Definición de conceptos básicos .............................................................. 2

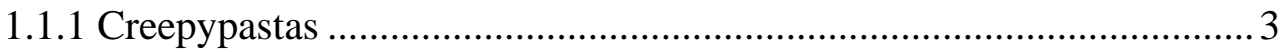

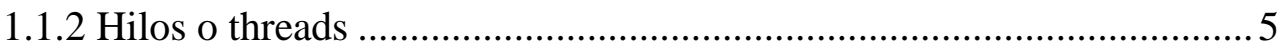

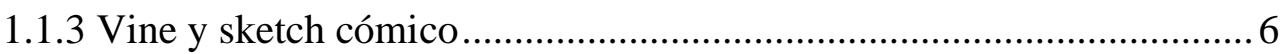

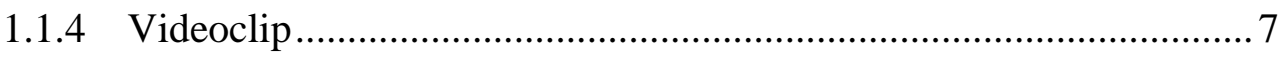

1.2 Análisis de casos similares o referenciales.............................................. 9

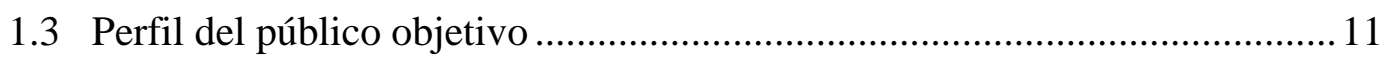

1.3.1 Perfil geográfico..................................................................... 12

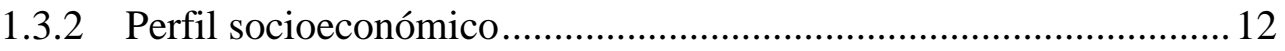

1.3.3 Perfil sociodemográfico …......................................................... 12

1.3.4 1.3.4 Perfil tecnográfico ............................................................ 13

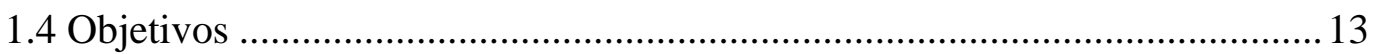

CAPÍTULO 2: REALIZACIÓN Y SUSTENTACIÓN ................................................. 15

2.1 Descripción general del proyecto .............................................................. 15

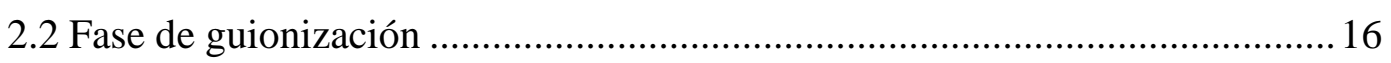

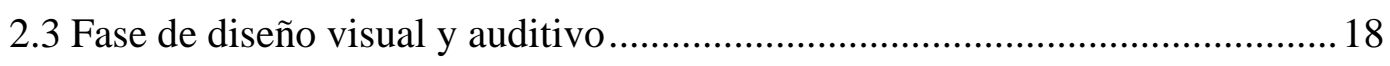

2.3.1 Valeria (primer episodio) .......................................................... 18

2.3.2 Macarena (segundo episodio) ………..............................................29

2.4 Fase de preproducción y realización ................................................................ 33

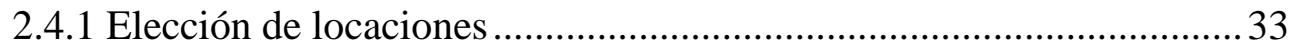

2.4.2 Selección del cast principal ............................................................. 34 
2.4.3 Definición del equipo técnico .34

2.5 Fase de postproducción .35

2.6 Validación con el público objetivo .35

2.6.1 Resultados de la primera sesión .36

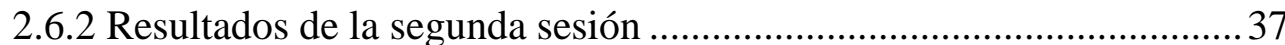

2.7 Diseño de distribución

CAPÍTULO 3: LECCIONES APRENDIDAS ........................................................41

3.1 Preproducción 41

3.2 Grabación 42

3.3 Postproducción .42

3.4 Validación 42

CAPÍTULO 4: LOGROS Y RESULTADOS 44

REFERENCIAS. .45

ANEXOS 47 


\section{ÍNDICE DE FIGURAS}

Figura 2.1 Fotograma de referencia de largometraje "Eternal Sunshine of a Spotless mind" (2004)......

Figura 2.2 Fotograma de referencia de cortometraje "Anima" (2019).

Figura 2.3 Fotograma de referencia de videoclip "I Promise" (2017)

Figura 2.4 Fotograma representativo de planos detalle y POV para establecer subjetividad 20

Figura 2.5 Fotograma representativo de planos subjetivos. 21

Figura 2.6 Fotograma representativo de planos de punto de vista externo..... .22

Figura 2.7 Fotograma representativo de planos con lentes angulares .22

Figura 2.8 Referencias y fotograma de muestra de atuendo 1 para Valeria 23

Figura 2.9 Referencias y fotograma de muestra de atuendo 1 para Chico 1 24

Figura 2.10 Referencias y fotograma de muestra de atuendo 2 para Valeria ..... .24

Figura 2.11 Referencias y fotograma de muestra de atuendo 3 para Valeria .25

Figura 2.13 Referencias y fotograma de muestra de atuendo 1 para Chico 2 .25

Figura 2.14 Referencias y fotograma de muestra de atuendo 4 para Valeria y atuendo 2 para Chico 2 .26

Figura 2.15 Referencias y fotograma de muestra de atuendo 5 para Valeria .27

Figura 2.16 Referencias y fotograma de muestra de atuendo 1 para Chico 3 .27

Figura 2.17 Referencias y fotograma de muestra de atuendo 6 para Valeria y atuendo 2 para Chico 3 .28

Figura 2.18 Referencias y fotograma de muestra de atuendo 7 para Valeria .28

Figura 2.19 Referencias y fotograma de muestra de atuendo 1 para Chico 4 .29

Figura 2.20 Fotograma de referencia de largometraje "Lost in Translation" (2003) ..... 30 
Figura 2.21 Fotograma de referencia de largometraje "One Hundred Days of Summer" (2009)

Figura 2.23 Muestra de encuadre final de episodio "Macarena"

Figura 2.24 Muestra de encuadres finales de juego de apertura de encuadres para episodio "Macarena". .31

Figura 2.25 Referencias de Arte para episodio "Macarena" .32

Figura 2.26 Gráfico de funcionamiento de estrategia de redes. .39 
Dirección web de las piezas y producciones de comunicación parte del trabajo

Valeria (Episodio 1): https://www.youtube.com/watch?v=9ucH8doYcQA

Macarena (Episodio 2): https://www.youtube.com/watch?v=0Te_4BQ0Gig 


\section{ÍNDICE DE ANEXOS}

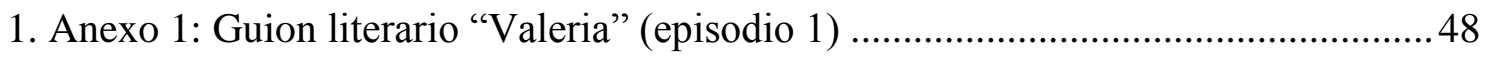

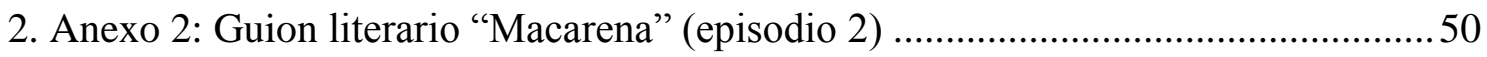

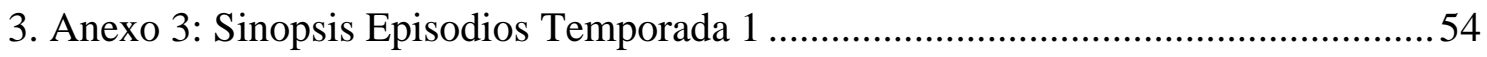

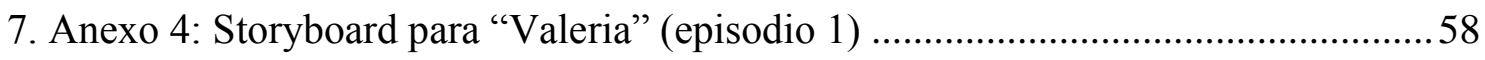

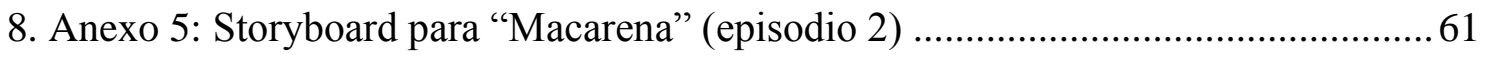

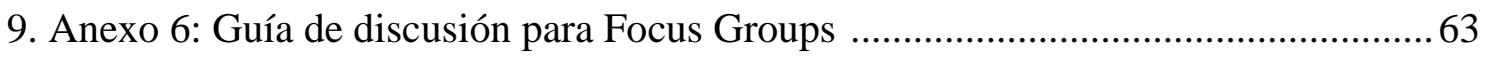

10. Anexo 7: Transcripción de resultados de Focus Groups .........................................65

11. Anexo 8: Transcripción de resultados de primera exhibición de los productos ........72

12. Anexo 9: Transcripción de resultados de primera exhibición de los productos .......74 


\section{RESUMEN}

En el siguiente documento se explica de manera detallada el proceso de creación y realización del proyecto de serie web "Romances de 20 centavos", formulado como una exploración de las posibilidades del relato de corta duración en el formato digital en un contexto en el cual las ofertas de las series web suelen basarse en modelos narrativos que buscan simular el mecanismo de series más largas. Es así como se plantea realizar este producto generando fórmulas menos exploradas y basadas en los recursos narrativos que tienen más efectividad en la duración corta como son la dosificación de información, el uso del suspenso y de la sorpresa.

Palabras clave: relato de corta duración, narrativa de corta duración, serie web, formato digital, recursos narrativos, cortometraje, serie de antología, género juvenil, dosificación de información, suspenso, sorpresa 


\begin{abstract}
This document explains carefully the creation and development of the web series project "Romances de 20 centavos", formulated as an exploration of the possibilities of the short- term storytelling in the digital format given a context where the web series current offer is usually based in narrative models that simulate the narrative mechanism of series with longer durations. That is why this project aspires to generate less explored formulas base on narrative resources that are more effective in a short story as the dosification of the information and the use of suspense and surprise.

Key words: short-term story, short-term narrative, web series, digital format, narrative resources, shortfilm, anthology series, teen drama, dosification of information, suspense, surprise
\end{abstract}




\section{INTRODUCCIÓN}

El uso de medios digitales está caracterizado por la inmediatez. Es en el contexto de esta realidad que la brevedad del contenido parece haberse convertido en una cualidad que favorece el consumo de determinados contenidos frente a otros. De acuerdo a los datos proporcionados por el estudio “Global Digital Report” de la agencia We Are Social (2019), el tiempo promedio de visita de los internautas a páginas de video se redujo de doce minutos y un segundo a once minutos y dieciocho segundos entre el año 2018 y el 2019 (p.141-153). Es por ello que la mayor parte de las series web busca tener una duración fugaz. Un $71 \%$ de las webseries españolas duran entre 2 a 10 minutos (Hernández, 2011, p.103).

No obstante, en el caso concreto del formato de la ficción serializada, traducida en este entorno bajo la forma de la serie web o web serie, la concisión es un parámetro que impone ciertos detrimentos puesto que el carácter serializado y las fórmulas convencionales del desarrollo del conflicto en sus narrativas no son siempre compatibles con el relato corto. Tal como señalan los autores Diego Montoya y Helena García (2016):

"Al momento de la construcción de guiones para dichos formatos, nos encontramos con una notable ausencia de literatura que dé pistas para la construcción de narrativas seriales y sobretodo con temporalidades y apuestas técnicas óptimas para web y dispositivos móviles ... debido a que se trata de un formato audiovisual emergente, la producción ha tomado como base teórica literatura propia del cine y la televisión tradicional adaptando en la práctica estructuras de larga duración a otras de cortas temporalidades." (p.103-105)

Es en este contexto que se surge la realización de la serie "Romances de 20 centavos" como una propuesta que no busca imitar los modelos o fórmulas de una serie de mayor amplitud, sino que, mediante distintos recursos, aprovecha potencialidades poco exploradas que puedan potenciar el relato corto para lograr alcanzar una mayor efectividad en el público objetivo y dentro del entorno digital. 


\section{ANTECEDENTES DEL TRABAJO}

\subsection{Definición de conceptos básicos}

Antes de comenzar el análisis de los antecedentes del caso, es necesario definir con claridad a qué nos referimos cuando se habla de narrativa corta, suspenso, sorpresa y dosificación de información.

Para comenzar, en este texto se utilizará el término "narrativa de corta duración" para referirse a una historia cuyo tiempo de consumo no excede los 10 minutos. En formatos más tradicionales y no digitales corresponde a modalidades como el cuento corto en la literatura o el cortometraje en el cine.

Los siguientes tres conceptos que serán explicados, se adscriben a lo que Chion (1992) denomina "procedimientos narrativos", definidos por él mismo como recursos que, bien empleados, permiten que un espectador sea atrapado por la historia por más que esta provenga de la anécdota más sencilla (p.163).

El primer concepto a definir es el de suspenso. En "el cine según Hitchcock” se define este término como el efecto que se produce cuando la audiencia advierte un acontecimiento o elemento de la historia que el protagonista desconoce y que afectará de manera decisiva la consecución de sus objetivos dentro de la historia. En contraparte, la sorpresa sucedería cuando espectador cae en cuenta del suceso inesperado que subvierte las expectativas sobre cómo se vienen desencadenando o cómo se desencadenarán los hechos de la historia pero no necesariamente antes que el protagonista. Estos conceptos son ejemplificados con el conocido ejemplo de la bomba que explotará bajo el escritorio del personaje. Si bien ambos mecanismos son útiles y necesarios durante la construcción de una historia, especialmente en una breve, como veremos más adelante, Hitchcock apunta que el suspenso suele ser una herramienta más efectiva dado que le otorga al público más minutos de tensión que en el otro escenario (Truffaut, 1966, p.59).

Por último, es necesario definir el término “dosificación de información”. Dicho término refiere a la manipulación en la presentación de los eventos que se hace al espectador mediante la elección qué momentos o datos son evidenciados o no en la 
narración. Tal como explica Chion (1992): “a menudo, para poder funcionar, una historia implica que haya un reparto desigual de la información entre los personajes y entre el narrador y el público" (p.171). Él denomina esto como la “división del saber”. En el cine, la dosificación de información puede sacar provecho del carácter audiovisual de la plataforma que obliga de por sí a hacer la entrega de la información más selectiva invitando a echar mano de recursos como el espacio en on/off, la edición, etc.

El entorno digital ha estado siempre inundado por relatos de corta duración en distintos formatos. Durante las siguientes páginas, se presentan algunos de los formatos más populares de narrativas virales en el entorno digital y se observará también cómo hacen uso de la dosificación de información, el suspenso y la sorpresa como recursos básicos de la narración de duración corta.

\subsubsection{El creepypasta}

El "creepypasta" es uno de los formatos de relato de internet más famosos y divulgados. $\mathrm{Su}$ origen se remonta a los inicios del entorno digital ya que nacieron como una serie de historias de terror o suspenso que eran compartidas vía e-mail o a través de chats mediante el copiado y pegado (Henriksen, 2018, p.1). Es por esto que recibe el nombre "creepypasta" (creepy= copy, pasta=paste). Hoy permanece en la cultura online y se ha diversificado a distintas plataformas.

El creepypasta se ha caracterizado siempre por ser un relato corto, lo cual facilitaba su consumo espontáneo y ligero. La mayor parte de ellos coincide en una estructura básica que es lo que permite que genere una narrativa de alto impacto y el consecuente deseo de viralización. Esta mecánica funciona a base de los recursos del manejo de expectativa y la sorpresa. El relato inicia situando al espectador en un escenario cotidiano al cuál súbitamente se introduce un elemento de carácter misterioso, sobrenatural o simplemente atípico que genera en el protagonista y en el lector una sensación de incertidumbre que, a su vez, invita al planteamiento de una serie de expectativas acerca de qué puede ocurrir, normalmente basadas en el tratamiento que estas recibirían en un relato de terror de carácter más largo como un largometraje o una novela. Sin embargo, estas expectativas son rápidamente frenadas con un final sorpresivo, inesperado y atronador que las revierte. 
Vale la pena resaltar también que el juego de expectativa/sorpresa se basa también en la manipulación de las proporciones de la duración de los actos del conflicto que estipula la tradición aristotélica, bajo la que se rigen la mayor parte de los relatos, y las expectativas que la audiencia espera respecto a esto en base a su experiencia previa con otros relatos más largos. El inicio o contextualización en la situación cotidiana de la que se hablaba en el párrafo anterior (equivalente al mundo ordinario) es extensa en comparación con la duración de los dos actos posteriores, cuando debería conformar tan solo un cuarto de la narración. Esto por supuesto para sumir al lector en esta realidad común y hacerlo sentir en control antes de revolcarlo con la introducción del elemento fuera de lugar. En un relato de duración larga, este elemento coincidiría con el detonante o el primer plot point, dando inicio a un segundo acto que debería conformar dos cuartos del relato. Además, la introducción relativamente larga sugiere al lector a nivel subconsciente que se tratará, por tanto, de un segundo acto proporcional a esta. No obstante, mientras el público se prepara para la sucesión de eventos de este segundo acto, el escritor frena sus expectativas al imponer repentinamente el final de alto impacto de manera sorpresiva. Es así que el "creepypasta” juega también con las expectativas del manejo de tiempos para hacer efectiva la brevedad del relato.

Para ejemplificar el funcionamiento narrativo señalado, se puede analizar el relato conocido como "La estatua", uno de los más populares en la red. Este básicamente cuenta la historia de una pareja que deja a sus hijos encargados con una niñera para salir a cenar. Esta es la contextualización ordinaria y relativamente extensa de la que se habló en el párrafo anterior. Después, se suma el elemento fuera de lo común: la niñera llama para pedirles a los padres si puede tapar la estatua de ángel de la casa dado que la atemoriza. Mientras el lector asimila esta información y se plantea qué sucederá, el cierre de la historia fuerza su entrada abruptamente pues el padre contesta acelerado pidiéndole a la muchacha que llame a la policía dado que ellos no tienen una estatua como tal en su domicilio. La llamada se corta, el narrador nos cuenta que para cuando los esposos llegaron a su hogar, los hijos y la cuidadora estaban muertos.

Al mismo tiempo, la mecánica del creepypasta se relaciona también con el uso de la dosificación de la información puesto que el carácter impactante del final se relaciona estrechamente con el sesgo de la información que se entrega al espectador. Normalmente esto se debe al apego con el punto de vista del protagonista, que tiene también un conocimiento limitado de la realidad diegética del relato. Esto es fácil de visibilizar en 
otro creepypasta muy conocido que cuenta la historia de una niña asustadiza que va a dormir confiando en que su fiel perro la cuida desde bajo la cama. Cada vez que siente temor al oír un goteo que viene de otra habitación, baja su mano y el perro la acaricia lamiéndola. No obstante, cuando despierta y acude a ver de dónde venía el goteo, descubre a su mascota muerta con la sangre cayendo acompañado del mensaje "no solo los perros lamen". El final nos pilla por sorpresa al lector debido a que este, al haber seguido la historia desde el punto de vista de la niña, desconoce al igual que ella que el cadáver del perro estaba en la habitación.

No obstante, a veces el creepypasta nos entrega como lectores inclusive menos información de la que tienen los protagonistas, como en el caso de "La estatua", donde la sorpresa y reversión de expectativas se generan porque desconocíamos que tal estatua no existía en la casa, lo cual sí era bien sabido por la pareja protagónica.

\subsubsection{Los hilos o threads}

Otro fenómeno de internet más reciente son los "hilos" originados tradicionalmente en la plataforma Twitter, aunque suelen migrar a otras como Facebook o Instagram bajo la forma de capturas de pantalla. Aunque no siempre tienen un carácter narrativo, se han popularizado recientemente aquellos que cuentan historias. El formato consiste en contarlas de manera fragmentada a través de diversos tweets. Aunque algunos casos puntuales suelen ser bastante extensos, la mayor parte pueden ser leídos en su totalidad en menos de 5010 minutos. Otra forma popular que han tomado es la de una serie de "memes" o de capturas de pantalla de conversaciones que narran también una historia breve en menos de 10 o 20 imágenes con poco texto.

Lo particular de este formato es que exige un sistema en el cual cada fragmento (publicación o imagen) fidelice al lector y lo motive a continuar con la historia pasando a la siguiente fase. Por tanto, a menudo los threads organizan la información de manera que cada elemento contenga un elemento sorpresivo que satisfaga al lector y al mismo tiempo genere suspenso para que transcurra al siguiente. Por ejemplo, un conocido hilo humorístico consiste en una serie de capturas de pantalla de una conversación por chat en la que una muchacha recibe un mensaje de su ex novio en estado etílico (denotado por los errores al escribir) pidiendo volver y ella le pide que por favor la deje en paz ya que no es la primera vez que se hayan en esa situación. Este es un primer elemento inesperado 
que, a su vez, genera expectativa sobre cómo continuará la conversación. En la siguiente imagen, descubrimos que él está en la puerta de la casa de ella, repitiendo la mecánica anterior. En el siguiente, nos enteramos que ella le dice que no desea verlo porque en estos momentos se encuentra con otro muchacho. Una vez más, la sorpresa y expectativa se renuevan cuando él comienza a escribir bien y notamos que se trataba de una farsa. El juego continúa cuando nos enteramos que ella también le mentía pues está sola y así sucesivamente.

También encontramos otros géneros en este formato como aquellos hilos policiales o detectivescos donde los autores pretenden estar resolviendo un crimen en las publicaciones sucesivas donde cada una muestra una prueba nueva y sorpresiva hasta llegar a un desenlace poco esperado. En todos, la mecánica sorpresa-suspenso es la base de la efectividad de la narrativa.

Al igual que en el creepypasta, la dosificación de información está ligada íntimamente a la identificación y el seguimiento de la historia de la mano de un protagonista o narrador que también cuenta con una visión parcializada de las cosas.

\subsubsection{El vine y el sketch cómico}

Un relato corto de formato más audiovisual es el vine y los sketches cómicos. Ambos tipos de video no suelen exceder los cinco minutos y están diseñados para un consumo fugaz y una viralización espontánea. El formato se popularizó bajo el cobijo de la aplicación móvil "Vine", que más tarde cayó en desuso. No obstante, el género sobrevivió a la plataforma y se expandió a redes como Instagram y Facebook. En nuestro país, la mayor parte de creadores de contenido avocados a esta modalidad comenzaron su trayectoria en Facebook e Instagram y actualmente se encuentran en su apogeo.

$\mathrm{Al}$ igual que los ejemplos anteriores, la raíz de su mecanismo narrativo se basa en la brevedad, el uso de la dosificación de información y la sorpresa. No obstante, estos videos aprovechan estos recursos de manera más variada pues no se puede encontrar una estructura fija recurrente como ocurría con los creepypastas sino más bien distintos usos que, de una manera u otra, desembocan en las herramientas ya mencionadas como clave de su funcionamiento como historias.

Por ejemplo, en un video de la popular influencer Ximena Galiano, observamos cómo se va de vacaciones con su amiga y, durante el viaje, ambas se entristecen en 
numerosas ocasiones enunciando frases como "lo extraño" o "a él le gustaría estar aquí". Cuando están de regreso a sus hogares, vemos a sus respectivas parejas esperándolas con carteles para darles la bienvenida, pero cuando ellas llegan ansiosas, a quienes abrazan con melancolía es a sus mascotas. Aquí podemos observar dosificación de información (el hecho de que en ningún momento en las oraciones se mencionara de quién se hablaba y la falta de refuerzo visual), manejo de expectativa que crea suspenso (tanto la manipulación debido a que se sabe que el espectador relacionará esas frases con la figura del enamorado debido a los antecedentes de la experiencia y también al colocar las tomas de las parejas esperándolas al llegar) y sorpresa (con el final inesperado al ver a las mascotas en las que nadie había pensado).

Sin embargo, en otro video, observamos a Ximena mandando notas de voz a chats grupales acerca de su aversión hacia el juego navideño "amigo secreto". Aquí, observamos distintas pequeñas situaciones o gags en los que se utilizan las herramientas mencionadas, como cuando está hablando sobre que el año anterior una amiga le regaló una taza muy bonita pero que era merchandising de la Universidad de Lima, en este momento voltea la taza que ha tenido en la mano durante todo el video y descubrimos el logo de la institución. Una vez más, hallamos un gag operado mediante la dosificación de la información (no vemos ese lado de la taza hasta el momento adecuado) y sorpresa (tampoco sabíamos que estaba relacionada al núcleo de la historia y que formaría parte de la línea narrativa). En ambos ejemplos podemos observar distintas estructuras, pero ambas hacen uso de los mismos ingredientes y basan su éxito en ellos. Uno los utiliza a nivel macroestructural y el otro a nivel microestructural.

Otro punto interesante a recalcar en el uso de expectativa, sorpresa y manipulación de información con respecto a este formato específico es que, a diferencia de los anteriores casos, aquí se aprovechan los recursos de manera visual. La dosificación de información y los elementos sorpresivos no son revelados de manera verbal sino debido al uso del espacio on/off y el montaje.

\subsubsection{El videoclip}

Si bien es preexistente a la cultura digital, el videoclip encontró en el internet una nueva etapa para una divulgación mayor. Tal como señala el autor Eduardo Viñuela (2013), “el videoclip ha dejado de ser un producto televisivo para encontrar un espacio en el internet, 
donde las posibilidades de la web 2.0 han dado lugar a una audiencia creativa que ha desarrollado nuevas tipologías" (p. 167).

Si bien no todos los videoclips cuentan con características narrativas, muchos de ellos sí y aprovechan los recursos de los que trata este documento para potenciar la efectividad de la brevedad de sus narrativas, delimitada por la duración de la canción que no suele exceder los 6 minutos. Al igual que los vines y sketches, el videoclip no utiliza las herramientas mencionadas bajo una fórmula o estructura heterogénea, sino que se apropia de ellas de distintas formas. Sin embargo, lo más resaltante de este formato específico es que suele concentrarlas en el momento final, con el propósito de lograr un impacto que haga al video recordable y, por tanto, viralizable. La falta de posibilidades de audio más allá de la música y la adecuación obligatoria a esta pueden ser un detrimento para el desarrollo de una narrativa compleja y aristotélica conformada por muchos intentos del personaje por superar sus obstáculos y distintos puntos de inflexión, pero esto es compensado a menudo con un final memorable.

Por ejemplo, en el conocido y premiado videoclip de LCD Soundsystems para la canción “Oh, baby” podemos observar cómo una pareja inventa una máquina capaz de teletransportar objetos al hacerlos ingresar por un portal para que salgan por otro. El video muestra poco conflicto al interior de la historia. Se mudan, el invento progresa. Todo va bien hasta que repentinamente ella fallece en un asalto y él, desconsolado, ingresa con ella en los brazos al portal, pero no continúa la caminata hasta llegar al otro puerto, sino que se queda atrapado adrede entre ambos, irónicamente o dramáticamente rotulados con las palabras "here" and "there". Como podemos ver, se trata de un final fuerte, sorpresivo y de alto impacto que dota al relato de sentido y compensa la falta de progresión narrativa en el resto del transcurso de la historia. Los ejemplos donde este patrón se cumple son innumerables.

Los ejemplos de formatos de relato corto en el entorno digital son innumerables. No obstante, los las modalidades presentadas en este capítulo nos permiten tener un vistazo hacia el funcionamiento básico de sus esquemas narrativos y el manejo que hacen de los recursos de los que debate este documento. 


\subsection{Análisis de casos similares o referenciales}

El universo de las series web es sumamente amplio. De acuerdo a un estudio realizado en España, se hallaron al menos 70 webseries vigentes producidas tan solo en España en la plataforma de Youtube (Hernández, 2011, p.102). Debido a este gran volumen de competidores, en este documento se hace imposible hacer un análisis extenuado de cada una de las series web disponibles como competidoras, por ello se ha realizado una clasificación breve en tres conjuntos que agrupan estos productos de acuerdo a las diferencias y similitudes en sus sistemas narrativos. Este catálogo se formó en base a la observación de distintas webseries premiadas a nivel mundial con galardones como los Webby Awards, series con elevados números de suscriptores o con reconocimiento a nivel local.

El primer grupo estaría conformado por aquellas series que buscan imitar a nivel macroestructural el modelo aristotélico aplicado a la línea transversal del producto serializado tal como en una serie de formato largo. Es decir, cuentan con una narrativa única con un protagonista que se plantea un objetivo que se extiende a lo largo de los capítulos y donde cada uno de estos se equivale a un momento específico de la estructura dramática clásica (detonante, primer plot point, etc.). Aunque estas series logran cumplir con la estructura a nivel transversal, no logran reproducir esto al interior de cada episodio pues la brevedad exigida por el entorno digital no lo permite. Por tanto, más que presentar un episodio donde un protagonista se enfrente a un obstáculo y realice múltiples acciones para conseguirlo, lo que se presenta es un protagonista en una situación adversa concreta e inmediata que realiza una o como máximo dos estrategias para resolverla. A este grupo pertenecerían series como Fake News Writter, Marble Hornets o, a nivel local, Manual de Soltería. La duración promedio de los episodios de este conjunto es de 7 a 20 minutos.

Por ejemplo, Fake News Writter cuenta la historia de un joven periodista frustrado que toma un trabajo escribiendo propaganda conservadora, pero debe ocultarlo de su roommate liberal. La duración promedio de un episodio es de 7 u 8 minutos y se transmite por Youtube. Para tener una idea de la estructura típica de un capítulo, podemos tomar como ejemplo el primer episodio, donde vemos al protagonista en su situación de desempleo. Este capítulo termina cuando él consigue el empleo, como podemos ver, el tiempo ha sido demasiado corto como para llegar al planteamiento de un segundo conflicto mayor como es el del roommate. Cuenta con 8650 suscriptores. 
Por otra parte, Marble Hornets es uno de los ejemplares de serie web más antiguo y más exitoso del internet. También se transmite a través de Youtube y tiene 530000 suscriptores. Cuenta con 92 episodios y la duración de cada uno varía entre los 7 y los 9 minutos. Trata de la experiencia de un joven con el personaje de "Slenderman", un ente creado en internet en creepypastas. Cada episodio narra un acercamiento hacia este personaje, presentando inicialmente el contexto en el cual se da, uno o dos obstáculos presentados a modo de hallazgos, sustos, etc. y un final que frecuentemente corresponde a un "jumpscare".

Entre los ejemplos locales, podemos encontrar "Manual de Soltería" y "Los cinéfilos". La primera serie mencionada cuenta con 267 mil suscriptores en Youtube y está constituida por 50 episodios que duran entre 12 y 15 minutos. La serie busca asemejarse al formato de las sitcoms y cuenta las desventuras de un muchacho que queda soltero después de una relación muy larga, pero la historia se expande también a sus amigos desarrollando líneas argumentales para ellos. La estructura se asemeja mucho al de una serie de mayor duración por episodio y busca completar fidedignamente la estructura aristotélica por lo menos en la storyline principal. Por otra parte, "Los cinéfilos" es uno de los proyectos digitales más exitosos dentro del nicho que conforma su público objetivo. Cada episodio dura menos de 5 minutos y se compone por una sola escena, un contexto situacional único que presenta un conflicto que se plantea por primera vez y se resuelve dentro del mismo capítulo. Cuenta con 838 mil suscriptores.

El segundo grupo estaría conformado por aquellas series denominadas de “antología”. En ellas, cada episodio presenta personajes y conflictos diferentes que se resuelven o no dentro del mismo episodio. Estas sí consiguen completar una estructura aristotélica en cada entrega y son las que hacen un mayor uso de la sorpresa, suspenso y dosificación de información para potenciar su efectividad. A este grupo pertenecerían series como Alter, Love Death Robots o, a nivel nacional, Making Off, Historias de rodaje. La duración promedio de un episodio está entre los 5 y los 15 minutos.

Alter cuenta con 778 mil suscriptores y narra historias adscritas al género del terror, pero en códigos y subgéneros muy distintos, así como un estilo visual independiente. Algunos se inclinan más al suspenso, otros al horror e incluso pueden encontrarse algunos cortometrajes de comedia. Son filmados por distintos realizadores. El estilo narrativo y el uso que hacen de las herramientas de storytelling son muy variados y distintos en cada entrega. 
Por otra parte, Love Death Robots realiza sus emisiones a través de la cadena de streaming de Netflix y cuenta también con episodios de menos de quince minutos que no solo presentan personajes independientes y conflictos variados sino géneros distintos, desde la comedia hasta el horror, pero todos enmarcados en la ciencia ficción y la temática futurista. Los episodios también hacen uso de estilos narrativos y visuales diversos.

Making off es una serie web local que logró alcanzar los 462 mil suscriptores. Esta sí cuenta con un género claro en todos los episodios que es la comedia. En cada episodio narra la historia de un personaje asociado a un cargo específico dentro de un rodaje cinematográfico y cuenta un relato situacional breve que critica de manera cómica el arquetipo o estereotipo de este personaje. Cada episodio dura menos de 5 minutos.

Por último, contamos con las series que hacen un uso más experimental de la narrativa. Con frecuencia, se apoyan en un universo transmediático para culminar la entrega de la información de sus historias o de sus universos ficcionales. Las estructuras narrativas son variadas. A esta categoría pertenecerían producciones como la serie noruega Skam o la británica Shield 5.

Skam es un proyecto digital que surgió para apoyar la estrategia de redes de la serie televisiva del mismo nombre. La duración de cada episodio es diversa y también su estilo narrativo porque algunos podían tratar desde una conversación telefónica o un chat que dejaba abierto qué ocurriría en el episodio por televisión como una historia completa que cerraba la línea argumental de personajes secundarios.

Por otra parte, Shield 5 es una serie de la red social Instagram que cuenta una historia policial en entregas menores a un minuto complementadas por un material gráfico que se publica al mismo tiempo en la cuenta. Cada episodio es tan corto que llega a configurar un solo giro dramático que mueve la historia de entrega a entrega. Cuenta con 207 mil suscriptores.

\subsection{Perfil del público objetivo}

El público objetivo de esta serie web está dirigido a jóvenes de habla hispana pertenecientes a los sectores socioeconómicos A, B y C entre las edades de 18 a 27 años. 


\subsubsection{Perfil geográfico}

A nivel geográfico, el público objetivo está conformado por jóvenes de habla hispana debido a que, al emitirse a través del formato digital, sus posibilidades no se limitan a la jurisdicción de un país o región concreta. Además, cuenta con una temática y un tratamiento narrativo y visual que no hace alusión a ninguna localidad concreta ni limita su decodificación para los habitantes de ninguna nacionalidad. Más bien, apela a escenarios, situaciones, conceptos y emociones de carácter universal. De acuerdo al estudio "Global Digital Report 2019” de We Are Social (2019), tan solo en América Latina hay un $73 \%$ de penetración de Internet (p.34).

\subsubsection{Perfil socioeconómico}

Con respecto al perfil socioeconómico, el público objetivo se orienta más hacia miembros de los sectores A, B y C, debido a que, a nivel latinoamericano, se trata de los sectores que tienen un acceso mayor y más frecuente a dispositivos digitales y conexión regular y frecuente a internet. Asimismo, más allá de la disponibilidad tecnológica que tienen a su alcance, son los grupos que hacen más uso de los medios digitales como fuente de entretenimiento y consumo de ficciones, a diferencia de los sectores más bajos cuyo tiempo de ocio aún está más orientado hacia los contenidos televisivos. De acuerdo a Ipsos, un $88 \%$ de usuarios de los sectores $\mathrm{AB}$ accede frecuentemente a YouTube y otras plataformas de video similares y un $83 \%$ lo hace en el sector C (Ipsos, 2017)

\subsubsection{Perfil sociodemográfico}

Este grupo humano, en su mayoría, se dedica a estudiar (ya sea en universidades o institutos), trabajar (a nivel profesional, técnico o sin preparación) o a la conjunción de ambas ocupaciones. De acuerdo a los estudios de Ipsos (2017), el 39\% de los jóvenes internautas son trabajadores mientras que el $42 \%$ son estudiantes en nuestro país .Es por esto que se caracterizan por un ritmo de vida ajetreado que favorece el consumo de contenidos de poca duración y que estén disponibles en distintos tipos de pantallas para diversas ocasiones de consumo. 


\subsubsection{Perfil tecnográfico}

Más allá de un perfil psicográfico, debido a la heterogeneidad de este grupo de edad, se hace más necesario definir un perfil tecnográfico que hable acerca de sus usos, hábitos y actitudes con respecto al medio digital.

De acuerdo a los estudios de Ipsos (2017) acerca del perfil del internauta limeño, en promedio un internauta del grupo de edad de este público objetivo se conecta a internet 6.6 veces por semana. El 76\% lo hace a través de un smartphone, el $37 \%$ mediante una PC y el $26 \%$ por medio de laptops. El $67 \%$ de su uso de internet está destinado al entretenimiento. Un $89 \%$ de estos usuarios ingresa de manera frecuente al portal Youtube. De acuerdo a otro estudio de esta misma encuestadora, las horas en las que los usuarios más acceden al portal YouTube son durante el almuerzo y la tarde.

\subsection{Objetivos del proyecto}

Es en este contexto que este proyecto se propone como objetivo principal:

- Explorar las potencialidades de las narrativas de corta duración en el formato de las series web.

De la misma manera, se plantean los siguientes objetivos secundarios

- Explorar las potencialidades del uso del suspenso y la sorpresa como recursos clave en las narrativas de corta duración

- Explorar la dosificación de información como recurso clave en las narrativas de corta duración

Bajo la premisa de que las historias de duración breve operan bajo los mismos principios que las narraciones más prolongadas más no emplean estos recursos necesariamente de la misma manera, el proyecto busca lograr su propósito mediante dos objetivos secundarios ligados íntimamente a dos recursos clave que utilizan las narrativas cortas para potenciar su efectividad. Estas herramientas vendrían a ser la dosificación de información, el suspenso y la sorpresa.

Vale la pena recalcar que no se trata de recursos exclusivos del relato breve, pues también los encontramos como ingredientes esenciales de historias de mayor amplitud temporal. No obstante, en las narraciones de duración extremadamente limitada, el uso de estas dos herramientas narrativas gana protagonismo y llegan a ser la piedra angular o 
pieza clave del funcionamiento del relato en compensación de todos aquellos elementos que la carencia de tiempo no permite desarrollar. 


\section{REALIZACIÓN Y SUSTENTACIÓN}

\subsection{Descripción general del proyecto}

Para comenzar este acápite, se adjuntan los links de reproducción de los dos episodios piloto realizados para este proyecto:

Valeria (Episodio 1): https://www.youtube.com/watch?v=9ucH8doYcQA

Macarena (Episodio 2): https://www.youtube.com/watch?v=0Te_4BQ0Gig

Con el objetivo de explorar las posibilidades de las narrativas de duración breve, se creó un concepto de serie en el que cada capítulo no dura más de 6 minutos y se explotan los recursos del suspenso, sorpresa y dosificación de la información como los ingredientes clave sobre los que se erige la narrativa. Cada capítulo narra una historia distinta, protagonizada por diferentes personajes, por lo cual se adscribe al género de las series de antología.

La serie cuenta con un eje temático transversal y un hilo narrativo que une todas las historias. El eje temático es el desamor, este fue elegido debido a que es un tema afín, cercano y de interés al grupo objetivo juvenil al que nos estamos dirigiendo. Por otra parte, las historias se encuentran conectadas debido a que cada historia comienza y termina con el trasvase de mano en mano de una moneda entre el protagonista del episodio vigente y el del siguiente. Este ingrediente ayuda a hilvanar todos los relatos y sirve como un gancho atractivo para los espectadores pues se trata de una generación acostumbrada a consumir en contenidos de ficción conceptos como los multiversos, las narrativas crossmedia y las transmedia. Se han realizado dos pilotos que permiten visibilizar el concepto de la serie y evaluar su funcionamiento. 


\subsection{Fase de guionización}

Durante la fase de guionización, se buscó que cada capítulo explorase cada uno de los objetivos secundarios planteados (Ver Anexos 1 y 2). El primer episodio está relacionado a los recursos del suspenso y la sorpresa y cuenta la historia de una muchacha que se encuentra en el transporte público escuchando una melodía de carácter romántico. Ella hace contacto visual con otro muchacho y parecen agradarse. No obstante, como espectadores, nos trasladamos al punto de vista del joven y oímos a través de sus audífonos que escucha una canción con un carácter opuesto a la de ella. Por tanto, sabemos anticipadamente como espectadores que se trata de una conexión catastrófica. Aquí es donde encontramos por primera vez el recurso del suspenso. En una escena posterior, los vemos peleando mientras oímos ambas canciones sobrepuestas una a la otra de manera desastrosa. Vemos cómo esta serie de eventos ocurren con dos chicos más, empleando siempre la música como recurso principal para denotar la falta de "sincronía", el desencuentro de personalidades y la poca compatibilidad entre las parejas que la chica elige. Finalmente, la canción de la muchacha se acaba y esta se queda pensativa. La canción vuelve a empezar y ella vuelve a conectarse con ella. Hace contacto visual con un chico nuevo, este le sonríe. Nos trasladamos al punto de vista de él y de manera anticipada sabemos que él también oye la misma canción que ella. Una vez más, un momento de suspenso. Sin embargo, cuando volvemos a la protagonista ella, cansada, se rinde y le voltea la mirada. Ambos chicos continúan la ruta sin mirarse, pero oyendo la misma canción en el mismo tiempo sin hacer contacto. Aquí está el elemento de sorpresa. El uso del suspenso y la sorpresa para este episodio está íntimamente ligado al uso del punto de vista, debido a que esta entrega adelantada de la información comentada previamente se hace accesible al espectador mediante el cambio de punto de vista de un personaje a otro haciendo uso de lo que Chion (1992) denomina como "focalización interna variable" (p. 166-167)

El segundo episodio se basó en el recurso de la dosificación de información. Este narra la historia de otra muchacha que se levanta pensativa una mañana en su cama con su pareja. Mientras este aún está adormilado, le transmite su angustia diciéndole "¿sabes qué me jode? cuando te levantas extrañando algo que sabes que era una mierda pero por alguna razón lo extrañas". Él, sin prestarle atención y sin salir de su sueño, le responde “a mí me jode el café con leche”. Acto seguido, aparece en la pantalla una taza de café llenándose de leche. Así comienza una extraña conversación en la que ambos enumeran 
una serie de detalles cotidianos que les incomodan y estos van acompañados de su contraparte visual en insertos de planos detalle de lo que hablan. El juego para cuando ella le dice que le molesta el olor a cigarro en la almohada mientras él fuma. Luego de esto, ambos repiten todos aquellos elementos que habían enlistado, pero en los insertos observamos lo que no habíamos visto en el espacio en off y podemos ver que lo que tanto les perturbaba eran cosas que les molestaban el uno del otro. El relato culmina cuando ella repite su diálogo inicial (“¿sabes qué me jode? cuando te levantas extrañando algo que sabes que era una mierda, pero por alguna razón lo extrañas") pero despierta sola en la cama. Así es como se hizo uso de la dosificación mediante la propuesta de la manipulación del espacio en off, de la descontextualización para el espectador del pasado de la pareja y de que nos ubicábamos dentro de recuerdos en un recuerdo. Asimismo, en este relato, se juega con dos recursos o procedimientos narrativos relacionados a la dosificación de información que son la información implícita y la implantación. La información implícita ocurre cuando se otorgan pistas o información falsa al espectador debido a inferencias que él mismo realiza acerca de la realidad que se le presenta pero que no son necesariamente verdaderas. Chion (1992) ejemplifica esto diciendo que si el público ve a un hombre en una habitación durmiendo asumirá automáticamente que es su dormitorio (p.174-175). En nuestro caso, cuando el espectador recibe la información de los primeros encuadres de ambos personajes en la cama, su intuición lo lleva a pensar que deben estar circunscritos al tiempo presente, aunque esto nunca haya sido dicho explícitamente, sino que sea una inferencia de una información supuestamente implícita. Por otra parte, la implantación consiste en introducir elementos esenciales para la resolución de la trama de manera que sean advertidos y recordables para el espectador pero que no llamen su atención lo suficiente como para que se percaten de que son la clave para entender la historia (Chion, 1992, p. 176-178). Tobías (2004) ejemplifica esto con la frase "esconder los huevos en el gallinero", es decir, colocar esta información donde parezca natural de modo que no resalte pero que permita que el espectador, al final del relato, se quede con la sensación de “cómo no me percaté, siempre estuvo allí" (p.123125). Esto ocurre en nuestra historia cuando se introduce la frase inicial de la protagonista que resulta ser la clave de todo el relato pero pasó inadvertida en su momento ya que fue camuflada como simplemente el detonante de la discusión, lo cual a su vez le permite ser recordada hasta el final del episodio. 


\subsection{Fase de diseño visual y auditivo}

\subsubsection{Valeria (primer episodio)}

\subsubsection{Dirección de fotografía}

Para el primer episodio, a nivel de dirección de fotografía se buscó simular la estética del videoclip. Esto debido a dos motivos. El primero fue que se trataba de una audiencia acostumbrada a una estimulación sensorial y una estética acorde a la de este formato en lo que respecta al consumo de contenidos audiovisuales. Por otra parte, dado que se trata de una narrativa basada ampliamente en el recurso de la música, esta misma sugería un tratamiento semejante al videoclip. Asimismo, esto ayudaría a trabajar el manejo de expectativas del espectador para el uso del suspenso y la sorpresa dado que estas se orientarían a las expectativas de género del videoclip.

La otra gran arista que ha guiado el tratamiento fotográfico de esta puesta en escena fue la construcción de la subjetividad. La idea era no solo identificarnos con la protagonista sino sentir la historia y los sucesos del modo que ella los vivía. Por ello, se planteó un comienzo de las escenas mediante el uso de planos detalle y planos POV que nos sumergieran lentamente en su mundo antes de presentar su rostro. Acto seguido, para las escenas del cruce de miradas de trabajó con especial cuidado en la elección de planos para mantener este punto de vista subjetivo. Asimismo, se repitió el mismo proceso al diseñar los planos para los co-protagonistas para realizar el trasvase de punto de vista. Por el mismo motivo, para estas partes del relato se optó por utilizar lentes de $35 \mathrm{~mm}$ o 50mm para mantener la mirada subjetiva. Con excepción de los planos detalle.

La subjetividad no solo se construyó mediante la escala de planos sino a través de la movilidad de los mismos. Acompañando el movimiento del vehículo de manera naturalista pero que también sufriría variaciones con respecto al cambio de estado de ánimo de la protagonista, comenzando con un bamboleo suave al inicio de la historia acorde a su visión contemplativa y romántica del mundo y culminando con un movimiento frenético conforme se convierte en un ser duro, irritable, inestable y contrariado.

No obstante, así como se planteó esta mirada subjetiva también se estipuló la alternancia eventual con una mirada objetiva al final de cada escena de cruce de miradas, 
para cuando oíamos ambas canciones sonando en paralelo. Esta buscaba representar esta anticipación del espectador a los hechos pro encima de la protagonista y planteaba además un elemento característico para la serie, que era jugar con esta mirada externa cargada de ironía que en cierto modo enjuicia a los personajes construyendo la figura de una vista satírica acerca de las relaciones entre pareja.

Para complementar la explicación de estos conceptos, se presentan las referencias visuales planteadas para este video.
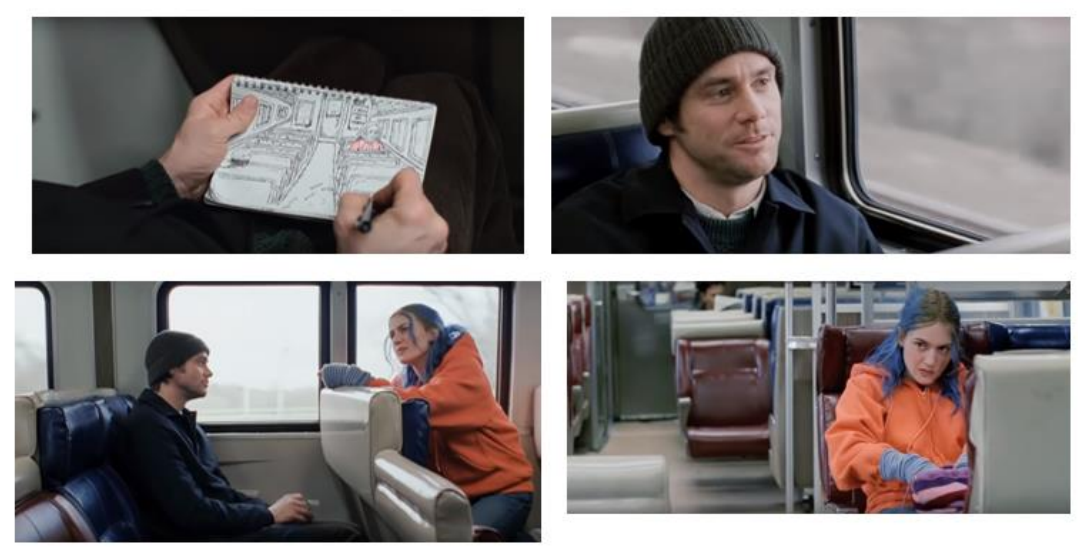

Eternal sunshine of a spotless mind(2004)

Figura 1.1 Fotograma de referencia de la película "Eternal Sunshine of a Spotless Mind" (2004)

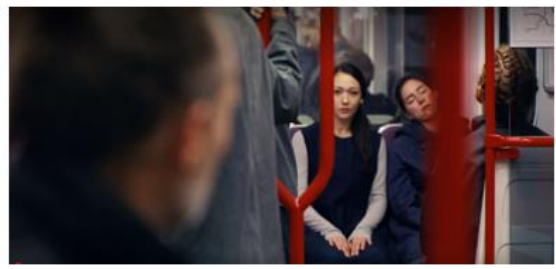

Anima (2017)

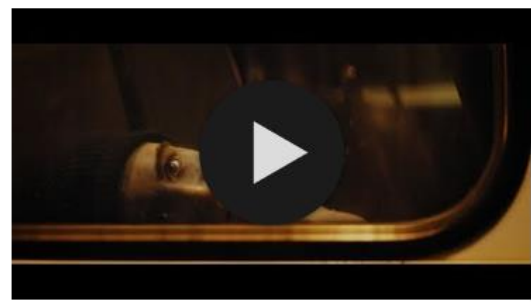

I promise-videoclip (2017) 
Figuras 1.2 y 1.3 Fotogramas de referencia de cortometraje "Anima” y videoclip "I Promise"

Para las escenas de discusión, donde era esencial entender el contexto de pelea y la connotación de falta de sintonía visualmente frente a la falta de diálogo, se buscó crear un ambiente caótico que representase el estado de ánimo de la protagonista. Es por esto que se planteó el uso de lentes cada vez más angulares, que deformasen la imagen cada vez más conforme cada pareja era peor que la anterior en términos de compatibilidad.

Para ilustrar esta propuesta, se presentan algunos encuadres del producto final para ejemplificar los planteamientos explicados en este capítulo
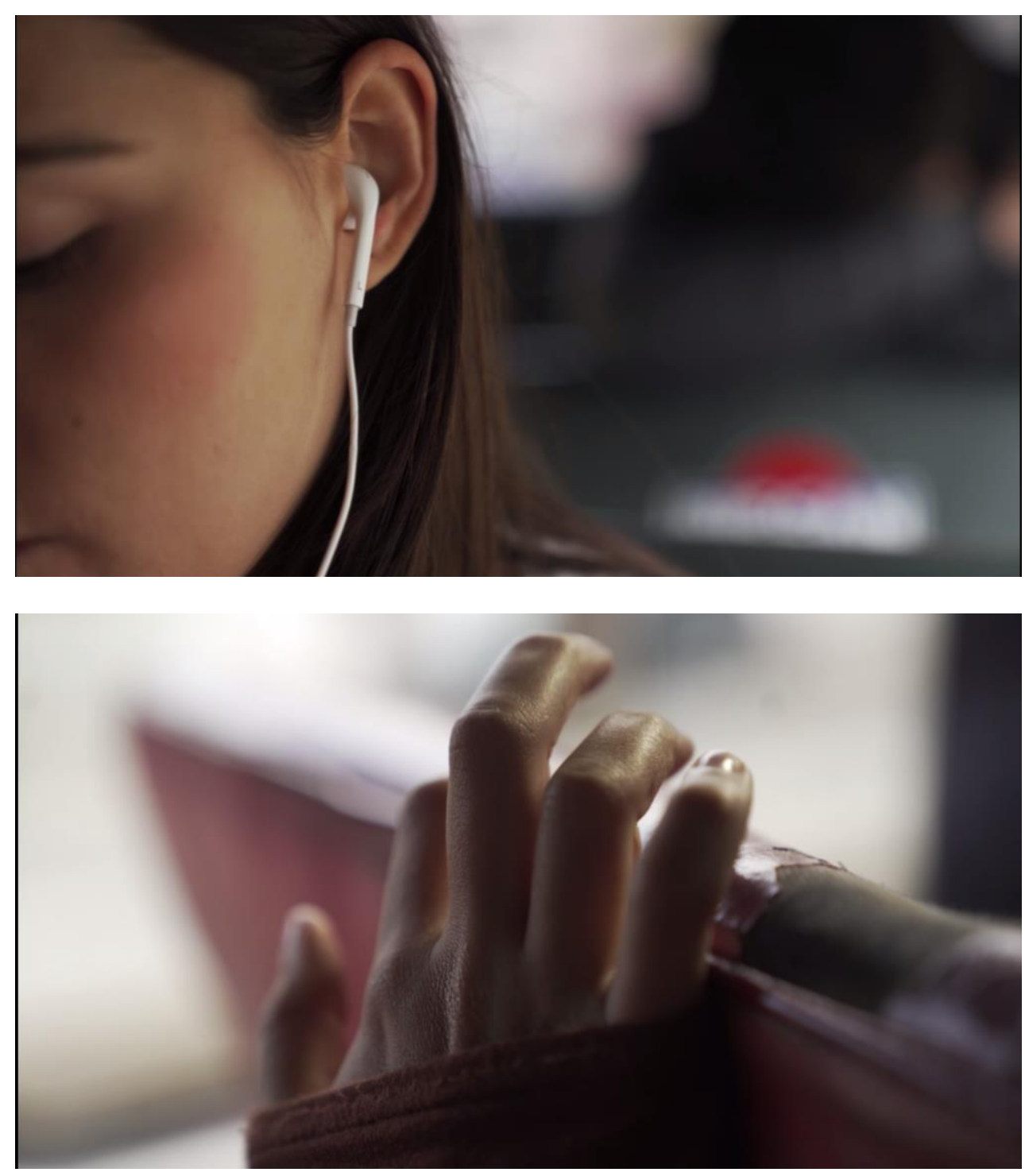


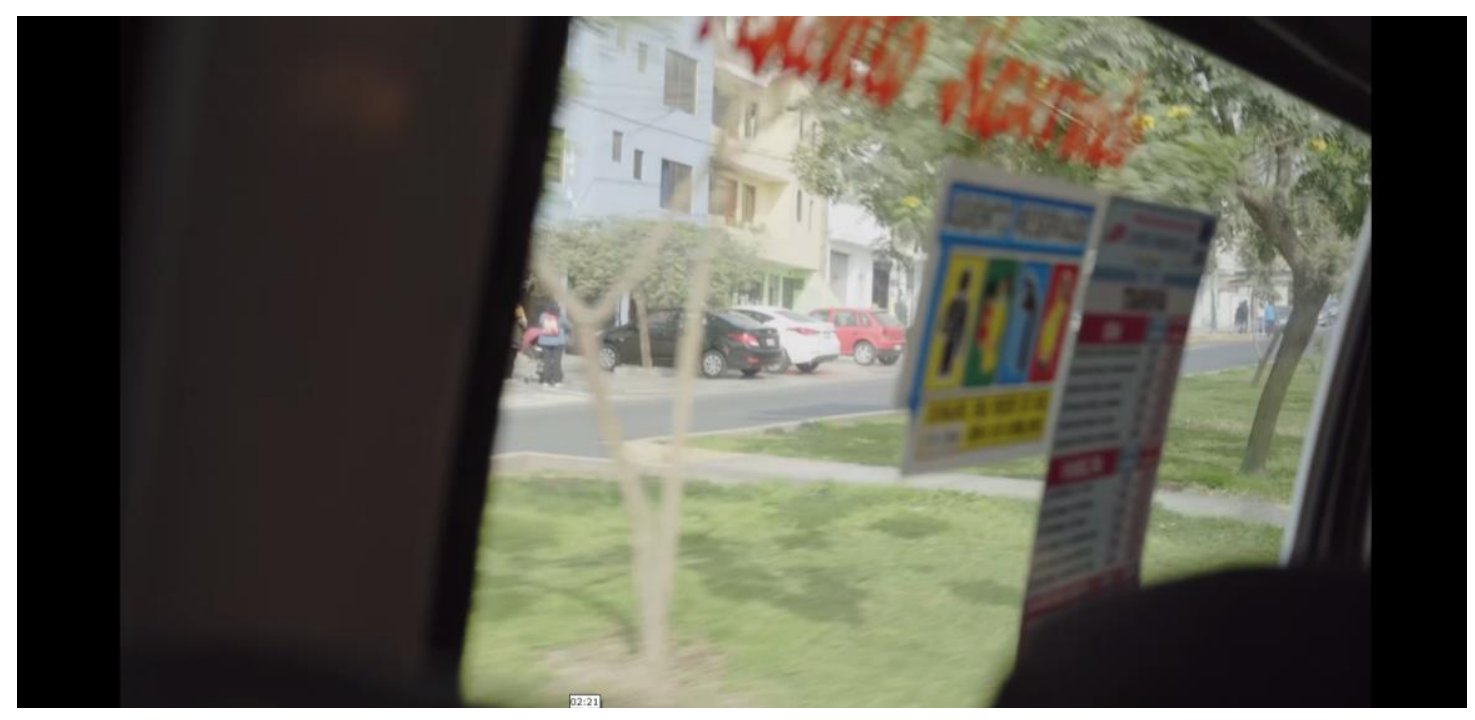

Figura 2.4 Fotogramas representativos de Planos detalle y POV para establecer subjetividad
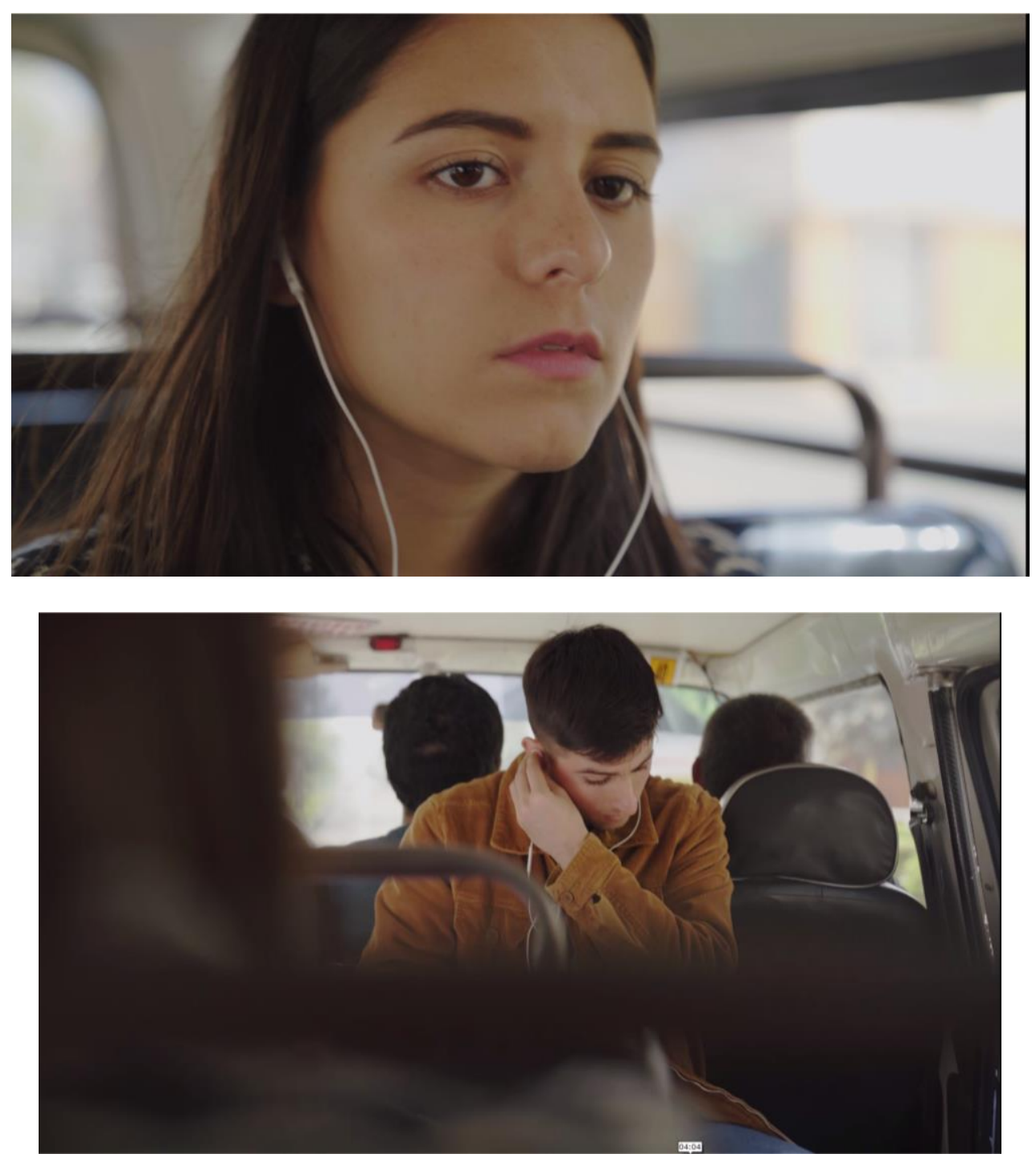

Figura 2.5 Fotogramas representaivos de planos subjetivos 

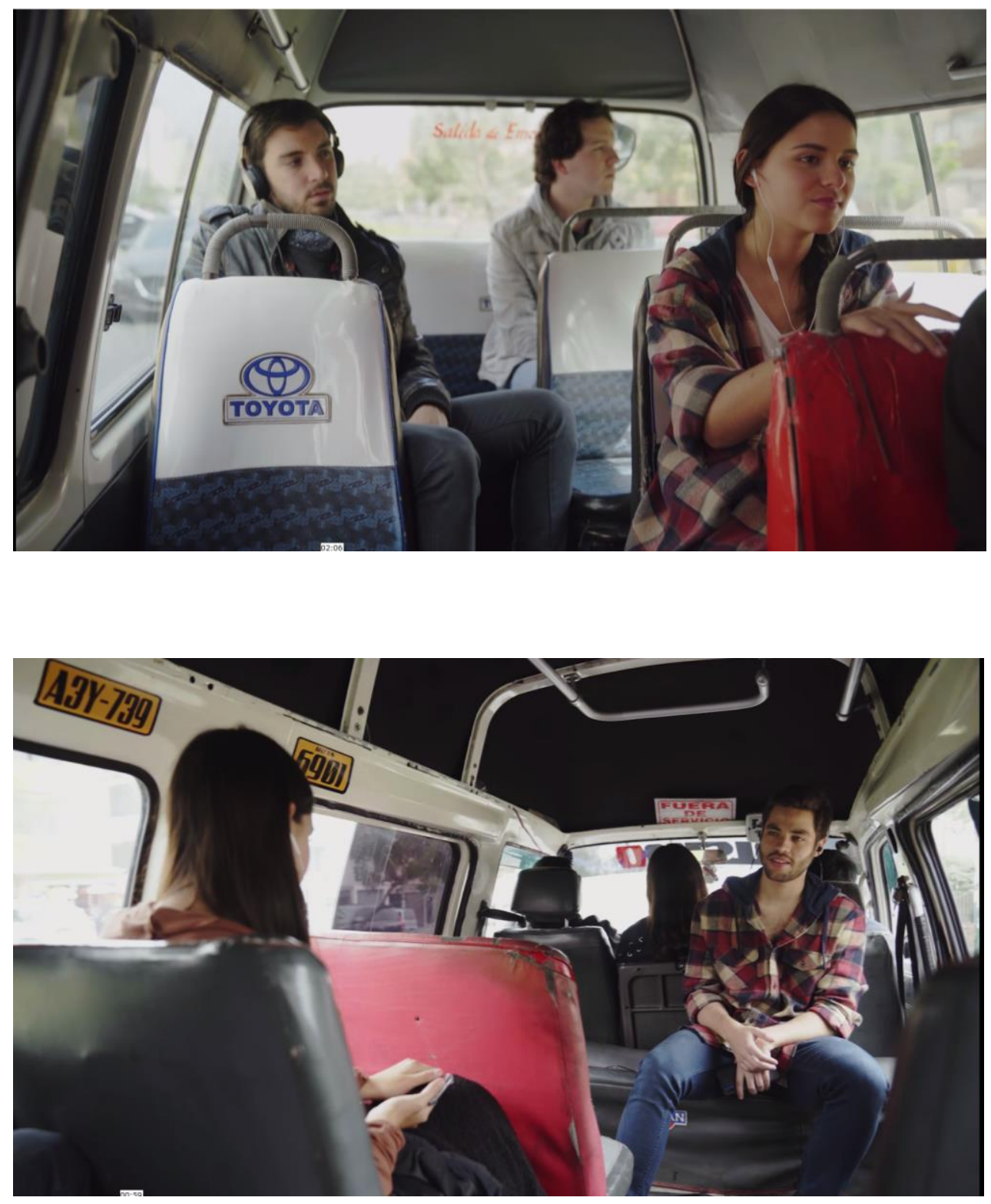

2.6 Fotogramas representativos de planos de punto de vista externo

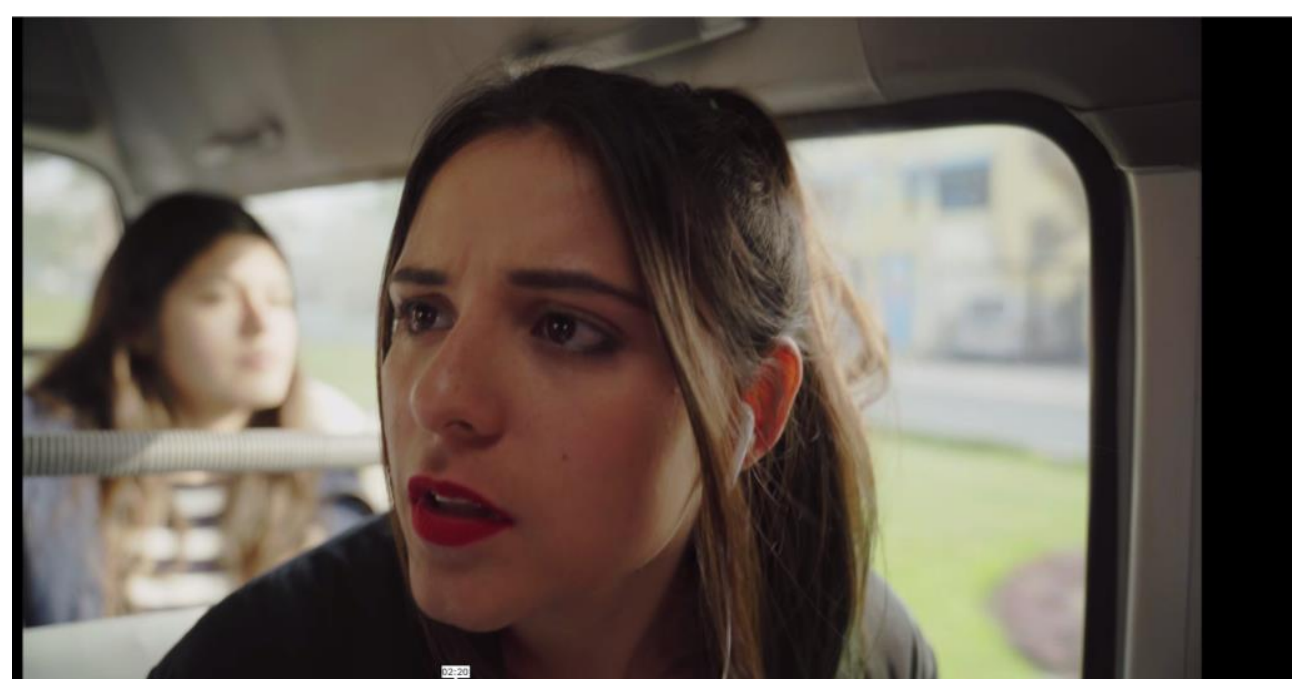

2-2.7 Fotograma representativo de planos de pelea con lentes angulares 


\subsubsection{Dirección de arte}

A nivel de dirección de arte, se buscó reproducir un ambiente cotidiano pero dotándolo de un aura juvenil y acorde al público objetivo. Por lo que se realizó una selección rigurosa de los vehículos en los que transcurriría la historia. Asimismo, el vestuario estuvo orientado a cumplir la función de construir el progreso del personaje durante la historia, pues una vez más, ante la falta de diálogos, esto necesitaba hacerse visible. Es por ello que el arte buscó representar cómo la protagonista cambiaba después de la ruptura con cada una de sus parejas, acoplando determinados rasgos de ellos pero también volviéndose cada vez más dura y alejada de la chica sensible que se presentó en una primera escena. Esto se realizó mediante la adaptación de su vestuario y peinado basándonos en distintas subculturas identificables y familiares para la audiencia juvenil. Cada muchacho correspondía a una y, una vez concluida la relación, ella tomaba el estilo y alguna prenda representativa de él en la siguiente escena.

Las referencias de los atuendos para cada escena y los atuendos finales utilizados en las escenas fueron los siguientes:
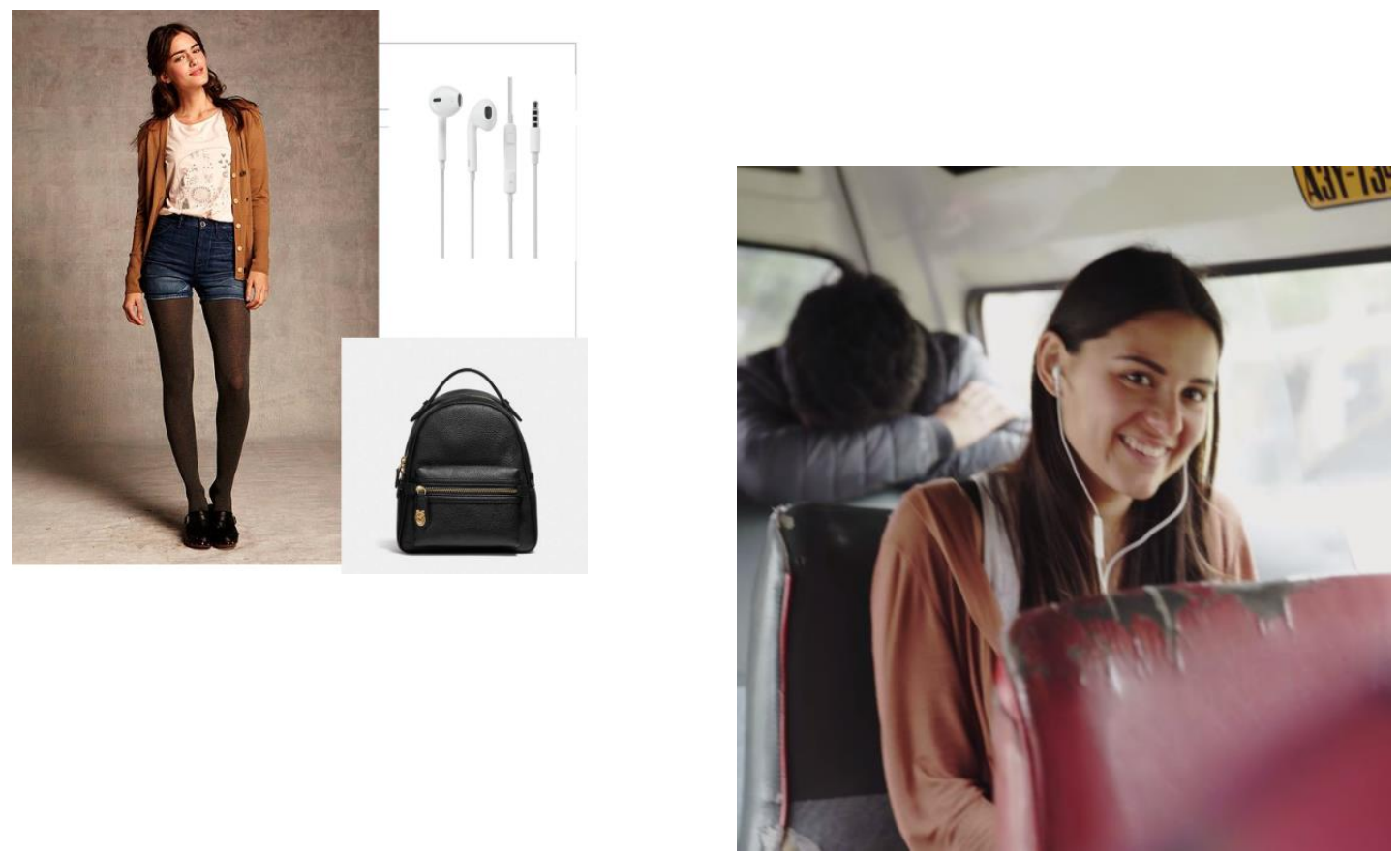

Figura 2.8 Referencias y fotograma de Atuendo \#1 para Valeria 

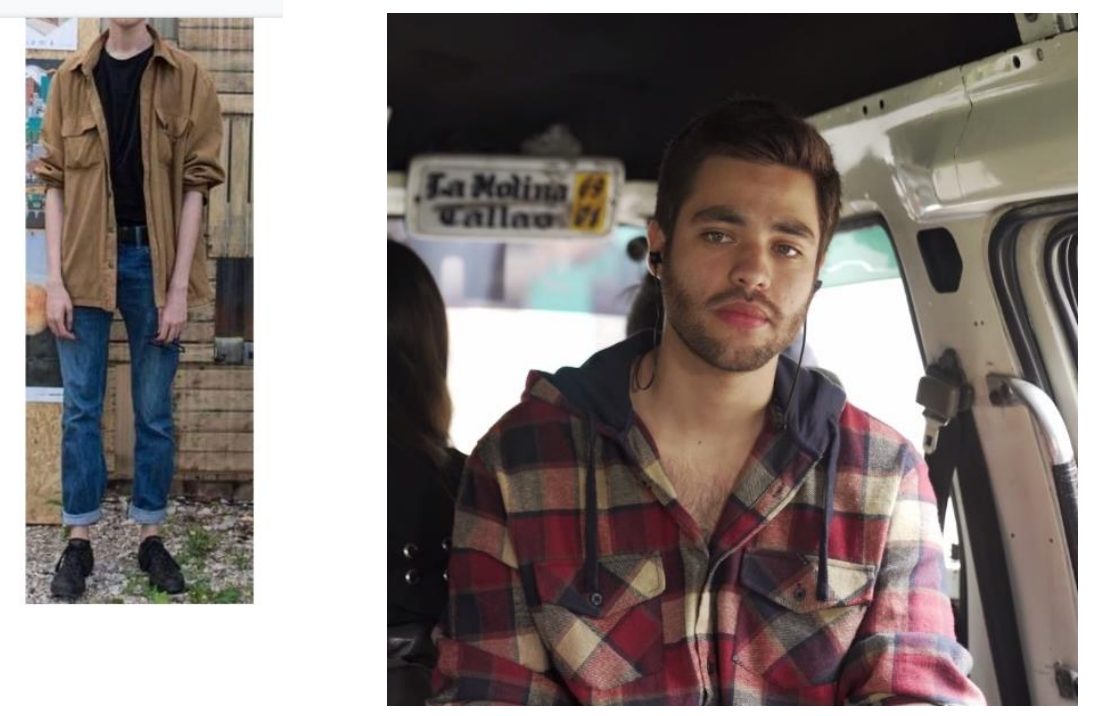

Figura 2.9 Referencias y fotograma de Atuendo \#1 para Valeria Atuendo \#1 para Chico \#1
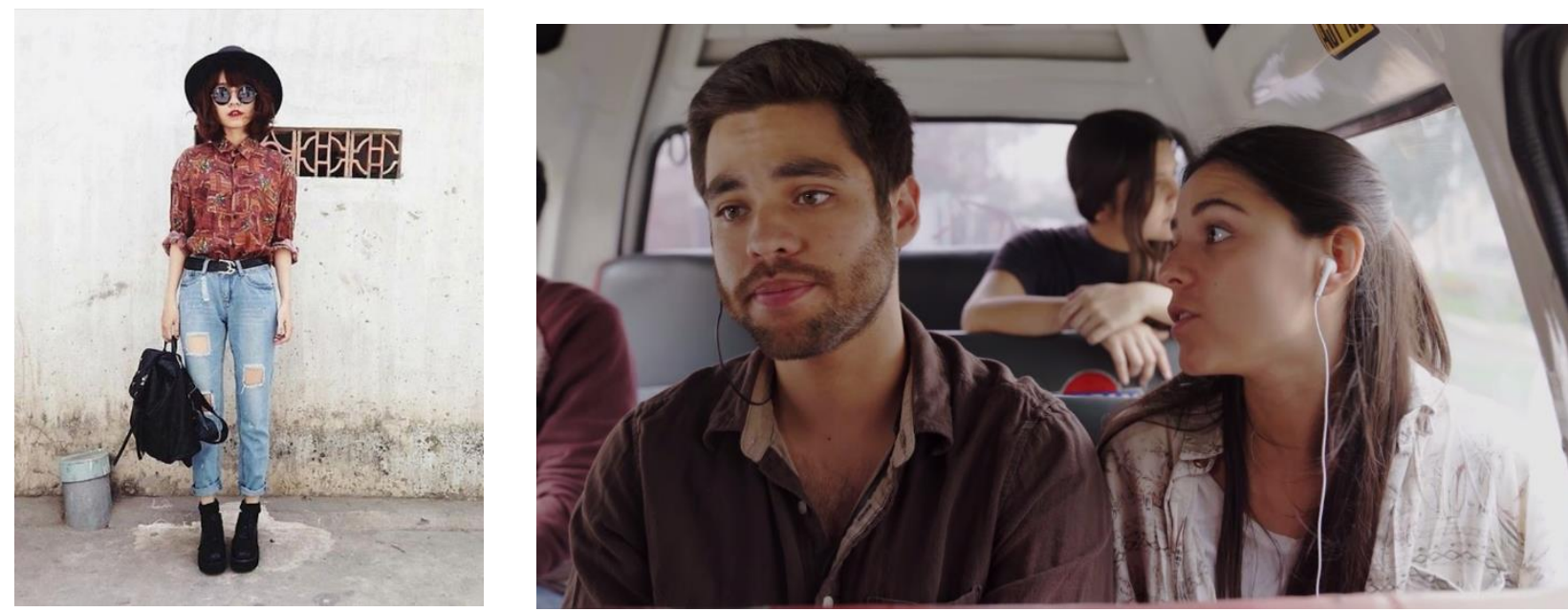

Figura 2.10 Referencias y fotograma de Atuendo \#1 para Valeria Atuendo \#2 para Valeria 

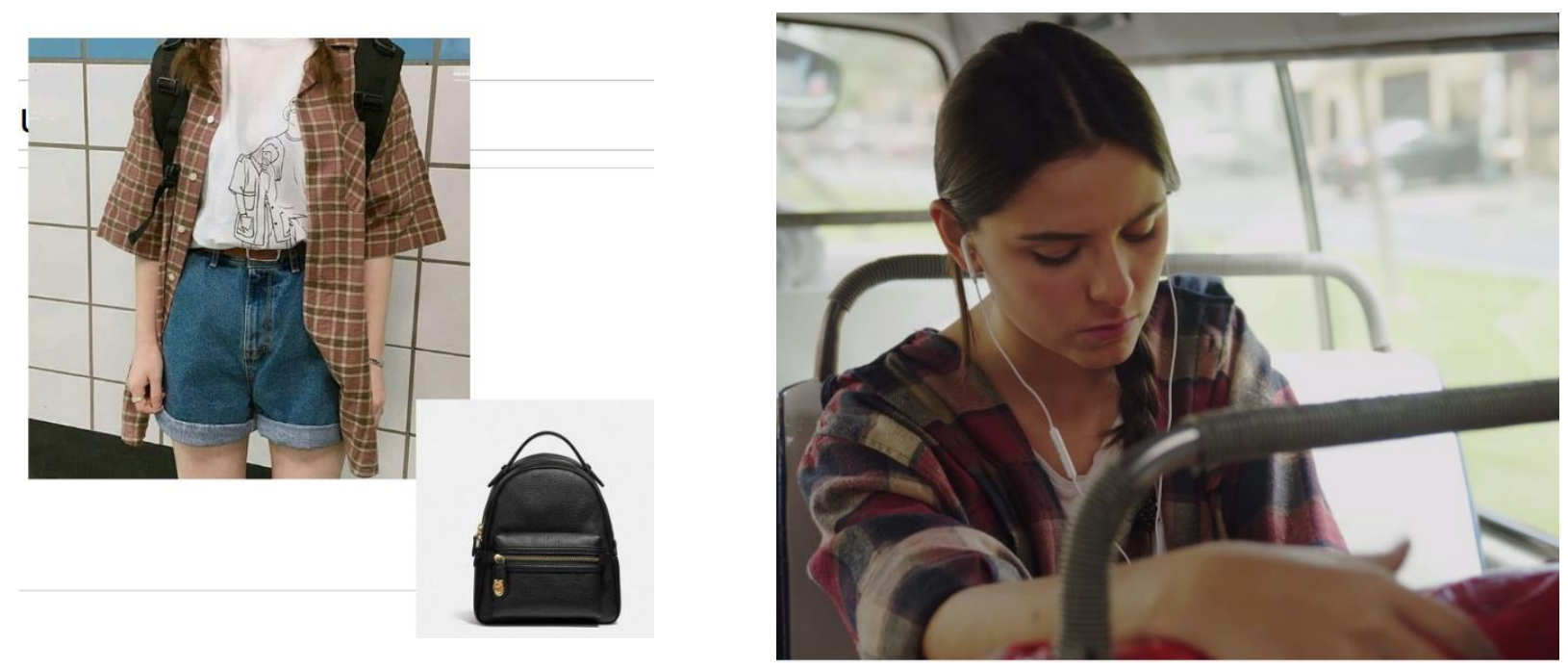

Figura 2.11 Referencias y fotograma de Atuendo \#1 para Valeria Atuendo \#3 para Valeria
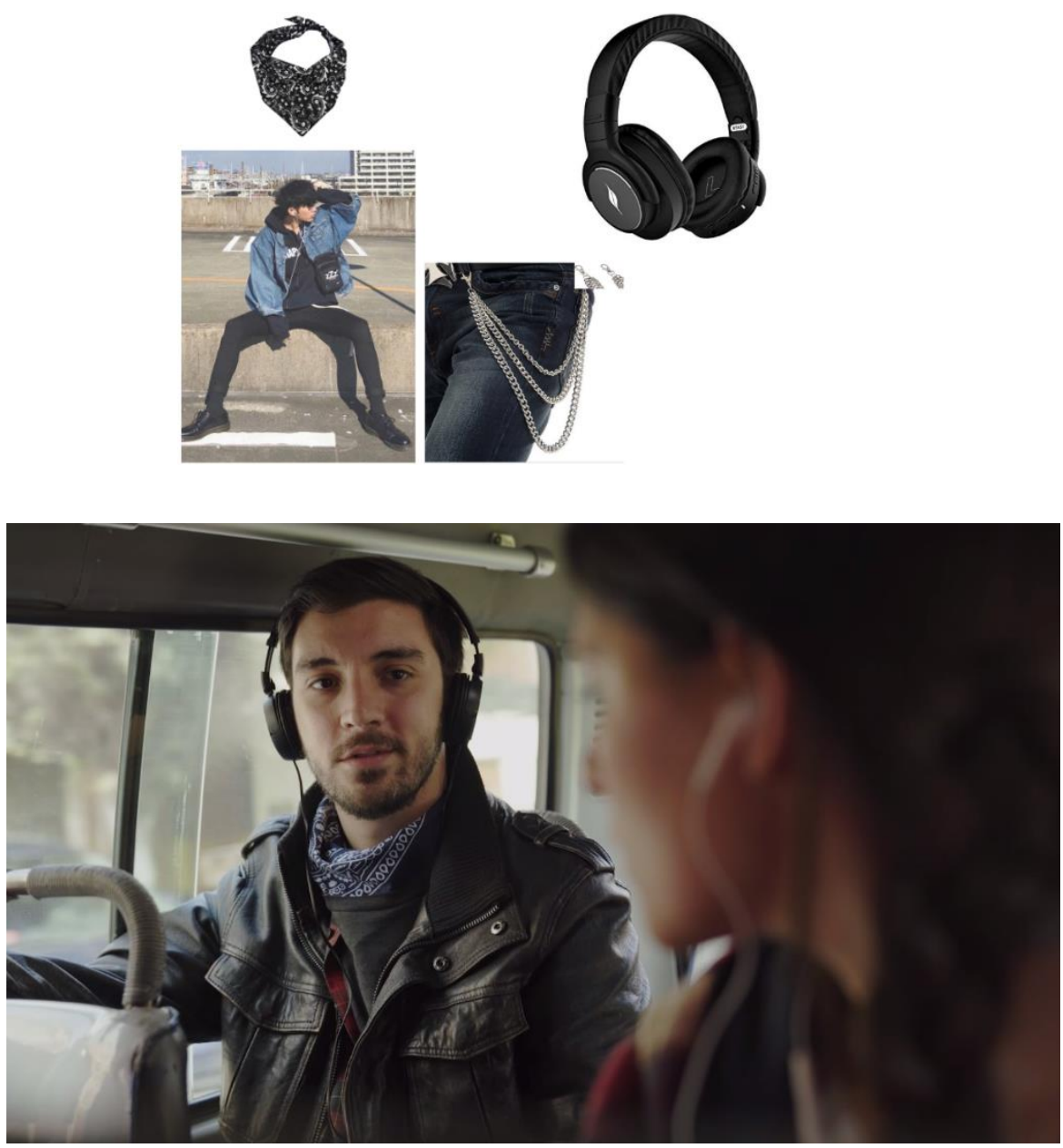
Figura 2.12 Referencias y fotograma de Atuendo \#1 para Valeria Atuendo \#1 para Chico \#2
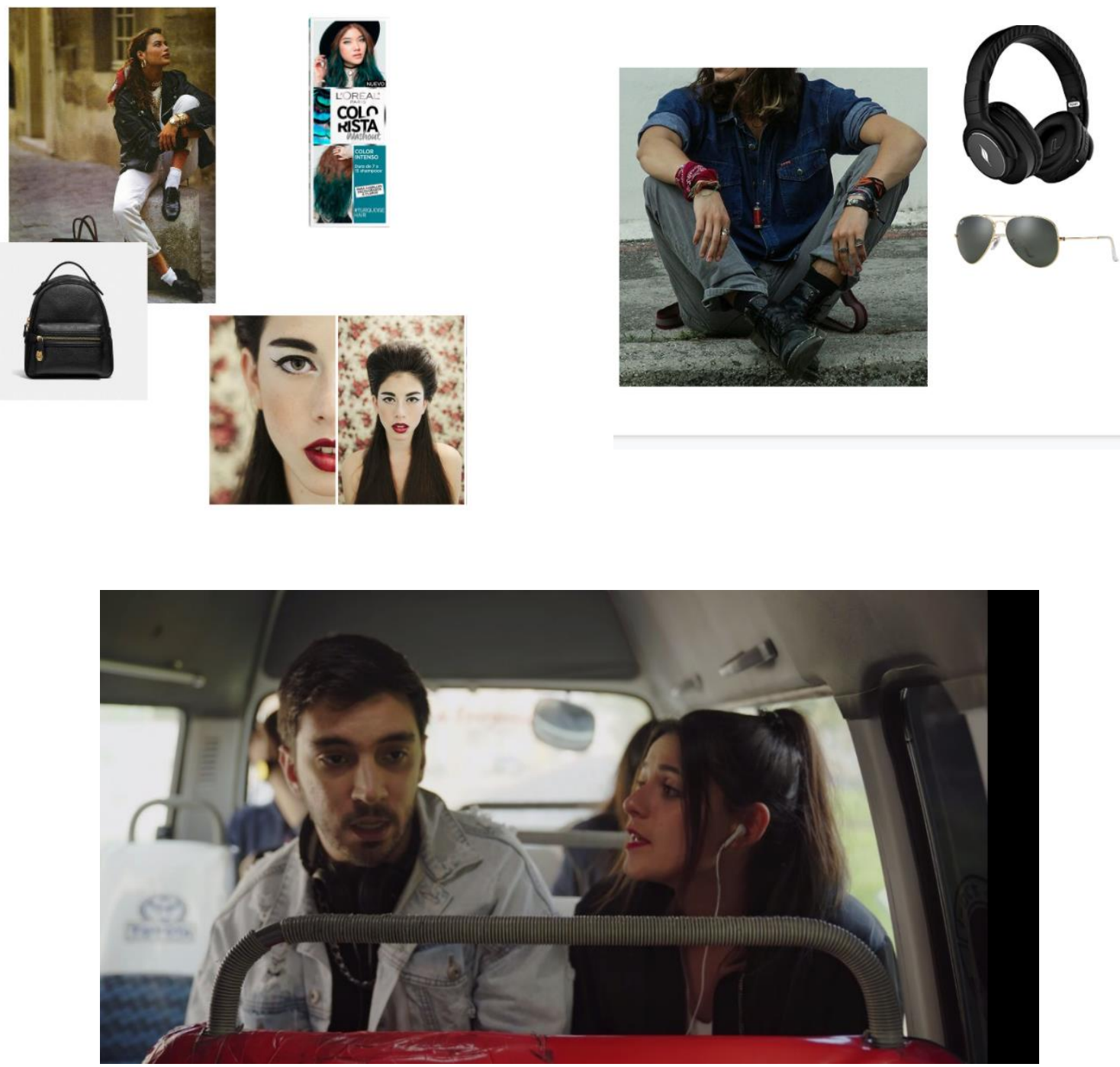
Figura 2.13 Referencias y fotograma de Atuendo \#1 para Valeria Atuendo \#4 para

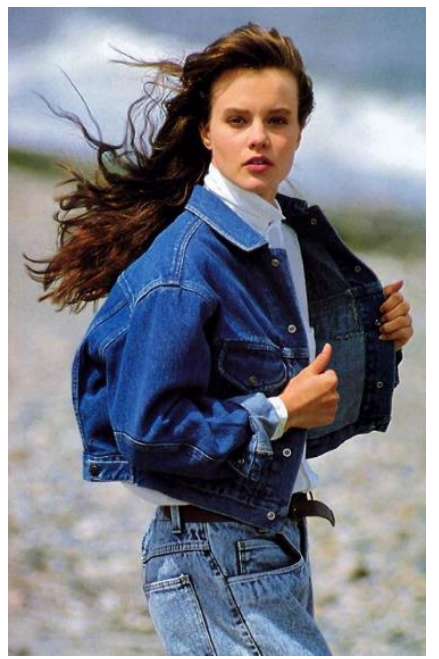
Valeria y \#2 para Chico \#2

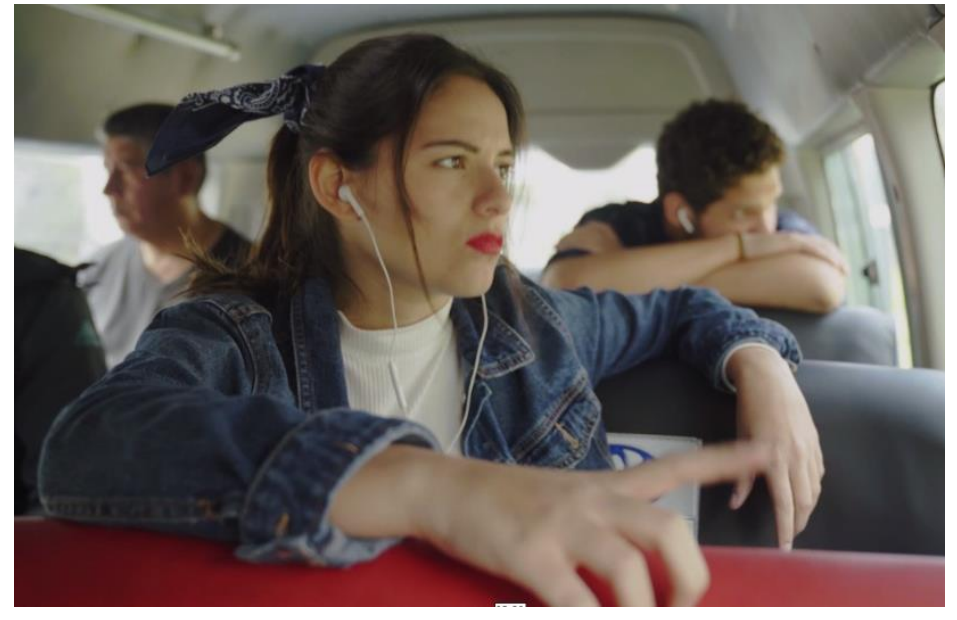

Figura 2.14 Referencias y fotograma de Atuendo \#1 para Valeria Atuendo \#5 para Valeria
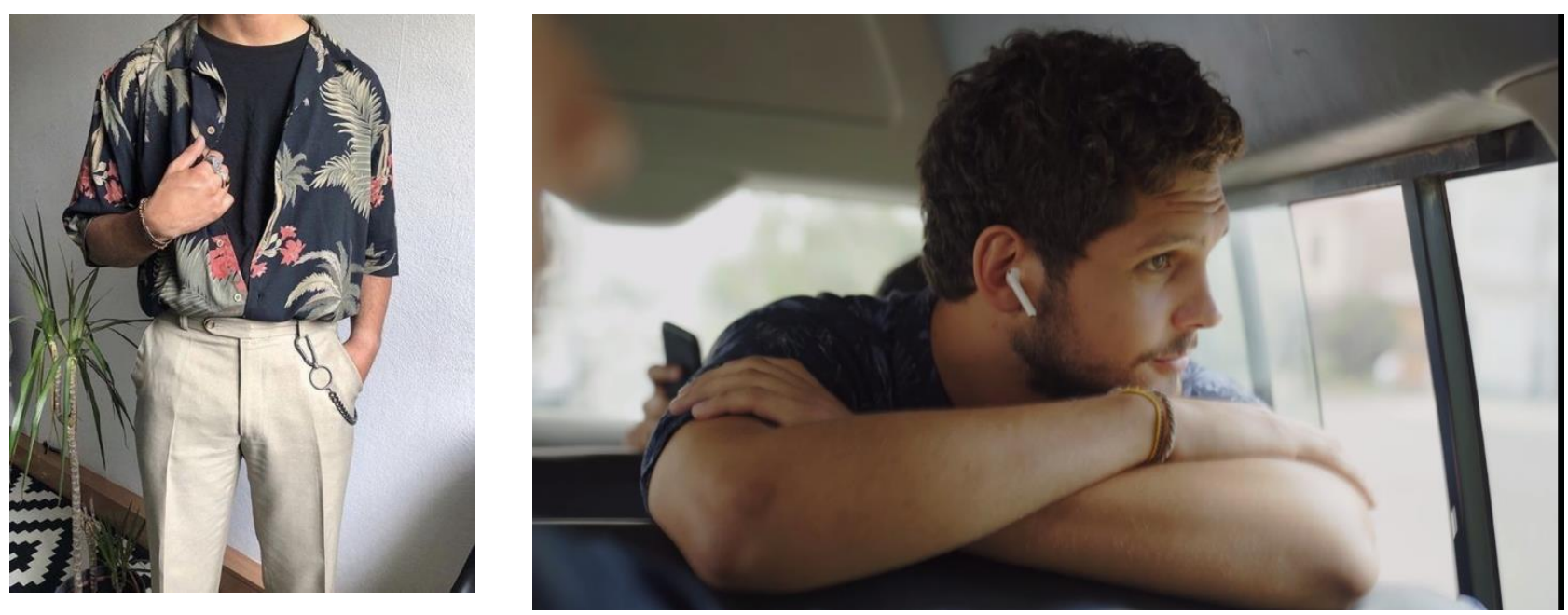

Figura 2.15 Referencias y fotograma de Atuendo \#1 para Valeria Atuendo \#1 para Chico \#3 

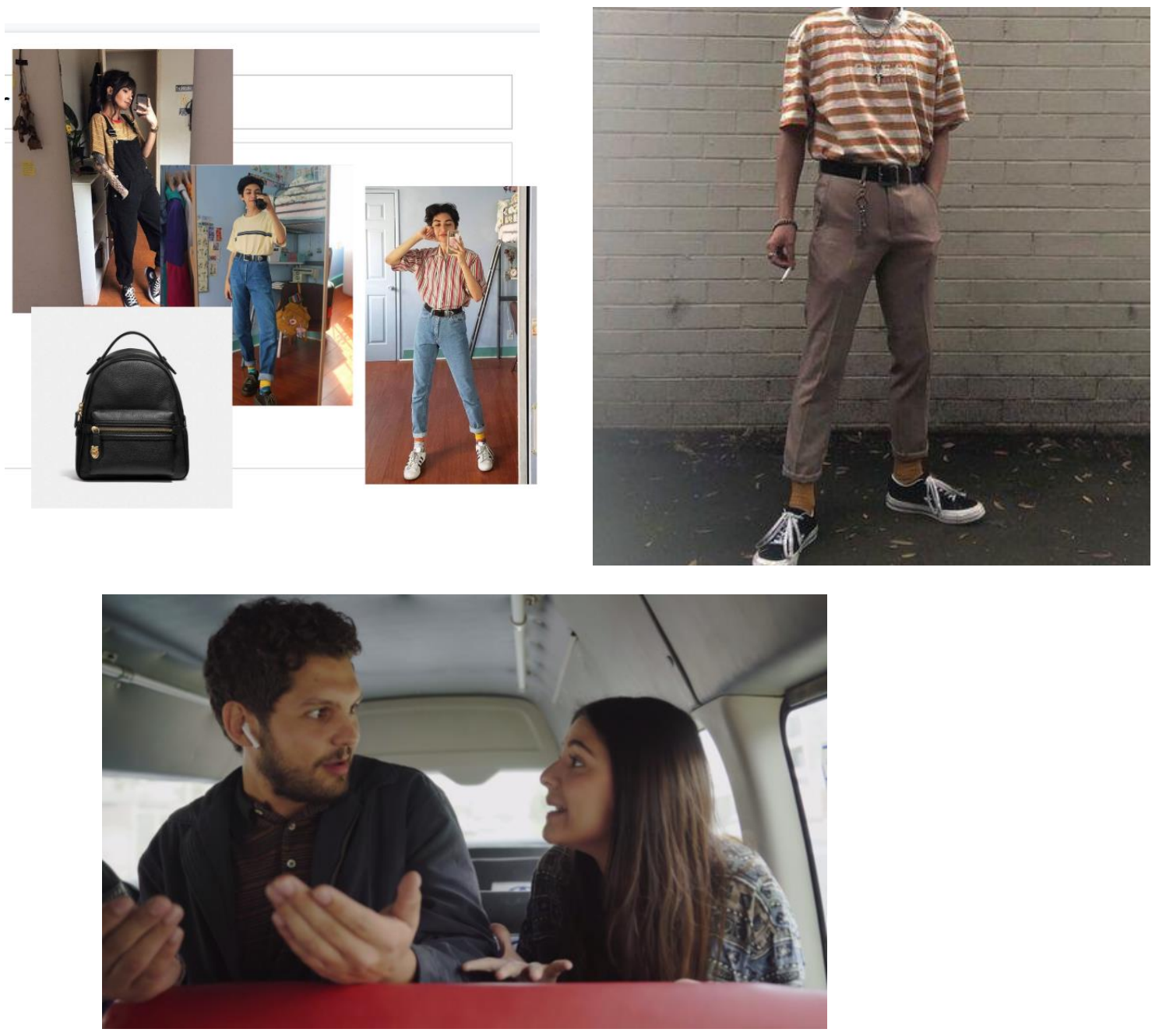

Figura 2.17 Atuendo \#6 para Valeria y \#2 para chico \#3
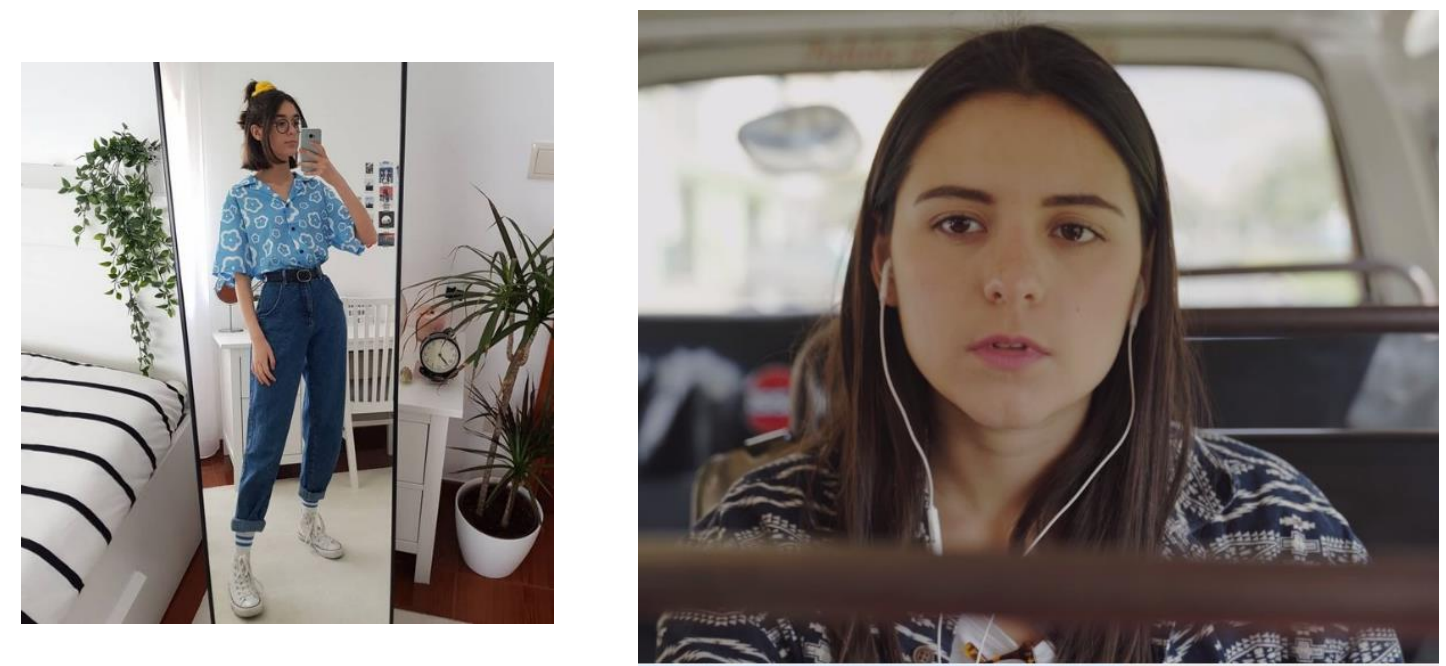

Figura 2.18 Atuendo \#7 para Valeria 

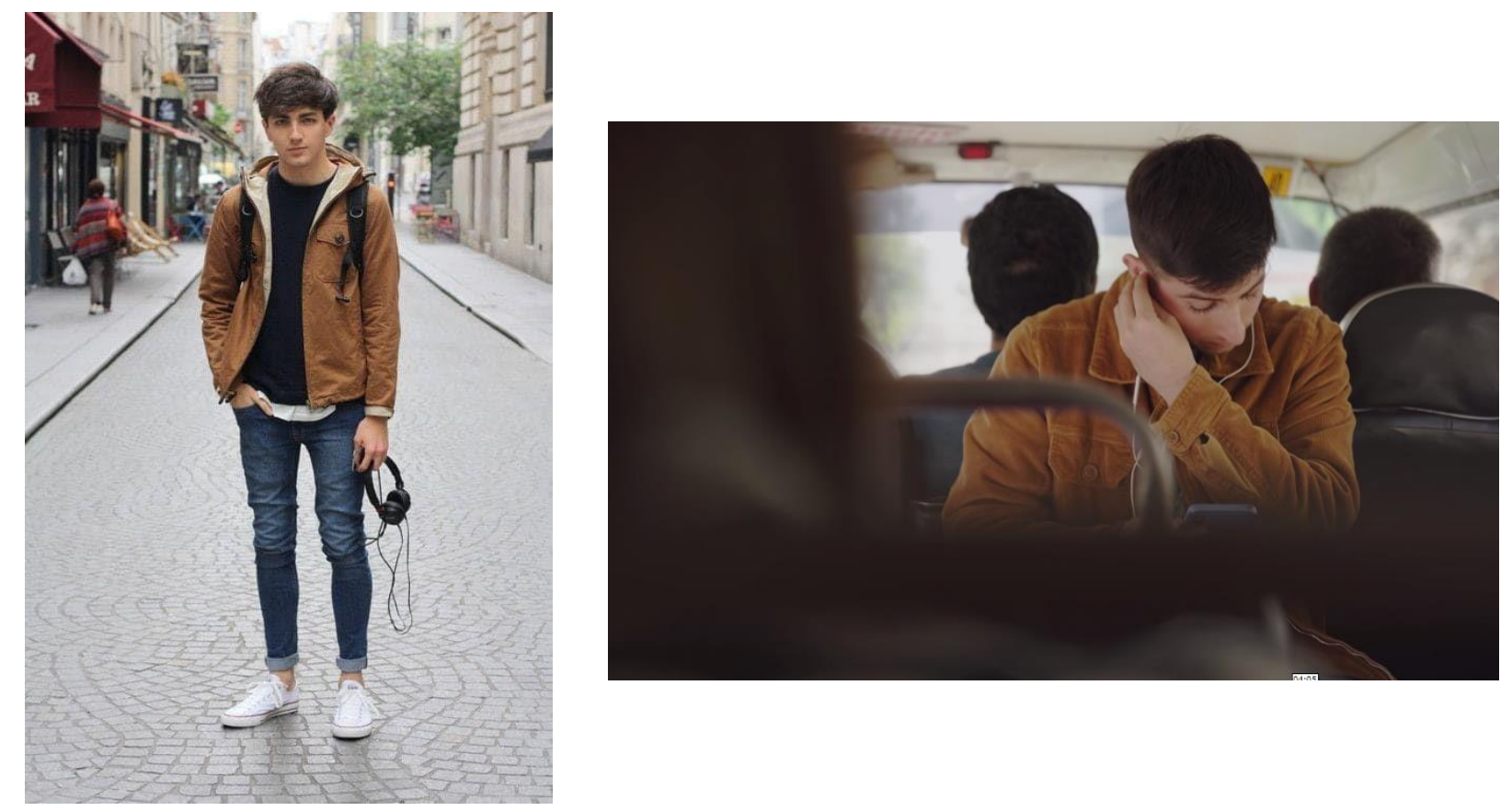

Figura 2.19Atuendo \#1 para chico \#4

\subsubsection{Diseño de sonido}

Por otro lado, a nivel sonoro también se trasladó la propuesta de construir la subjetividad de los personajes. Esto mediante la alternancia entre el carácter diegético y extradiegético de la música, presentándola primero como oída pero los personajes pero luego, al convertirse en música de ambiente, no se separa del personaje sino que más bien se vuelve aún más representativa de su interioridad pues expresa que, en ese momento, para ella/él esa es su realidad. Es así como ve la vida, como percibe la situación. Es además, por supuesto, el juego de la alternancia entre músicas lo que edifica la construcción de significado del estado de ánimo y de la falta de sincronía entre los personajes. En otras palabras, el diseño sonoro es la base de esta historia.

\subsubsection{Macarena (segundo episodio)}

\subsubsection{Dirección de fotografía}

Para este producto la fotografía también recogió el pilar básico de la serie de construir una mirada externa e irónica hacia la pareja. Esto se construyó mediante la elección de grabar la mayor parte del cortometraje en un plano secuencia fijo de la pareja en la cama. 
Fuera de dos planos iniciales que nos presenten a los personajes al despertar y nos introducen en sus mundos y sus estados de ánimo radicalmente distintos y fuera de sincronía, la escena principal se mantendría con este único two-shot que asfixia a los personajes y al espectador como si forzase a la pareja a estar junta a pesar que se odiase. Otra razón para la elección de este encuadre es que se trata de un plano común en las películas románticas. No obstante, se buscó tergiversar este recurso al grabarlo de cabeza, mostrando de antemano que ocurre algo fuera de lugar en la relación y amplificando la sensación de incomodidad. En las siguientes páginas, se presentan las referencias de este encuadre así como un cuadro del producto final con fines explicativos.

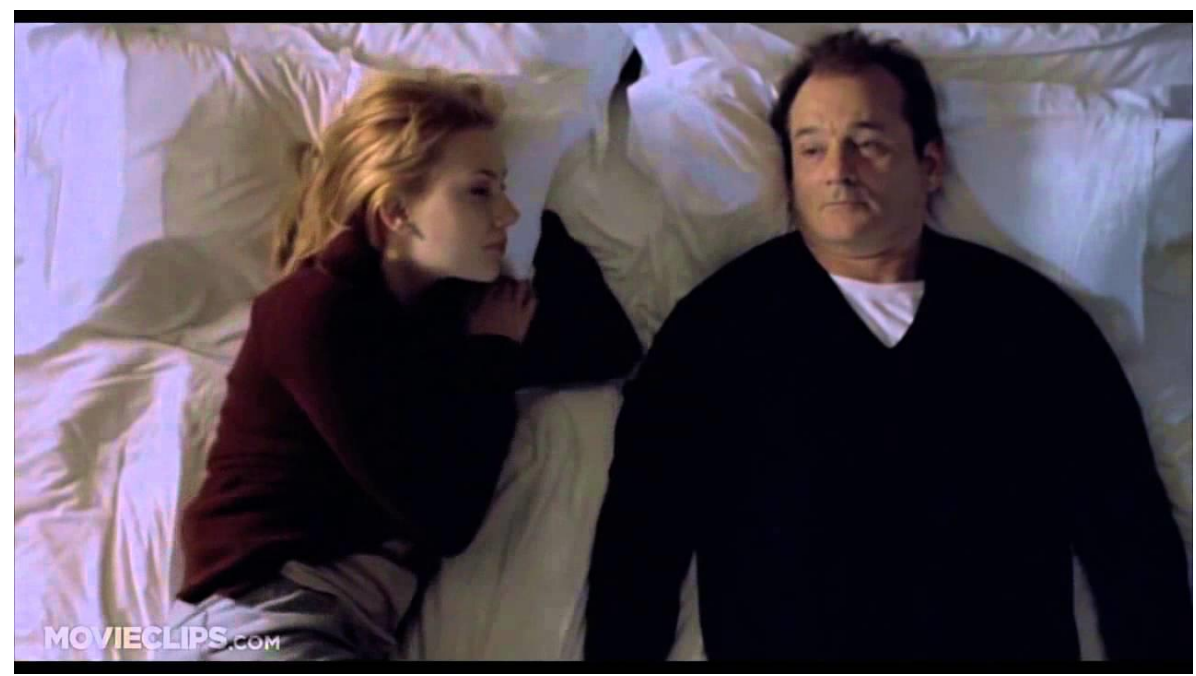

Figura 2.20 Fotograma de Referencia Película “Lost in translation” (2003)

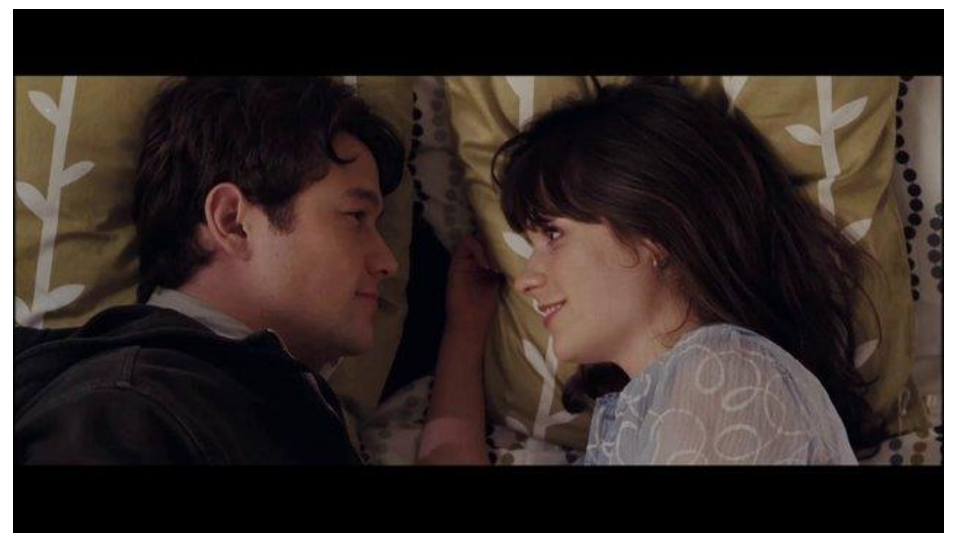

Figura 2.21 Fotograma de Referencia Película 500 hundred Days of Summer (2009) 


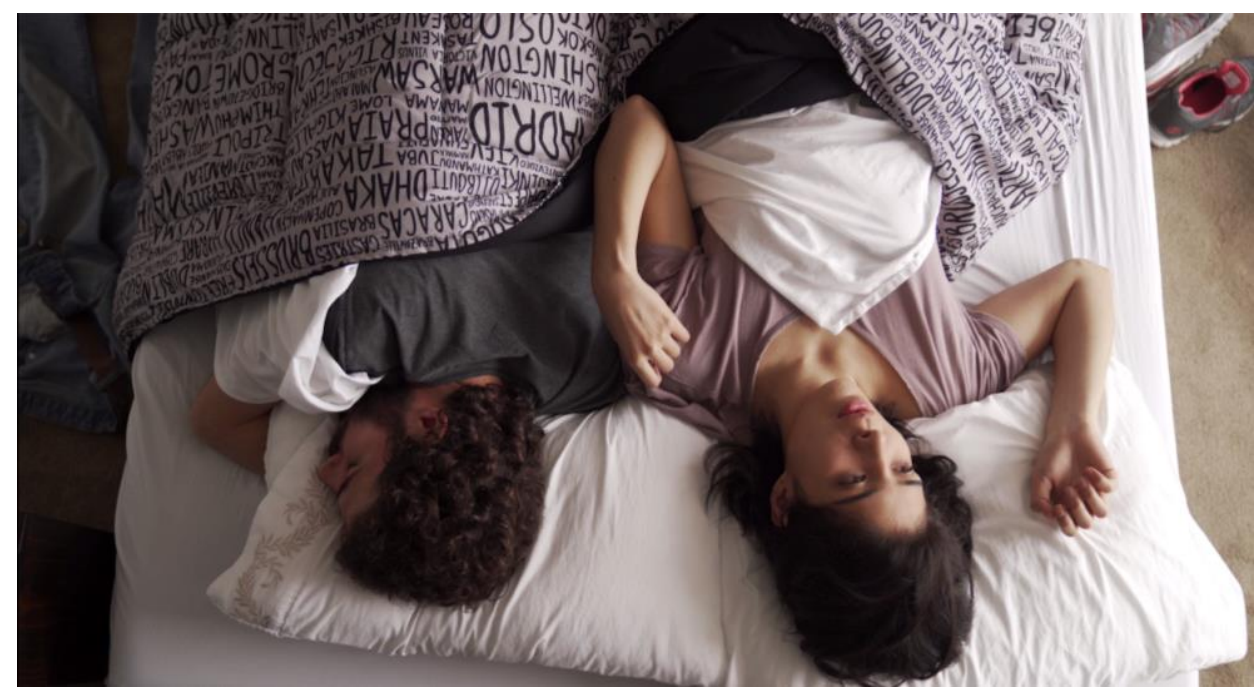

Figura 2.22 Muestra del encuadre final episodio Macarena

Asimismo, se buscó jugar con la dosificación de información de los insertos mediante el uso del espacio en on y off, mostrando primero la acción en planos detalle fuera de contexto, al igual que la conversación espontánea, y luego contextualizándolos al modificar la apertura del encuadre, al igual que los personajes empezaban a entender los reclamos que se hacían recíprocamente. Para graficar esta propuesta, se presenta un ejemplo de este juego de apertura del encuadre de manera ilustrativa.

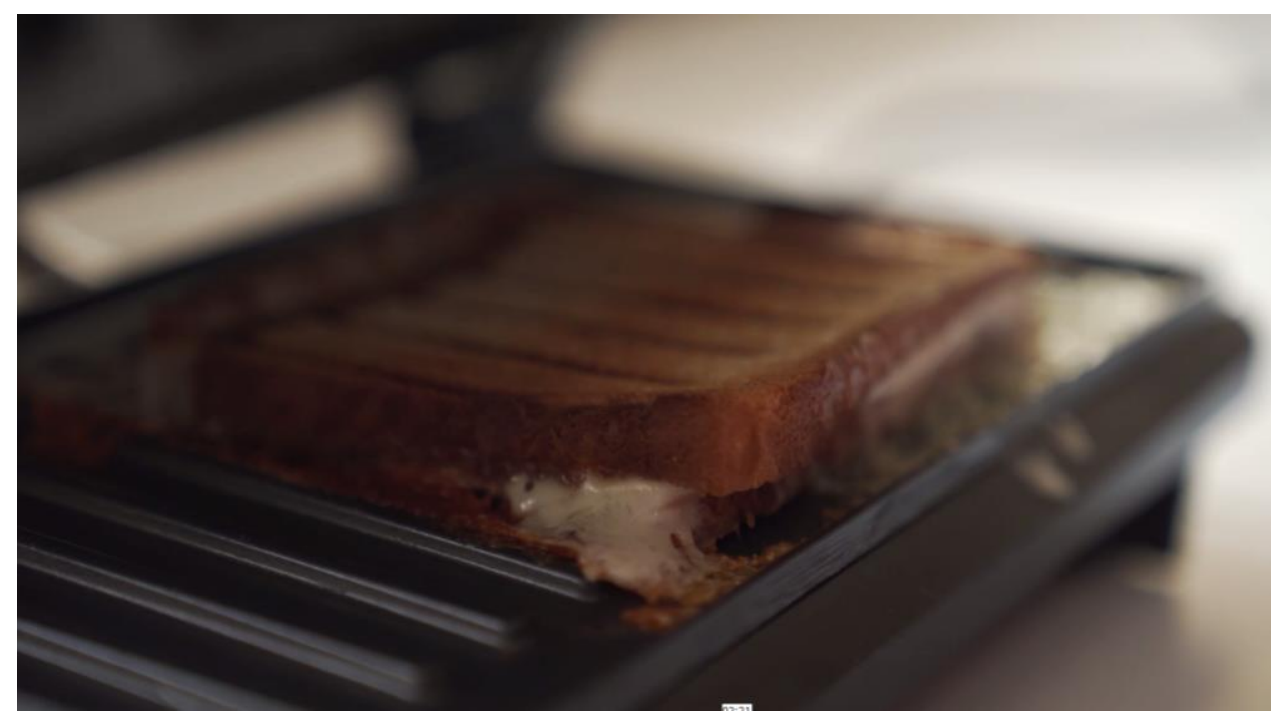




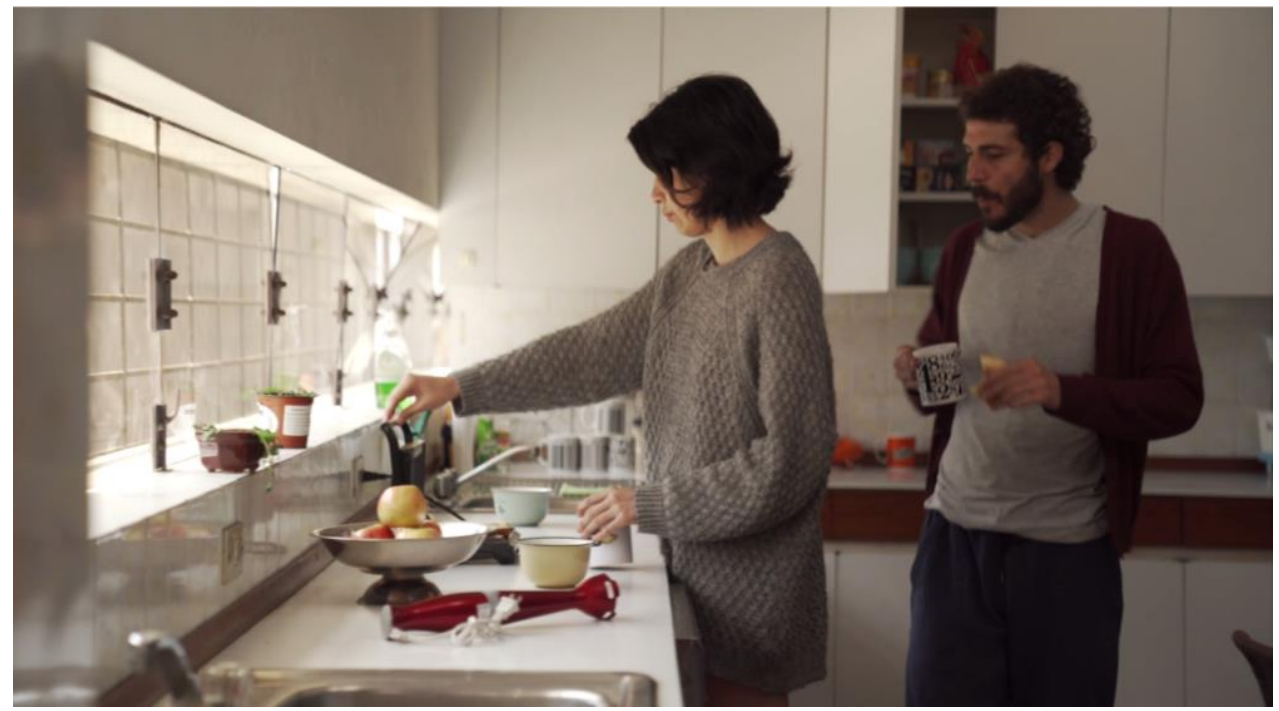

Figura 2.23 Muestra del juego de apertura de encuadres de episodio Macarena

Por otra parte, con respecto al tratamiento de luz y color, se buscó crear una atmósfera pulcra mediante el uso de una luz difusa, poco agresiva y balanceada al blanco. Esto debido a que se pretendía crear la figura de una convivencia aparentemente armoniosa y estética cuando realmente no era así.

\subsubsection{Dirección de arte}

El arte siguió también estos lineamientos, jugando con formas rectas, ambientes blancos y con predominancia de colores fríos. Asimismo, se buscó utilizar espacios amplios que permitieran un distanciamiento en los personajes inclusive en momentos cotidianos íntimos para que, acompañado con la frialdad de la paleta de colores, se erigiera la imagen retórica de esta pareja que, a pesar de convivir, mantiene sus distancias y son fríos uno con el otro pues no existe entre ellos una comunicación honesta y cercana.

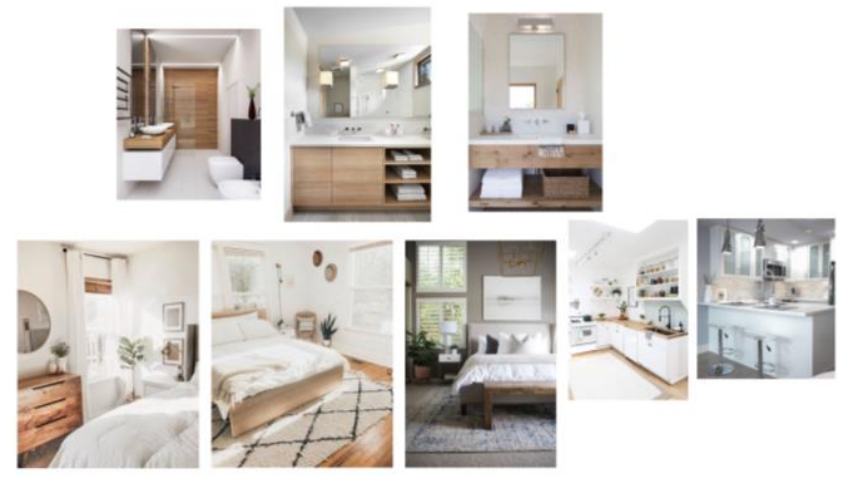

Figura 2.24 Referencias de arte para episodio Macarena 


\subsubsection{Diseño de sonido}

Con respecto al sonido, se planteó un tratamiento sonoro envolvente, puntual y estridente para los insertos de modo que, acompañados de su contraparte visual, transmitieran al espectador la misma incomodidad que generan diegéticamente para los personajes. También se planteó el uso de una música de carácter progresivo donde los instrumentos se acoplasen periódicamente sobre un mismo acorde básico generando una sensación de crescendo que apoye la subida de nivel de la discusión que se va acalorando. Todo esto hasta llegar a una cúspide cuando hallamos a Macarena sola y se contrapone aquí más bien el silencio, generando un contraste sensible para el espectador que se pueda asociar a la sensación que tiene ella. Por más que la música nos aturdía, sentimos ahora su ausencia y que nos hace falta.

\subsection{Fase de preproducción y realización}

\subsubsection{Elección de locaciones}

Para el primer episodio, se realizó la elección de cuatro vehículos de transporte público de acuerdo, como se mencionó previamente, a una paleta de colores eufórica dentro de los límites del realismo y a un estado de deterioro adecuado con la propuesta juvenil y poco anclada en la realidad local. Se decidió grabar en "custers" o "combis" debido a que la disposición de asientos favorecía diegéticamente el contacto visual y permitía jugar con una variedad de puestas de cámara que hicieran que el relato no se sintiese repetitivo una vez editado. Asimismo, se decidió que estos vehículos transitarían por la avenida los Fresnos en La Molina debido a que esta contaba con una atmósfera de clase media que apoyaba la búsqueda de una propuesta que se sintiese "universal". Por otra parte, la decisión de apoyó en temas logísticos ya que se trata de una avenida con poco tráfico y amplia de modo que el vehículo daría pocos giros que puedan afectar la continuidad provocar malestar físico en el equipo técnico.

Para el segundo episodio, se optó por utilizar una casa ubicada en el distrito de Surco que contaba con las características de amplitud, luminosidad, frialdad y paleta de colores que se incluían en la propuesta de la dirección de arte. 


\subsubsection{Elección del cast principal}

Para ambos episodios, se buscó trabajar con actores que no fuesen tan fácilmente reconocibles por la audiencia de modo que el recuerdo de personajes previos realizados por ellos no sea una interrupción o "ruido" para el espectador. No obstante, sí se necesitaba que fuesen actores profesionales puesto que las historias requerían de un trabajo a nivel corporal, gestual y de diálogo difícil de lograr con actores no profesionales. Para el primer episodio, se optó por contar con Paola Nanino como protagonista y con Ítalo Maldonado, Nicolás Vilallonga, Matías Campá y Bernardo Scerpella como coprotagonistas. Todas las elecciones se hicieron en base a la revisión de sus trabajos previos enfatizando la importancia del trabajo a nivel gestual y de la capacidad de escucha y reacción frente a sus co- intérpretes.

Para el segundo episodio, se optó por trabajar con Diana Chávez y Óscar Yepez debido a la revisión previa de sus trabajos y el empleo del diálogo en los mismos. Además, para este relato era imprescindible contar con una pareja que tuviese química en escena y estos dos actores habían realizado previamente performances juntos de manera satisfactoria. De mismo modo, pertenecían a la misma escuela de formación actoral (Ópalo), de modo que sus códigos de actuación estaban en sincronía.

\subsubsection{Elección del equipo técnico}

Se decidió que la cámara ideal para el registro sería la Sony a7iii, debido a que su tamaño compacto facilitaría el trabajo, especialmente para el primer episodio. Sin embargo, seguía siendo un dispositivo cuyo rango dinámico y resolución podría capturar la información necesaria para construir en la postproducción una imagen atractiva en términos de color y luz para el público objetivo y para ser un producto competitivo dentro del estándar de las producciones de la competencia directa e indirecta. Por otra parte, para el primer episodio se optó finalmente por no usar ningún estabilizador ni gimball externo debido a que la estabilización de la cámara era suficiente para lograr limpieza en el encuadre sin perder la sensación de subjetividad de estar en el vehículo como estipulaba a propuesta visual. Para el segundo episodio, se optó por utilizar un estabilizador simple para las tomas en mano pues también se buscó dotarlas de un poco de movimiento debido a que el público objetivo está habituado al movimiento en el encuadre en la mayor parte de los contenidos que consumen. 
Por otra parte, con respecto a la iluminación, el primer episodio fue grabado apoyándose en la luz natural con un pequeño refuerzo de una luz LED. Mientras tanto, el segundo fue grabado utilizando un equipo básico de fresneles ARRI, difusores y rebotadores dado que las características luminosas de la locación favorecían también el uso de la luz natural.

El registro sonoro se realizó por separado utilizando tanto un micrófono para registrar el sonido ambiental como pecheros para registrar el diálogo en el caso del segundo episodio.

\subsection{Fase de postproducción}

Durante la postproducción del primer episodio, el montaje se rigió por la musicalidad, siguiendo las pautas de la canción de base, aquella que escucha la protagonista. Se buscó utilizar los mismos criterios rítmicos de un videoclip sin perder de vista los ritmos necesarios para la decodificación narrativa de la historia. Asimismo, otra decisión importante tomada durante la post producción de este producto fue el utilizar como recurso el paneo de las músicas por las distintas salidas de audio. Esto permitió que la sobreposición de las músicas fuese caótica pero no perturbante para el oído. Asimismo, permitió construir un lenguaje en el que el espectador comprende que la salida del audio por un lado u otro se corresponde con la proveniencia diegética de la música del audífono de un personaje específico, lo cual es especialmente provechoso para el final. Por otra parte, para el segundo episodio, el montaje se rigió por un criterio de ritmo más narrativo y visual, que permitiese sentir la tensión deseada

\subsection{Validación}

Para la validación del producto, se realizaron dos focus group con miembros del público objetivo elegidos de manera aleatoria, sin ningún vínculo con los realizadores y ajenos a carreras profesionales afines al campo de las comunicaciones. Se buscó que hubiese una proporción equitativa de género y de edades. La discusión se llevó a cabo con una guía de preguntas que se puede encontrar adjunta a este documento. 


\subsubsection{Resultados de la primera sesión}

El primer grupo señaló que la serie sí fue de su agrado y que estarían dispuestos a consumir un tercer episodio. Señalaron que el episodio con el que generaron mayor conexión fue el primero puesto que les generó una sensación de intriga que los mantuvo pendientes y a la espera de saber qué pasará hasta el final y que esto les causó una sensación que definieron como "angustia" al ver que los chicos eran una pareja perfecta pero no llegaron a hacer contacto. Señalaron que el final los dejó reflexionando, es decir, que tuvo un alto impacto que los dejó pensando. Esto corrobora que los mecanismos de suspenso y sorpresa funcionaron de forma efectiva pues el suspenso fue lo que los mantuvo al hilo durante el desarrollo de la historia y la sorpresa del final fue lo que les generó esa sensación final inquietante que los dejó pensativos.

También señalaron respecto al primer episodio que les parecía un recurso interesante que no tuviera diálogos y que comprendieron perfectamente la propuesta de la superposición de las músicas. Además, señalaron que no les pareció que durase demasiado. Es más, lo sintieron más breve que el anterior por más que realmente dura casi el doble. Respecto a recomendaciones, dijeron que la primera transición de escenas (la primera pelea) no fue fácil de decodificar en un primer momento, pero sugirieron que esto podría arreglarse con un ajuste de color que generase la sensación de un clima distinto o un cambio en el montaje que permita ver con más facilidad que los vestuarios han cambiado

A cerca del segundo episodio, señalaron que también fue de su agrado pero que no generaron tanta empatía con él como con el anterior. Sugirieron un recorte en la duración de la escena final de la cocina. Ninguno señaló que el final o la dosificación de información fuese predecible. Del mismo modo, el elemento que sí les pareció confuso fue la moneda. Expresaron que sí les parece un ingrediente atractivo pero que no les quedó claro qué función cumple en el relato, por qué es una moneda el vínculo entre todos y no otro objeto y que no entendieron qué había pasado con ella al final del segundo episodio. Sugirieron que se le podría dar más protagonismo, pero al mismo tiempo señalaron que si este elemento fuese descartado, tampoco extrañarían su ausencia pues existe un vínculo temático que permite entender el concepto de la serie 


\subsubsection{Resultados de la segunda sesión}

Este grupo también señaló que la serie les agradó y que verían siguientes episodios. Ellos se sintieron más conectados con el segundo episodio. Señalaron que el primero les gustaba, comprendieron el juego con la música y sintieron también frustración con el final. No obstante, ellos sí expresaron que les parecía muy largo y que, cuando aparecía el tercer chico, ya habían comprendido la mecánica de la narrativa y el paso de este podría ser más rápido pues ya llegaban a cansarse y hasta a aburrirse.

No realizaron sugerencias mayores acerca del segundo pues fue el que más les gustó. En ambos casos, las mecánicas de dosificación de información, suspenso y sorpresa funcionaron adecuadamente. No obstante, ellos también señalaron que el ingrediente de la moneda no les quedó tan claro.

En base a los resultados de estas dos sesiones, se decidió realizar determinados ajustes de edición. En primer lugar, para el primer episodio se realizó un recorte de determinados momentos que los espectadores consideraron demasiado extensos. De esta manera, se logró reducir cerca de dos minutos de la duración total. Las escenas modificadas fueron el cruce de miradas con el primer muchacho, el cruce de miradas con el penúltimo y los traslados de la moneda. En el segundo episodio, se redujo la escena en la que ambos personajes desayunan juntos y, además, para reforzar el tránsito de la moneda que no había sido lo suficientemente explícito para todos, se le dio un tratamiento sonoro especial que reforzara su presencia. Adicionalmente, se trabajó con más detalle los niveles sonoros de la música de fondo para que cobrase mayor presencia.

\subsection{Diseño de distribución}

Para la distribución digital se realizó un diseño que permita una adecuada viralización y, mediante esta, la autosostenibilidad del proyecto a través de la participación de auspiciadores que busquen llegar al público objetivo juvenil al que se dirige este producto audiovisual y que deseen contagiar sus marcas del carácter de la serie.

Las plataformas elegidas son Instagram, Facebook y YouTube. Instagram vendría a ser la red de difusión principal debido a que es aquella que se encuentra en mayor crecimiento y que es más utilizada actualmente por el target. Aunque aún se ubique en el octavo 
puesto de las redes con más usuarios, es aquella que tiene más páginas visitadas en cada visita del usuario al alcanzar las 45 páginas por visita (Global Digital Report, 2019). En otras palabras, es utilizada por un sujeto más activo o los usuarios hacen más uso de esta interface que de otras, además, es una red cuya dinámica está basada en el contenido visual y audiovisual, donde la estética tiene una valoración crucial, a diferencia de otras redes donde publicaciones poco prolijas tienen menos detrimentos para alcanzar el éxito. Se trata también de una red que privilegia el engagement y la relevancia del contenido para el consumidor, y que beneficia a los productos y cuentas que logren estos requisitos dándoles más visibilidad y alcance orgánico. Al tratarse de un producto de entretenimiento que no se impone al espectador, sino que busca adaptarse y captar su interés, podría verse beneficiado por los mecanismos de esta red social y perfilarse como una opción atractiva en comparación con otros métodos publicitarios para los posibles auspiciadores interesados en tomar presencia en este medio. Las emisiones se apoyarán en la herramienta Instagram TV, actualmente en crecimiento en Latinoamérica, que permite llegar al espectador en el feed de noticias, pero implica que deberá interactuar mediante el botón de "continuar en Instagram TV" si desea terminar el relato, lo cuál será un indicador de conversión útil. Los KPI ideales para medir el desempeño de la serie serán el número total de seguidores de la cuenta, el número de nuevos seguidores por semana, el número de "ya no seguidores", el ratio de alcance, los me gusta, los comentarios, los repost, el ratio de engagement, los clicks en enlaces de biografía y de contenido y los clicks de pago.

Otra red utilizada será YouTube debido a que es la red donde los usuarios afirman que esperan encontrar o, más importante aún, donde buscan contenido del tipo al que se adscribe este producto audiovisual. A través de Instagram y Facebook, se espera llegar al consumidor que no está buscando activamente el contenido, aquel al cual el producto se le presentará como lo que en marketing tradicional y no digital se conoce como "bienes de impulso", es decir, aquel que el cliente no espera pero que está dentro de su esfera de necesidades o deseos (en este caso traducido a sus intereses) y que no conoce pero que decide consumir cuando se le presenta. En cambio, a través de YouTube se busca llegar a consumidores que busquen activamente el contenido ya sea porque no son ajenos al formato de la serie web o porque conocieron los episodios a través de otra red social o del boca a boca y deciden buscarlo en su plataforma predilecta para consumo audiovisual y, específicamente, audiovisual de ficción. Para ello, se integrará una estrategia SEO 
especializada para esta red de modo que se garantice y facilite la llegada del espectador mediante la búsqueda. Los KPI indicados para esta red serán la cantidad de suscriptores, el crecimiento de suscriptores por semana, el número de reproducciones, el número de reproducciones orgánicas y pagadas, los me gusta, los comentarios y los clics en enlace. Por otra parte, se utilizará la red social Facebook debido a que esta aún tiene relevancia en el segmento de edad y a que sigue perfilándose como una opción importante en cuanto a sus herramientas para compartir contenido no propio como es esta serie web. De acuerdo al Global Digital Report (2019), sigue siendo la red social con más usuarios activos (p.81). Sus objetivos en cuanto a ocasión de consumo son iguales a los de Instagram, pero dirigidos a un público que no haya migrado a dicha red social o no enfoque su consumo de este tipo de contenido en ella. Los KPI seleccionados son número de seguidores, número de nuevos seguidores semanales, número de "ya no me gusta", alcance orgánico y pagado de la página y de las publicaciones, me gusta, comentarios y comparticiones de las publicaciones, reproducción del video y total de interacciones.

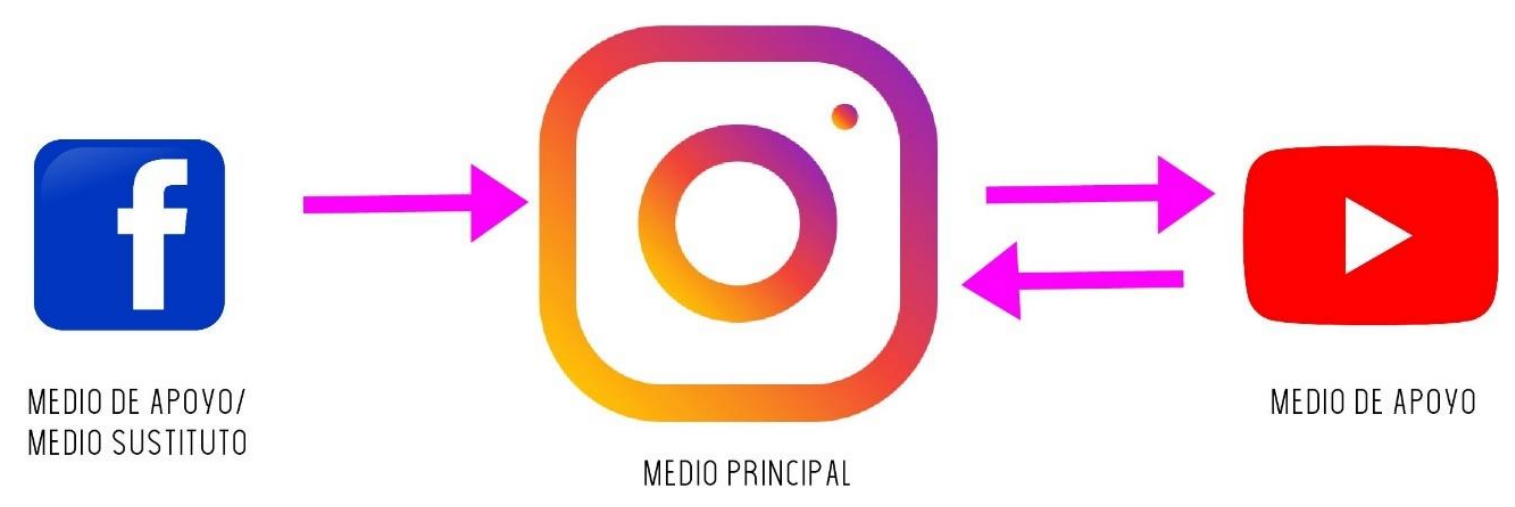

Figura 2. 25 Gráfico de funcionamiento de estrategia de redes

La estrategia general de distribución se basará en la búsqueda de tráfico orgánico apoyado en la divulgación por parte del público y de colaboradores influencers sumado a un impulso inicial generado mediante alcance pagado en el lanzamiento del proyecto y el de cada episodio. Esto se adscribe a lo que Miguel Florido (2019) describe como estrategia de social media mediante medios ganados y medios pagados (p.104). 
La frecuencia de lanzamiento de los episodios será con una distancia de 2 o 3 semanas debido que se necesita establecer un intervalo de tiempo que favorezca el generar engagement como clave y este no es solo difícil de lograr en un tiempo corto como el que resultaría con un lanzamiento semanal, sino que es imposible de mantener en el largo plazo dado que habría un periodo demasiado corto de emisión de contenido seguido de un tiempo demasiado largo de espera hasta una siguiente temporada. Entre los estrenos de los episodios se publicaría contenido de mantenimiento y generación de expectativa que incluiría videos y fotos de making off, recordatorios o evocaciones del episodio ya emitido bajo la forma de stills, gifs, frases, etc. que inviten a la conversación, trailers o adelantos de video o fotos del próximo episodio, etc. 


\section{LECCIONES APRENDIDAS}

Este proyecto trajo consigo una larga serie de lecciones valiosas respectivas a las fases de pre producción, grabación, postproducción y validación de la primera versión del producto finalizado.

\subsection{Preproducción}

A nivel de preproducción, fue muy importante tener claros los fines del relato y los recursos que podrían colaborar con este o no al trabajar las propuestas con los directores de área pues, al tratarse de relatos tan breves, distintos elementos que causasen ruido podrían interrumpir la decodificación del mensaje de la historia. Por ejemplo, en un momento el área de foto propuso el trabajo de los insertos del episodio "Macarena" en cámara lenta. No obstante, el realizarlos de este modo hubiese cambiado por completo el mensaje puesto que este tratamiento de cámara trae consigo connotaciones nostálgicas, idealizadas y románticas que hubiesen transmitido la idea de que "a pesar de los detalles fastidiosos eran momentos agradables" lo cual es ligeramente distinto a la idea que el guion ponía sobre la mesa.

Asimismo, a pesar de ser relatos de duración breve, esto no implica que no requieran una inversión mínima para asegurar su calidad ya que, para alcanzar el nivel profesional deseado y la estética planteada para su atractivo como relatos cortos para el competitivo entorno digital, se requería de contar con un equipo capacitado, un elenco apropiado, una dirección de arte bien trabajada y costos de producción que pudiesen acelerar los procesos de rodaje. Del mismo modo, no solo era necesaria una inversión monetaria adecuada sino también contar con tiempos de rodaje adecuados para asegurar la calidad de cada toma y permitir al equipo trabajar sin estrés para poder tomar las decisiones correctas sin presión. Otra lección valiosa es que, al menos durante el rodaje, es importante que el director asuma solamente las funciones que le corresponde y no las del productor puesto que su labor requiere su concentración completa. 


\subsection{Grabación}

Durante el rodaje se entendió que incluso en locaciones limitadas de espacio como es una combi, existe una gran cantidad de posibilidades de cobertura visual y que ligeras variaciones de escala y ángulos de planos pueden crear distintas denotaciones y connotaciones. Por ejemplo, planos más frontales del personaje de Valeria sirvieron para marcar su interioridad y situar al espectador en ella mientras que ángulos más laterales fueron más apropiados para cubrir las interacciones y establecer ejes de mirada. Las escalas no solo permitieron variedad, sino que ayudaron a fijar en el punto de vista de qué personaje estábamos y a acentuar la progresión de las emociones del personaje.

\subsection{Postproducción}

La fase de postproducción fue la que trajo consigo más lecciones. Para comenzar, se utilizó la capacidad del lenguaje para la reescritura utilizando de manera distinta a la pensada el material existente. Este fue el caso en el episodio "Valeria" puesto que bastantes elementos fueron re pensados tal como se explicó previamente. Además, se corroboró la influencia que tiene la música en la decodificación del relato ya que en el episodio "Macarena" el corte con música y el corto sin música generaban sensaciones, percepciones y hasta mensajes distintos. Inclusive géneros diferentes. También hizo notoria la necesidad de reiteración para fijar elementos que son un punto de interés como la moneda pues esta no llegó a ser clara con la cobertura realizada.

\subsection{Validación}

Por otro lado, la validación trajo consigo interesantes resultados. Se pudo observar cómo los relatos suscitan efectos y sensaciones diferentes entre los espectadores dependiendo de su experiencia emocional previa. No sólo en términos de gustos sino de la decodificación del mensaje. Asimismo, fue interesante ver cómo al tratarse de relatos breves que muestran situaciones concisas y ancladas en un espacio-tiempo específico sin brindar mucho contexto sobre los personajes y sus relaciones, distintas interpretaciones afloran entre los videntes, relacionadas también frecuentemente a sus vivencias. Mientras algunos interpretaban la falta de compatibilidad de "Valeria" con sus prospectos como 
un mal producto del azahar, otros consideraban que se trataba de un problema del personaje a nivel interno y que era quizá ella quién hacía que las relaciones no funcionasen y no se daba cuenta, otros consideraban que el personaje tenía una recurrencia por relacionarse con personas tóxicas que le harían daño. Mientras tanto, en "Macarena", mientras algunos se enfocaban en la desesperación de cuestionarse por qué los personajes no terminaban una relación que claramente no funcionaba y el final les pareció irónico, otros se sintieron identificados con la situación y les pareció paradójico pero también identificable y humano. 


\section{LOGROS Y RESULTADOS}

Para medir los resultados del proyecto, se realizaron dos proyecciones a modo de estreno con miembros del público objetivo y profesionales del campo. La primera dinámica contó con un público conformado por 34 miembros y la segunda con 74. En ambos casos, primero se proyectaron ambos episodios tras una breve presentación del proyecto y después se dio lugar a un conversatorio en el que la audiencia expresó sus opiniones, sugerencias, comentarios y dudas con respecto a los dos episodios. En la primera sesión este diálogo se realizó con la ayuda de un moderador y sin la presencia de la directora ni ningún realizador de los productos. El segundo conversatorio se realizó con la directora.

La recepción de ambos episodios fue, en términos generales, muy buena. La cualidad más resaltada por la audiencia fue el hecho de que se trataba de una exploración de nuevas formas de narrar distintas a las estructuras clásicas que suelen ver en pantalla. Esto es bastante positivo pues tiene una relación estrecha con el objetivo general que se propuso ya que este consiste en explorar nuevas potencialidades en el formato corto más allá de imitar cabalmente las fórmulas tradicionales de las estructuras de formatos de duración más larga. El público recibió con entusiasmo y señaló que le gustaba el uso de recursos como la música o la reiteración y resignificación de diálogos aparentemente banales para contar una historia y plasmar un concepto. Señalaron que consideraban que se trataba de situaciones en cierto modo "abstractas" o "metafóricas" distintas al desarrollo de conflicto usual que suelen ver en pantalla. Además, señalaron que querían seguir viendo más episodios de la serie para saber qué nuevos recursos se utilizarían para narrar desamores en estos relatos cortos. 
Uno de los recursos más valorados de estas fórmulas atípicas fue el uso de la música y la ausencia de diálogo durante en primer episodio. Se apreció bastante las metáforas de los audífonos, la sincronía/ asincronía de las canciones, etc. para dar a conocer la situación y el concepto representados. La audiencia también expresó simpatía y aprobación particular hacia la canción principal (Puente de André Urban) puesto que dijeron que era bastante apropiada en cuanto a melodía y también en cuanto a la letra para representar el estado emocional de la protagonista y el sentido general del episodio.

Asimismo, otro aspecto muy valorado en las opiniones de estos dos grupos fue cómo se estructuraron los finales. Al público le gustó que se tratase siempre de finales que retorcieran las expectativas y los dejaran con un alto impacto que provocaba una reflexión. Esto también está ligado al objetivo secundario del aprovechamiento del recurso de la sorpresa.

Por otra parte, también se mostró un sentimiento de empatía por la temática de la serie y se señaló que les gustaba porque los finales mostraban la realidad amarga o agridulce de cómo son las relaciones amorosas. El paso de la moneda como nexo entre historias también les pareció un recurso importante y los dejó interrogándose por qué.

En base a estos resultados se puede concluir que la consecución de los objetivos planteados al inicio de este proyecto fue satisfactoria. Dado que la meta principal estipulada fue explorar nuevas posibilidades en narraciones de corta duración se puede afirmar que esto se logró ya que fue el principal atractivo señalado por la audiencia. Ya sea porque apreciaron el uso de la música, de los insertos de imágenes, la no temporalidad, etc. la arista común de la mayor parte de los comentarios positivos es que existe una valoración positiva hacia el uso de recursos y fórmulas distintas. Asimismo, el impacto generado por los finales de ambos episodios es una muestra de cómo los procedimientos narrativos aplicados y fijados en los objetivos secundarios alcanzaron también resultados óptimos. 


\section{REFERENCIAS}

Chion, M.. (1992). Cómo se escribe un guión. Madrid: Cátedra S.A.

Florido, M. (2019). Curso de Marketing Digital. Madrid: Social Business.

García, H., Montoya, D. (6 de Septiembre del 2016). Estructuras narrativas en relatos cortos y serializados para la web. Anagramas, 15, pp 103-118.

Henriksen, L. (Invierno del 2018). "Spread the Word": Creepypasta, Hauntology, and an Ethics of the Curse. University of Toronto Quarterly, 87, p266-280.

Hernández, P. (16 de Septiembre del 2011). Las Webseries: Evolución y características de la ficción española producida para Internet. Revista Faro, 13, pp 94-104.

Holiday, R. (2014). Growth Hacker Marketing. Madrid: Social Business.

IPSOS Perú. (2017). Perfil del internauta limeño. 12/10/2019, de IPSOS Perú Sitio web: https://www.ipsos.com/es-pe

IPSOS Perú. (2017). Perfil del smartphonero. 12/10/2019, de IPSOS Perú Sitio web: https://www.ipsos.com/es-pe

IPSOS Perú. (2017). Perfil del adulto joven. 12/10/2019, de IPSOS Perú Sitio web: https://www.ipsos.com/es-pe

Scolari, C. (2015). Narrativas transmedia: Cuando todos los medios cuentan. España: Grupo Planeta.

Tobías, R. (2004). El Guión y la Trama. Madrid: Ediciones Internacionales Universitarias.

Truffaut, F. (1966). El cine según Hitchcock. París: Simon \& Schuster.

Viñuela, E. (14 de Mayo del 2013). El videoclip del siglo XXI: el consumo musical de la televisión a internet. Univ. de Oviedo 33011, p167.

We Are Social. (2019). Global Digital Report. 12/10/2019, de We Are Social. Sitio web: https://wearesocial.com/global-digital-report-2019 


\section{Filmografía y videos}

Anderson, P., Frauman, E., Murphy, S. (productores) y Anderson, P. (director). (2019). Anima [película]. Reino Unido: PASTEL

Bregman, A., Golin, S. (productores) y Gondry, M. (director). (2004). Eternal Sunshine of a Spotless Mind [película]. Estados Unidos: Anonymus Content, This is That Productions

Copolla, S., Katz, R. (productores) y Copolla, S. (director). (2003). Lost in Translation [película]. Estados Unidos, Japón: American Zoetrope, Tohokushinsha Film

Donen, J., Fincher, D. (productores) y Miller, T. (creador). (2019). Love, Death, Robots [serie]. Estados Unidos: Blur Studios, Netflix

Fake News Writter. (15 de Octubre del 2018). Fake News Writter Episode 1 YouTube Series. [archivo de video]. Recuperado de: https://www.youtube.com/watch?v=Ar2I002XYIM

Manual de Soltería (18 de Noviembre del 2015). Manual de Soltería- Episodio 1. [archivo de video]. Recuperado de: https://www.youtube.com/watch?v=MXFs $98 \times \mathrm{PhQ}$

Marble Hornets. (20 de Junio del 2009). Entry \#1 [archivo de video]. Recuperado de https://www.youtube.com/watch?v=Bn59FJ4HrmU

Novick, M., Tuchinsky, J., Waters, M., Wolfe, S. (productores) y Webb, M. (director). (2009). (500) Days of Summer [película]. Estados Unidos: Dune Entertainment

Radiohead. (2 de Junio del 2017). Radiohead-I promise [archivo de video].

Recuperado de https://www.youtube.com/watch?v=0sFvFVkeGVg 
ANEXOS 


\section{Anexo 1: Guión literario Valeria}

"EP 1. VALERIA"

\section{Escrito por: Ana Paula Pareja}

\section{INTERIOR. COMBI. DÍA}

Una moneda de 20 centavos sale del un bolsillo de pantalón de un cobrador de combi. La moneda pasa de las manos de este a las de VALERIA. VALERIA juguetea con la moneda en las manos.

\section{ENTRA TÍTULO}

1. INTERIOR. COMBI. DÍA

El audífono toca al oído de VALERIA una canción de predominancia acústica y melodía suave (https://open.spotify.com/track/3HSLuKQ1gDWySVDXw2rDob) . Mira su teléfono. Levanta la mirada. Una silueta pasa para bajar de la combi y ella la sigue con la mirada hasta la altura de la puerta. La silueta baja y cuando VALERIA está apunto de apartar la mirada, la regresa y se queda mirando. Ve a un chico que está oyendo música también. El muchacho levanta la cabeza y cruzan miradas, se sonríen mutuamente. El audífono del muchacho toca a su oído una canción de ritmo vivaz que enuncia "no me despiertes si te vas"

(https://open.spotify.com/track/3Vc3qeR0IOMJDu2MXs8o3s a partir del minuto 1:56). Se oyen las dos músicas en paralelo, superponiéndose una a la otra mientras ambos siguen cruzando miradas.

2. INTERIOR. COMBI. DÍA

Oímos el caos de las dos músicas sonando en paralelo mientras los chicos, sentados uno al lado del otro y con un audífono puesto y el otro no, parecen discutir. Ella parece reclamarle mientras él es indiferente y relajado. 
3. INTERIOR. COMBI. DÍA

El audífono toca al oído de VALERIA la misma canción que oía el muchacho. Al principio está desganada y fastidiada pero de a pocos parece ir tomándole gusto al ritmo. Levanta la mirada y ve a otro muchacho en el mismo lugar que el anterior. Cruzan miradas y sonríen. Ella es más desenvuelta y pícara esta vez. El audífono del muchacho toca a su oído un metal/ rock duro (canción por definir). Se oyen las dos músicas en paralelo, superponiéndose una a la otra mientras ambos siguen cruzando miradas.

4. INTERIOR. COMBI. DÍA

Oímos el caos de las dos músicas sonando en paralelo mientras los chicos, sentados uno al lado del otro y con un audífono puesto y el otro no, discuten. Es una discusión más ferviente que la anterior. A él se le nota claramente irritable y ella tratando de calmarlo

5. INTERIOR. COMBI. DÍA

El audífono toca al oído de VALERIA la misma canción que oía el muchacho anterior. Se le ve irritable. Hace contacto con un muchacho nuevo. Él le sonríe. El audífono del muchacho toca a su oído una música de carácter vivaz (https://open.spotify.com/track/6KGsabR7dxAVp0Llomz0Jz desde el seg $00: 15$ )

6. INTERIOR. COMBI. DÍA

Oímos el caos de las dos músicas superpuestas mientras los chicos, sentados uno al lado del otro, discuten fervientemente. Ella está claramente irritada.

7. INTERIOR. COMBI. DÍA

El audífono toca al oído de VALERIA la misma canción del chico anterior. Cansada, la cambia y empieza a escuchar la canción que oía en la primera escena. Levanta la mirada y encuentra a otro chico en el asiento de los chicos anteriores. Cruzan miradas, ella está desconfiada. Él sonrié. El audífono toca al oído del muchacho la misma canción que VALERIA está oyendo. Sin embargo, VALERIA, agotada, le aparta la mirada. Ante esto, él también baja la mirada. Se oyen las dos fuentes de música tocando en sincronía perfecta mientras vemos a los dos chicos sin mirarse. 


\section{Anexo 2: Guión literario Macarena}

"EP. 2 MACARENA"

Escrito por: Ana Paula Pareja

0. INT. COMBI. DÍA

VALERIA entrega al cobrador su moneda y este se dirige hacia el fondo del vehículo donde le entrega a MACARENA su cambio. Vemos como la moneda de 20 centavos cambia de las manos de él a las de ella. Vemos como la moneda de 20 centavos pasa a entrar al bolsillo de MACARENA.

ENTRA TÍTULO

1. INT. CUARTO. DÍA

MACARENA se despierta y abre los ojos, recostada de lado en su almohada. Permanece así unos segundos, pensativa. Gira el cuerpo a un lado y descubrimos a su lado echado a FRANCO que aún duerme, con el cuerpo recostado hacia el otro lado. El chico se acomoda un poco en la cama, mostrando que no está dormido del todo.

$$
\begin{array}{r}
\text { MACARENA } \\
\text { ¿Sabes qué me jode? }
\end{array}
$$

FRANCO emite un sonido gutural de desgano, como quien sigue medio dormido y no quiere hablar realmente

MACARENA

Cuando te levantas extrañando algo que sabes que era una mierda pero, por

alguna razón lo extrañas

FRANCO no contesta por un rato.

FRANCO

(medio dormido)

A mí me jode el café cortado

INSERTO: Vemos brevemente un chorro de leche vertiéndose en una taza de café 
MACARENA respira frustrada

MACARENA

(con frugalidad, como quien se rinde a la conversación banal)

Me joden los empaques de galleta

INSERTO: Vemos la mano de MACARENA entrando al bolsillo de un saco y suena el plástico dentro

FRANCO ya está más despierto y con el cuerpo boca arriba tal como MACARENA

\section{FRANCO \\ (desperezándose)}

Me jode el sonido de mierda de los

cubos de colores

INSERTO: Vemos un giro de un cubo Rubix

MACARENA

Me jode cuando los vidrios se empañan

INSERTO: MACARENA pasa la mano sobre un espejo de baño empañado y lo despeja al nivel de su mirada

\section{FRANCO}

Me jode el aceite quemado

INSERTO: Vemos un sándwich sofriéndose en una sartén

MACARENA

Me jode el olor a pucho en la almohada

Mientras MACARENA dice esta línea, vemos a FRANCO

fumando. La mira y ella lo mira enojada. Él apaga el pucho en el velador amargado

FRANCO

Me jode el aceite quemado

INSERTO: vemos el sándwich sofriéndose en la sartén. Vemos desde el pasillo detrás del marco de la puerta de la cocina a MACARENA frente a la sartén. La silueta del FRANCO pasa por delante

Los muchachos por fin se miran de frente echados en la cama y se sostienen la mirada

MACARENA

Me jode cuando los vidrios se empañan 
Inserto: MACARENA limpia un espejo de baño empañado al nivel de su mirada, limpia con una pasada más con su mano y pasa FRANCO recién duchado detrás

FRANCO

Me joden los cubos de colores

INSERTO: El cubo gira y acaba perfectamente terminado. Es de noche, vemos los ojos de MACARENA. Vemos los ojos de Franco despiertos

MACARENA

Me joden los empaques de galleta

INSERTO: Vemos la mano de MACARENA entrar a un saco y se oyen los empaques dentro. El plano se abre y la vemos caminando por una acera con FRANCO y su mano dentro del blazer de él. La saca incómoda y empieza a caminar más lejos

FRANCO

(encendiendo de nuevo su cigarro)

Me jode el café cortado

INSERTO: Vemos un chorro de leche vertiéndose en una taza de café. La taza es colocada por MACARENA frente a FRANCO. Ella se siente al frente. Él le sonrie con hipocresía, ella le sonríe con hipocresía de regreso.

MACARENA

(EN OFF)

¿Sabes qué me jode?, cuando te levantas extrañando algo que sabes que era una mierda pero, por alguna razón lo extrañas

Mientras suena este diálogo, vemos los ojos de la chica despertando como al inicio. Gira el torso en la cama al igual que al comienzo pero al lado no hay nadie. Se queda mirando la cama vacía.

INSERTO: Macarena desayuna con su taza de café sola. La silla de en frente ahora está vacía

INSERTO: Macarena mira a través del espejo sin empañar el espacio vacío detrás donde antes estaba Franco INSERTO: Macarena camina sola por el parque, mete su mano al bolsillo. No suena. Saca la moneda de veinte centavos, le da vueltas y se le cae. No la recoge 


\section{Anexo 3: Sinopsis de episodios de la temporada 1}

\section{Valeria (Episodio 1)}

Valeria (21) reproduce en su teléfono su canción favorita. Una melodía de predominancia acústica y ritmo suave. La música fluye por sus audífonos, se compenetra con el ritmo. Cuando levanta la mirada, observa a un muchacho atractivo justo al frente. El chico se percata y, luego de un corto juego de miradas, hacen contacto visual y se sonríen. Como espectadores, pasamos al punto de vista del muchacho y oímos a través de sus audífonos que él escucha una canción diferente y con un tono mucho menos romántico y sensible. En una nueva escena, los vemos pelear mientras ambas músicas se superponen estruendosamente. La mecánica se repite con dos muchachos más, que oyen géneros distintos, hasta que, cuando ocurre con un cuarto muchacho que sí oye exactamente la misma canción que Valeria, esta está agotada de la situación y le aparta la mirada. Ambos chicos oyen la misma canción sin hacer contacto.

\section{Macarena (Episodio 2)}

Macarena (26) despierta pensativa al lado de Franco (30), quien aún duerme. Lo contempla unos segundos y le dice "sabes qué me jode, cuando te levantas extrañando algo que sabes que es una mierda pero por alguna razón lo extrañas". El muchacho, adormecido le contesta que él detesta el café con leche. En seguida, vemos un chorro de leche cayendo en una taza de café. Macarena le contesta que ella odia los empaques de galleta y vemos una. La dinámica prosigue con ellos contándose mutuamente aversiones aleatorias que vemos en pantalla hasta que Macarena le manifiesta su aversión hacia el olor a cigarro en la almohada mientras él fuma. Los jóvenes se repiten todos los diálogos que se han dicho pero, esta vez, vemos en los insertos de imágenes que realmente se referían a hábitos que odiaban uno del otro. Finalmente, volvemos a oír a Macarena decir "sabes qué me jode, cuando te levantas extrañando algo que sabes que es una mierda pero por alguna razón lo extrañas" y la vemos nuevamente despertando como al inicio, pero Franco no está al lado. 


\section{Javier (Episodio 3)}

Oímos una conversación entre amigos en la que dos le manifiestan a un tercero, al que llaman Javier, que siempre pensaron que él y su enamorada de la infancia y de toda la vida (Diana) terminarían casándose. En paralelo vemos a un muchacho preparándose para salir de su casa de playa. La conversación en off continúa y empieza a cuestionar a Javier sobre si es realmente una buena idea haber mantenido toda su vida una sola relación y no haber estado nunca con otra chica. Mientras tanto, el chico sale de su casa, claramente nervioso y pensativo, hasta que llega a la playa donde lo esperan sus amigos arreglados y con copas de champagne en un toldo decorado. Los saluda, aún angustiado mientras la conversación en off se vuelve más insistente. La novia llega y él la mira deslumbrado. En la plática en off, Javier manifiesta que nunca tuvo ninguna duda en el fondo, pues siempre tuvieron mucho sentido como pareja. El chico se arrodilla y la gente aplaude. En medio del final feliz, la cámara se aleja de la pareja y nos lleva hasta un muchacho distinto en el fondo, detrás de la pareja. El amigo a su lado, cuya voz corresponde a una de la que oímos en la conversación en off, le dice “Javier, ¿estás bien?”. Su otro amigo le manifiesta que él siempre pensó que serían Diana y él quienes terminarían casándose porque habían sido pareja desde niños, esta conversación se convierte en aquella que escuchamos en off con anterioridad en el relato. El Javier real mira acongojado a los prometidos.

\section{Alexia (Episodio 4)}

En el aula de clases, Alexia (15) observa de lejos al chico que le gusta. Empezamos a oír su voz en off diciendo "me gustaría que apreciases la habilidad de combinar dos medias distintas". Acto seguido, vemos sus pies y cómo ha combinado de dicha forma sus calcetines. La voz de la niña continúa relatando de la misma manera una serie de habilidades extravagantes y totalmente fuera de lo común como encajar a la perfección un rompecabezas pero poniendo todas las piezas en el lugar incorrecto (formando una figura ininteligible en vez de la imagen de la caja), crear un repertorio de nuevas especies mutantes con galletitas de animales, tocar el piano sin presionar ninguna tecla sino usando la espalda del instrumento para hacer percusiones con cucharas, traducir al alfabeto occidental el código de la literatura china escribiendo al revés, etc. Mientras, las vemos representadas en pantalla. El relato concluye cuando volvemos al salón de clases y el niño 
al que miraba se le acerca, le entrega una nota y se va. Ella la lee y en el papel encontramos escrito todo el texto que oímos en la voz en off. La voz en off termina de leer la última oración que dice "pero si tú no puedes apreciar todas esas cosas en ti misma, nadie más lo puede hacer por ti”. Alexia se mira al espejo consternada.

\section{Andrés (Episodio 5)}

En medio del co-working, Andrés mira de lejos hacia el escritorio de Felipe. Oímos su voz mental preguntándose “¿Qué habría pasado si la computadora se hubiera pagado 10 minutos después?". Vemos un inserto de la instalación vacía por la noche mientras la computadora de Andrés se apaga. Cuando este se está yendo por fin, se choca con Felipe. Volvemos al presente y Andrés voltea la mirada antes que Felipe se de cuenta. Felipe lo mira de lejos, pero Andrés ya está mirando la computadora. La voz mental de Felipe realiza un comentario similar al de Andrés y vemos otra posibilidad de encuentro casual. El día avanza y mientras ambos muchachos cumplen su rutina y van a sus casas la dinámica de los insertos de escenas continúan mostrándonos escenarios en los que esta relación habría avanzado de encuentro a encuentro. Al llegar a sus hogares parecen estar arreglándose con desgano para atender a un evento al que no quieren acudir. Finalmente, cuando Andrés está terminando de arreglarse suena su timbre y mientras se acerca a la puerta oímos las voces de ambos chicos intercaldas diciendo "Si tan solo/ alguna de esas cosas...". Andrés abre la puerta y quién está allí es Felipe, ambas voces terminan diciendo juntas ...NO hubieran pasado". Los chicos se sonríen con incomodidad. "de repente no estaría enfrascado con este huevón”.

\section{Renzo (Episodio 6)}

Este episodio transcurre con la narración del protagonista hablando en un inicio sobre cómo lo divertido de las relaciones es que solo llegas a conocer partes de la persona con la que estás, mientras vemos sólo partes de su rostro o sus manos en la imagen y también encuadres de otras personas, lugares o situaciones pero siempre recortadas (propuesta que se aplicará a todo el episodio hasta el final). Explica cómo tú conoces solo una fracción de la historia de esa persona, aquella que ves en el tiempo que están juntos y viceversa. Como el tránsito de una moneda de veinte centavos, que pasa contigo un tiempo pero no sabes ni de dónde viene ni a dónde vendrá. Hasta el momento, esta narración es 
textualmente exactamente la misma que se escuchó en el trailer inicial de la serie antes de que comience, vemos en uno de los encuadres fragmentados un scroll rápido por la sección de sugerencias de YouTube por donde pasa brevemente este trailer. Al igual que en el trailer, la voz del muchacho se cuestiona si podemos llamar a este tránsito de la moneda hasta tus manos casualidad o teleología. A partir de aquí, la narración se extiende más allá de lo que nos mostraba el trailer. El muchacho explica que él preferiría pensar que es casualidad porque así se le haría más fácil tomar decisiones amorosas sin pensar que se juega el destino en ellas. Así es como termina relatándonos el conflicto que está sufriendo al no poder decidir entre dos chicas con las que está saliendo a la vez. Él se mofa de que para esa circunstancia su filosofía de que en una relación solo concoces "partes" de la persona es sumamente conveniente. Cuando su reflexión acaba y termina eligiendo a una, acabamos descubriendo que ella también estaba saliendo con dos muchachos, y que no terminó eligiendo a nuestro protagonista sino a otro. El protagonista afirma que esto es justo y ha ocurrido justamente porque ella sólo conocía partes de él mientras él, al mismo tiempo, solo conocía una parte de ella. El chico, fastidiado y decepcionado, se va a un bar, donde vuelve a cuestionarse el dilema de la coincidencia o el destino y termina optando por lo primero con amargura. En paralelo, cuando trata de pagar la cuenta, se le cae la moneda de 20 centavos del bolsillo y, cuando la recoge, una mano femenina ya la está recogiendo. Por primera vez en el episodio, vemos un cuadro completo y no recortado, es un general en que vemos a Renzo y a quien recogía la moneda, es Valeria, la protagonista de la primera historia. Los chicos se miran. Oímos la voz de Renzo reiterar que no existe amor sino que es pura casualidad y concluye "porque, al final, todo lo que conoces de la historia de la otra persona es una parte, sabiendo eso ¿qué podría salir mal?” 
Anexo 4: Storyboard para episodio Valeria
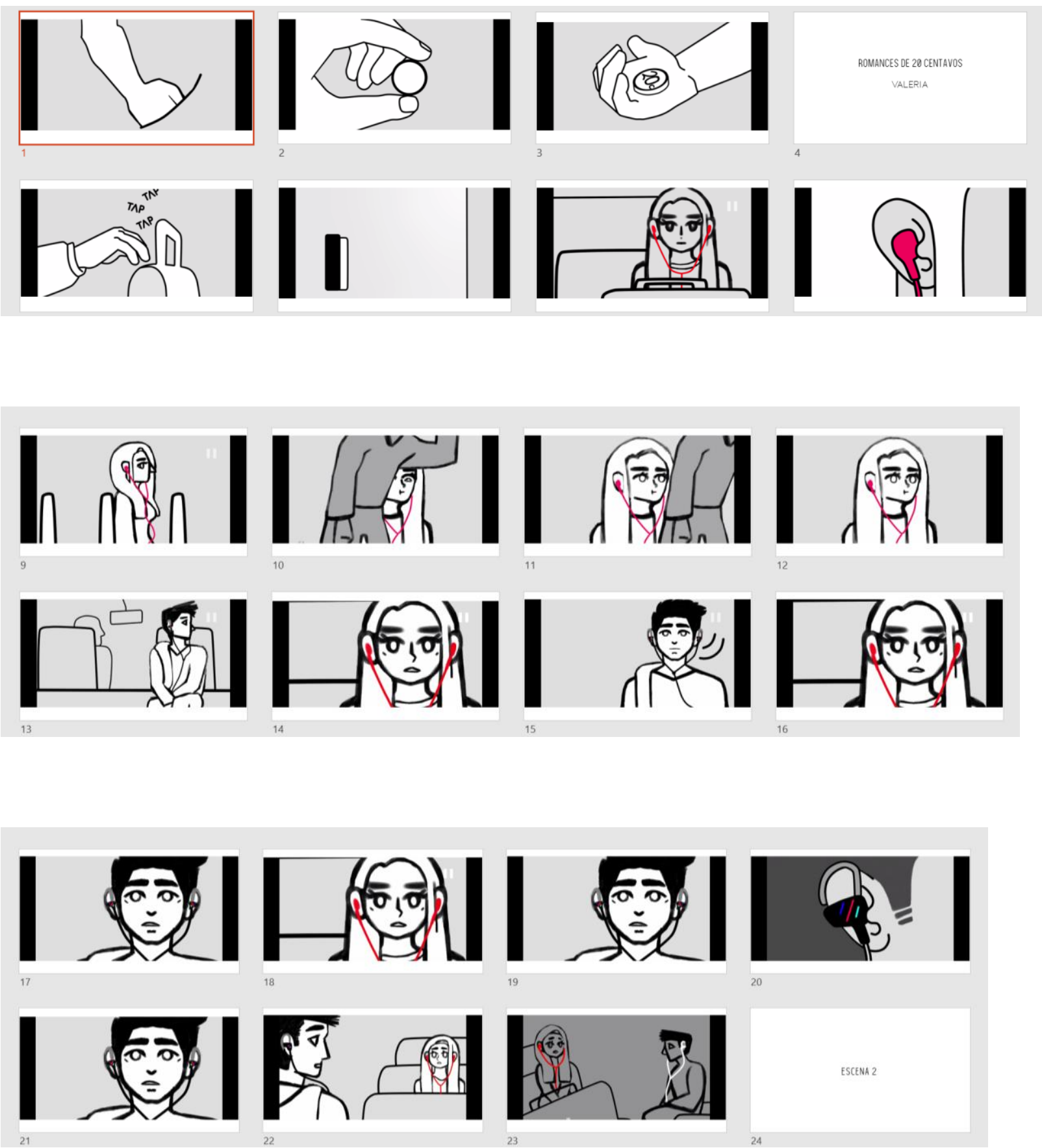

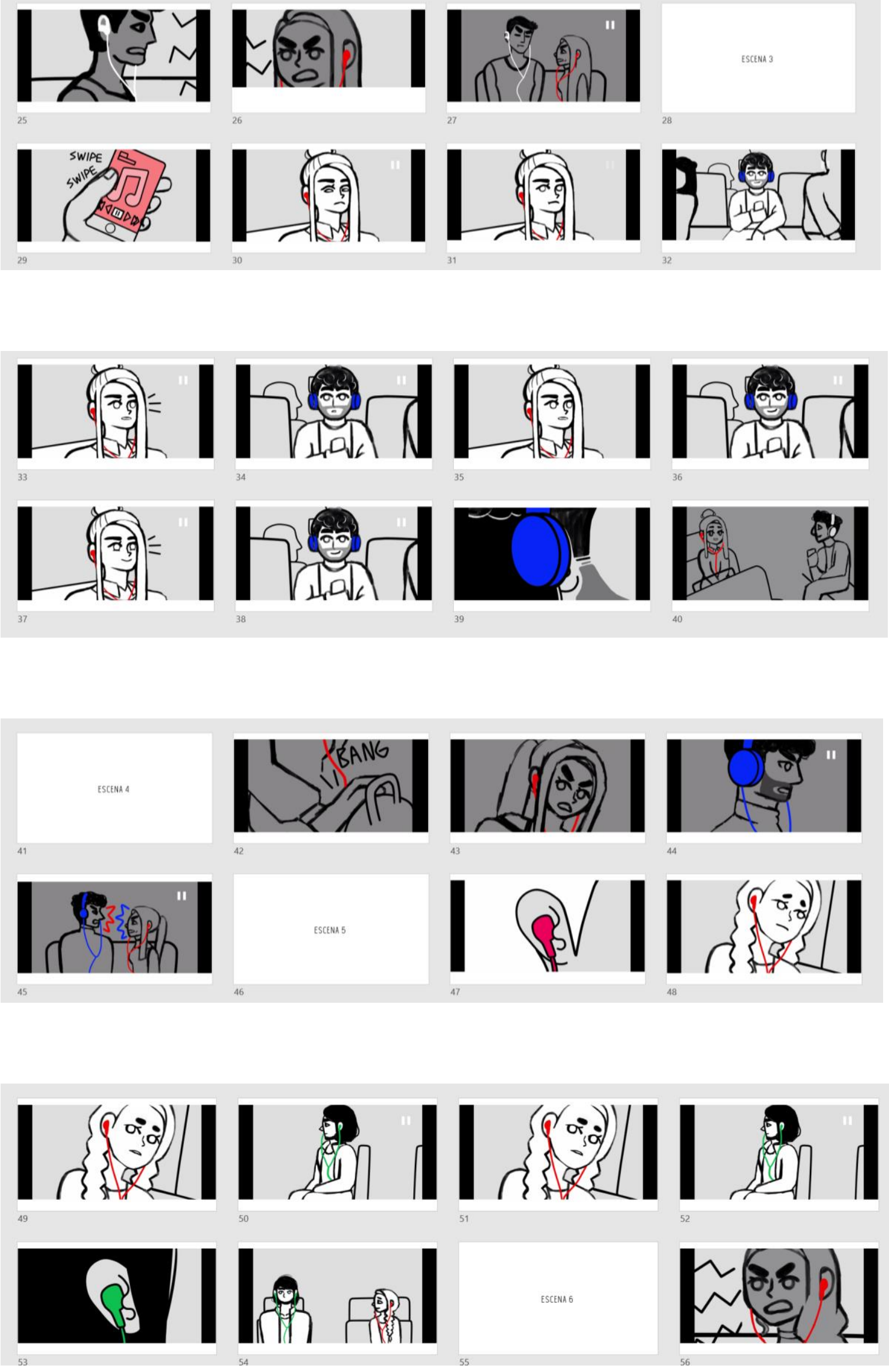

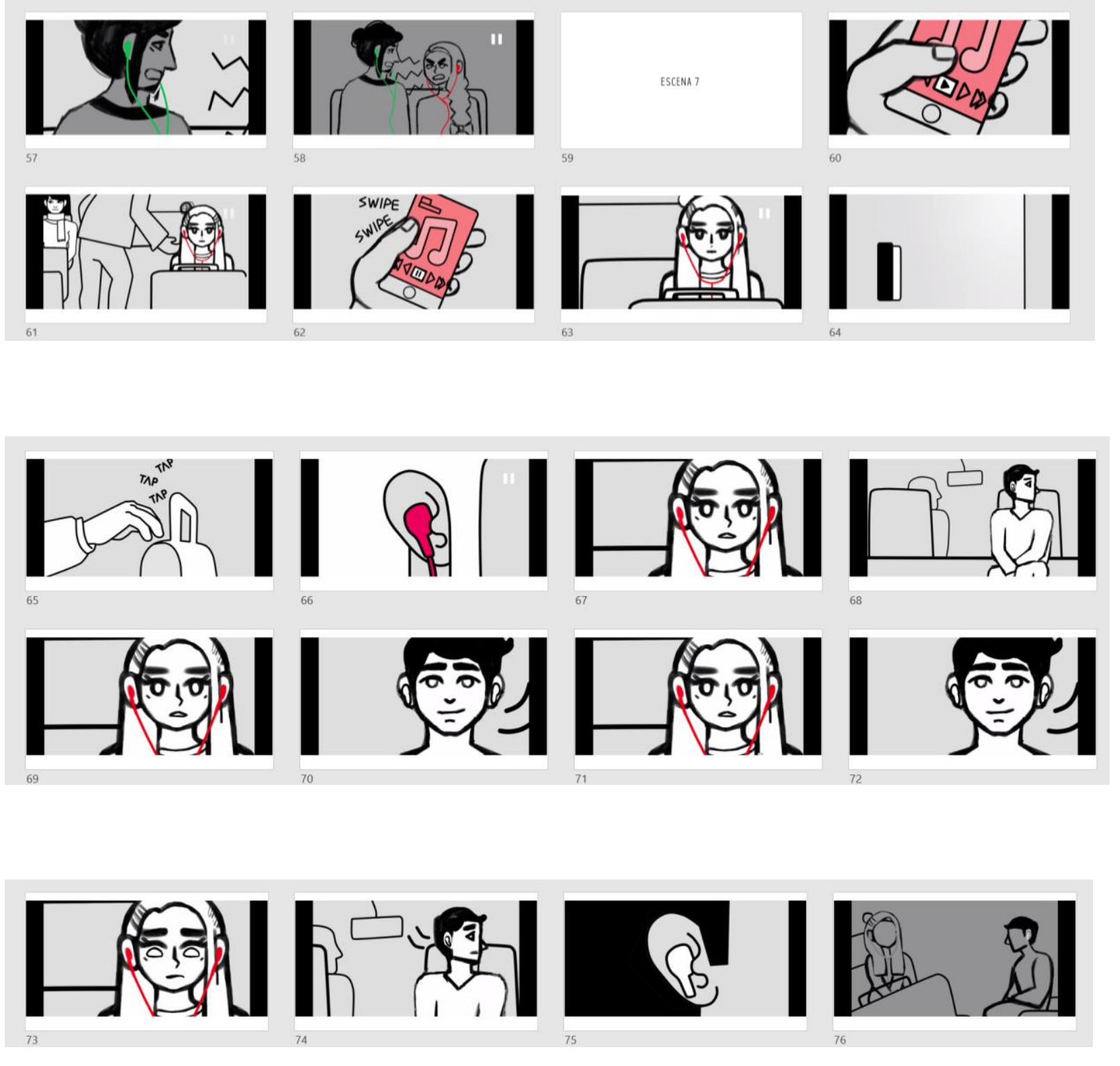
Anexo 5: Storyboard para episodio Valeria
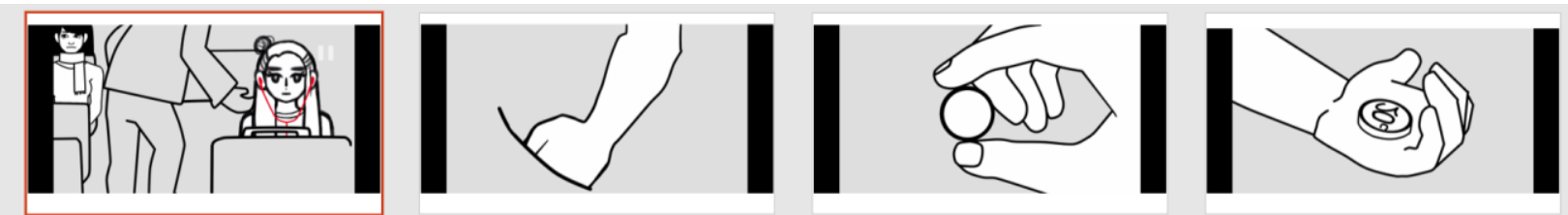

ROMANCES DE 20 CENTAVOS
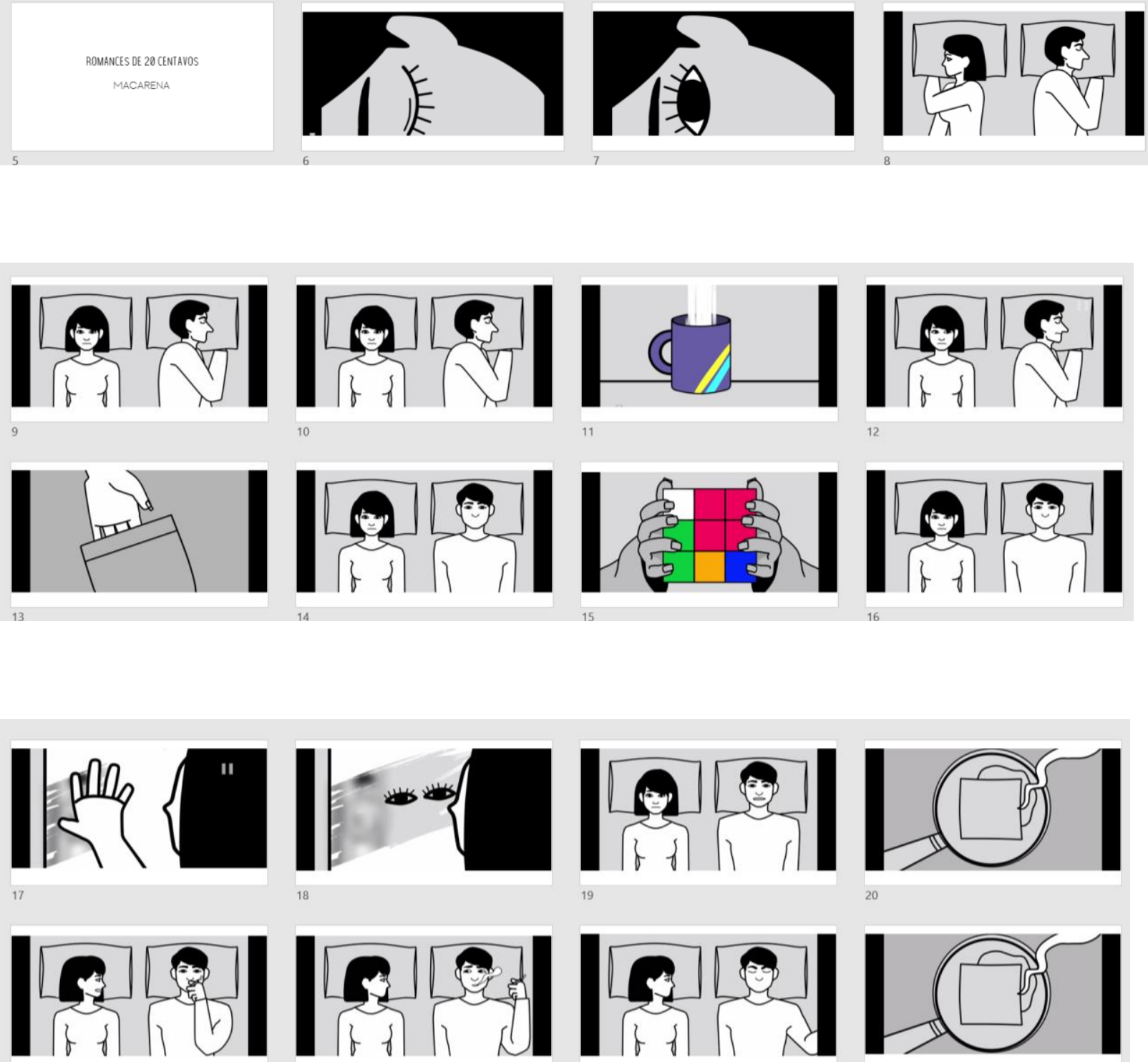

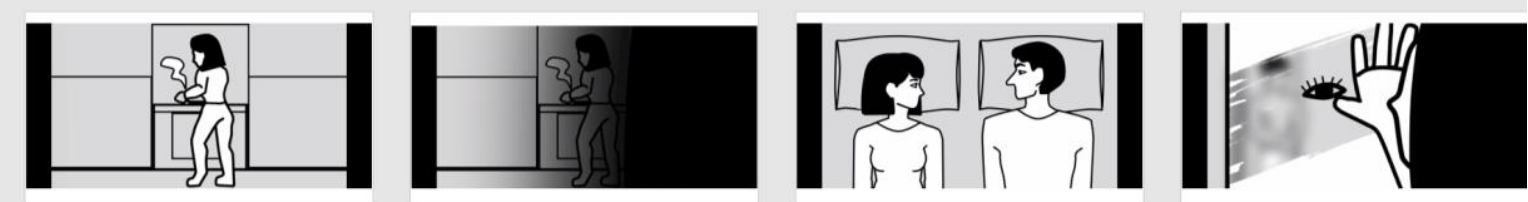

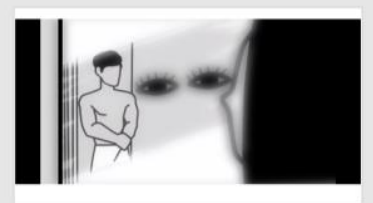
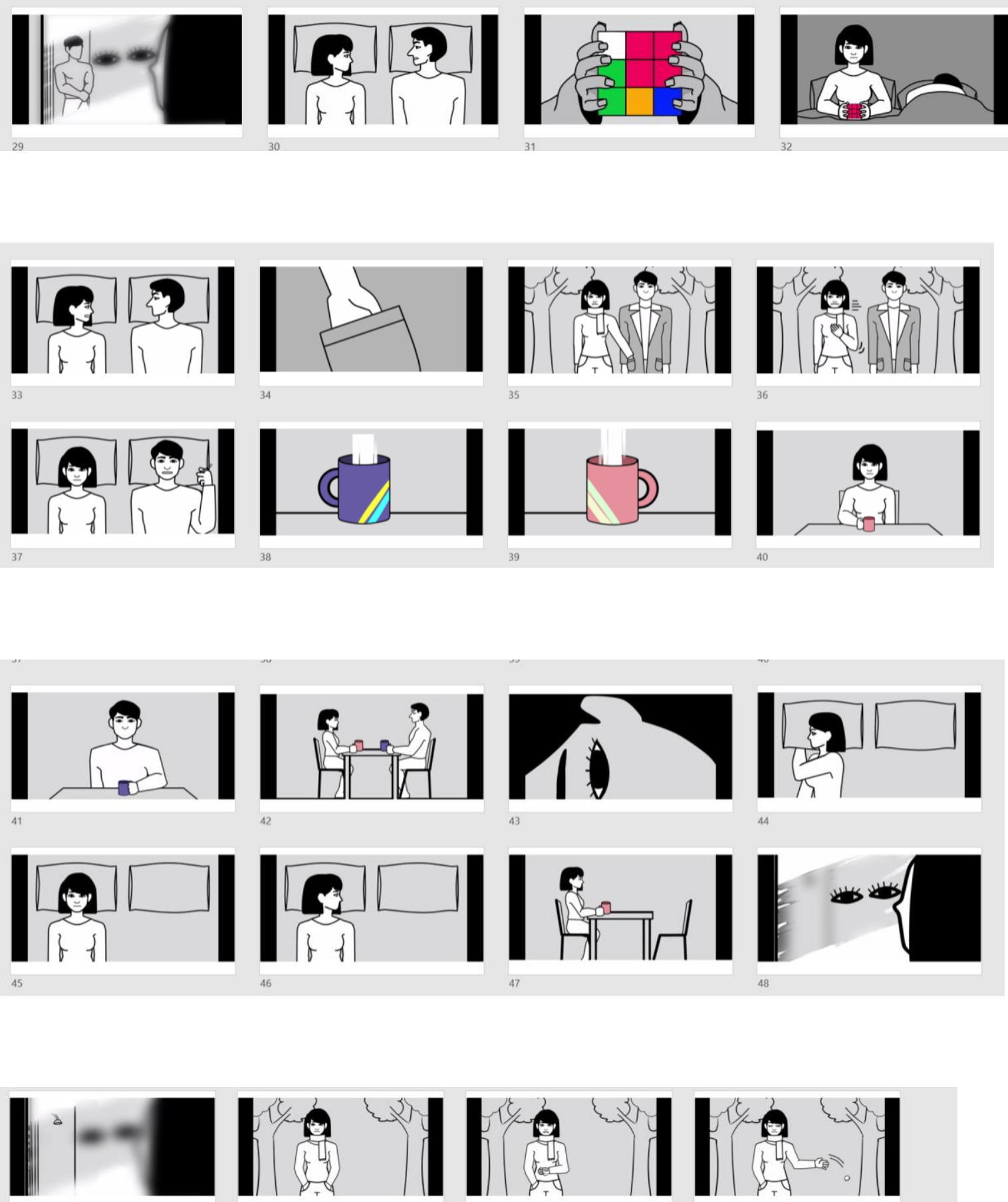

(8) 


\section{Anexo 6: Guía de discusión para Focus Group \\ GUÍA DE INDAGACIÓN PARA FOCUS GROUPS}

Presentación

- Agradecimiento de su participación

- Presentación del Moderador

- Presentar objetivo de la reunión:

Conocer las opiniones e impresiones de los sujetos conforme al proyecto "Romances de 20 centavos" y sus usos y hábitos en el consumo de ficción en el entorno digitañ

- Notificar que para evitar pérdida de información de sus comentarios, se procederá a la grabación.

- Notificar la confidencialidad del estudio.

- Describir las características generales de la dinámica:

- Duración del encuentro.

- Carácter anónimo de las opiniones vertidas.

- Dejar claro que se espera que se hable de sus opiniones y que no vamos a discutir experiencias personales.

- Dejar claro que nos interesa hacer una conversación grupal y que cada uno de ellos expresen libremente sus ideas y opiniones (que no hay buenas o malas ideas o respuestas a las cosas que vamos a discutir).

- Dejar claro que si bien no esperamos que se pida permiso para hablar, si esperamos que cada uno escuche al otro y espere que el compañero termine de hablar para expresar su opinión.

- Consultar si hubieran preguntas al respecto.

- Solicitar una presentación breve de cada uno de los participantes:

Antes de comenzar me gustaría saber un poquito sobre cada uno. Podrían presentarse y decir unas pocas palabras sobre ustedes: su edad, qué estudian/ a qué se dedican, etc.

\section{ACERCA DE LOS HÁBITOS EN EL ENTORNO DIGITAL}

1. ¿Cuáles son las plataformas que más utilizas diariamente en internet?

2. ¿Qué tipos de contenidos audiovisuales consumes en internet (videos, tutoriales, etc.) 
II. ACERCA DEL CONSUMO DE NARRATIVAS EN EL ENTORNO DIGITAL

3. ¿Qué contenidos de internet consumes que impliquen una historia?

4. ¿En qué plataformas prefieres consumirlos?

III. ACERCA DEL CONSUMO DE NARRATIVAS CORTAS EN EL ENTORNO DIGITAL

5. ¿Haz consumido alguno de los siguientes contenidos en internet: creepypastas, Threads o hilos, sketches de comedia, etc.

6. Se trata de historias de corta duración, ¿consideras que esta característica influye en tu motivación para verlas?

7. Alguna vez, antes de ver un contenido muy largo o serializado, ¿sientes pereza y prefieres no consumirlo?

8. ¿Qué series web o de streaming conoces que se caractericen por su corta duración? ¿Son de tu agrado? ¿Qué opinas sobre su brevedad?

\section{PRESENTACIÓN DEL PRODUCTO Y VALIDACIÓN}

9. ¿Qué les parecieron los episodios?

10. ¿Sintieron que se engancharon con la historia? ¿Qué fue lo que más les atrajo de ellos?

11. ¿Les parecieron relatos breves de duración? ¿esto fue de su agrado?

12. ¿Si llegasen a su feed de redes sociales como Instagram, Facebook o Youtube, los consumirían?

13. ¿En qué plataformas preferirían consumirlos?

14. ¿Qué recomendaciones podrían realizar acerca del producto?

v. DUDAS PUNTUALES SOBRE LA REALIZACIÓN

15. Respecto al segundo episodio, ¿qué opinan sobre la música/ausencia de música?

16. Qué opinan respecto al ingrediente de la moneda, ¿sintieron su presencia?

17. El concepto de la moneda en la serie, ¿les parece atractivo o relevante? 


\section{Anexo 7: Transcripción de sesiones de Focus Group}

\section{Primera Sesión}

Moderador: Antes de comenzar, quiero agradecerles su participación en este focus group. Mi nombre es Natalia y voy a moderar esta dinámica hoy. El objetivo de lo que conversaremos es, en una primera etapa a modo de introducción, conocer un poco sobre su consumo de ficciones en internet. Luego pasaremos a ver dos episodios de una nueva serie web y conversaremos respecto a ellos para saber sus opiniones. Como probablemente se han dado cuenta, estamos siendo grabados, pero todos los comentarios y resultados de esta plática serán usados con fines académicos y privados. La sesión durará de 30 a 40 minutos, los resultados son anónimos, no hablaremos sobre asuntos personales o privados. Buscamos que cada uno de ustedes pueda dar a conocer su opinión libremente y que todos puedan participar. No es necesario levantar la mano o pedir permiso para hablar, pero sí mantener un ambiente de respeto, esperar a que nuestros compañeros terminen de hablar y no interrumpirlos, etc. ¿Alguna pregunta antes de comenzar?

Moderador: Perfecto, para comenzar me gustaría saber sus nombres y apellidos y qué estudian o en qué trabajan en el caso de que trabajen. Podemos comenzar por aquí...

Participante\#1: Hola, ¿qué tal? Yo soy Rubén Samanez, tengo 19 años y estudio Ingeniería Industrial.

Participante \#2: Hola, mi nombre es María Fernanda Montoya y tengo 22 años. Estudio Marketing en la Universidad de Lima.

Participante \#3: Yo soy Brunella Noriega, tengo 23 años y estudio también Marketing en la Universidad de Lima.

Participante \#4: Mi nombre es Alexis Mego. Estudio Negocios Internacionales y tengo 22 años.

Participante \#5: Mi nombre es Andrea Robles y estudio psicología en la UPC. Tengo 23 años

Participante \#6: Hola, yo soy Rodrigo Tuesta. Tengo 23 años y estudio Marketing en la Usil.

Moderador: Gracias. Para comenzar me gustaría saber qué plataformas usan más en internet en el día a día.

Participante \#1: Yo utilizo más que nada Facebook e Instagram.

Participante \#2: Yo utilizo Instagram, no sé si Whatsapp cuenta. También utilizo YouTube para ver videos.

Participante \#3: Instagram, Facebook. 
Participante \#4: Facebook, Instagram, YouTube.

Participante \#5: Yo uso Facebook e Instagram.

Participante \#6: También Facebook e Instagram.

Moderador: Ok, ahora me gustaría saber qué videos consumen en internet, ¿de qué tipo son? Por ejemplo: tutoriales, videos cómicos, etc.

Participante \#1: Yo veo videos de peleas de artes marciales porque practico esto. También veo videos de comedia cortitos a veces en Facebook, tutoriales no mucho.

Participante \#2: Yo veo esos videos que te salen en Facebook o Instagram de "hacks" (trucos de manualidades para solucionar problemas cotidianos). También veo a veces sketches cómicos o videos motivacionales que me aparecen.

Participante \#3: Yo también veo bastantes videos de hacks, tutoriales de comida, stories de Instagram, también los videos de comedia o de animales (los demás participantes murmullan y se ríen señalandi que ellos también ven ese tipo de contenidos).

Participante \#4: Yo, la verdad veo todo lo que aparece en mi news feed y suele ser bien variado e incluir la mayoría de las cosas que han dicho

Participante \#5: Yo veo videos cortos en general. Tutoriales a veces.

Participante \#6: Yo veo bastantes videos de música, también tutoriales de guitarra.

Moderador: Muy bien, ahora hablemos sobre contenidos que tienen que ver con historias. Por ejemplo, creepypastas, hilos con historias. ¿Qué tipo de contenidos así suelen ver? Podemos quizá invertir el orden para variar un poco

Participante \#6: Mmm... yo he visto videos cómicos que tienen historias chicas, antes leía creepypastas pero ya no. A veces algunas publicaciones de historias

Participante \#5: Yo veo Netflix

Moderador: Por favor, me olvidé de mencionar esto. Hablemos de redes sociales más no de streaming. Es decir, no de Netflix, Hbo Go, etc.

Participante \#5: Ah, ok. Entonces creo que solamente en YouTube quizá haya visto algo así

Participante \#4: Yo he leído hilos de historias de celebridades, de casos policiacos, etc. También videos de comedia.

Participante \#3: Yo no sabría decir, aparte de lo que ya han dicho

Participantes \#2 y \#1: Yo igual

Moderador: Perfecto. ¿Alguna vez han visto una serie web?

Participante \#3: No en Netflix

Moderador: Sin contar con Netflix

Participantes: (Silencio) 
Moderador: Ok, al decidir si ven o no un contenido, ¿influye la duración de este? ¿Consideran que quizá nunca hayan visto una serie web

Participante \#2: Sí, yo creo que sí. Antes de ver un video miro la duración y si dura más de 10 minutos no lo veo. $\mathrm{O}$ a veces estoy viendo uno y me canso

Moderador: ¿Todos están deacuerdo con esa duración como aquella que los desmotiva a ver algo? ¿10 minutos aproximadamente?

\section{Participantes: Sí}

Participante \#5: Incluso menos, yo creo que no veo nada que pase de 5 o 3 minutos a menos que valga la pena

Participante\#4: Yo creo que depende del tipo de contenido

\section{Participantes: Sí}

Participante \#4: Y también de dónde porque, por ejemplo, en YouTube puedo ver videos de 10 o de 15 minutos pero en Facebook o Instagram mucho más cortos

Moderador: Buenísimo. Ahora pasaremos a ver la serie que les comenté. Veremos dos episodios y después conversaremos un poco de ambos.

(Proyección de ambos videos)

Moderador: Perfecto, cuéntenme un poco sobre qué les pareció

Participante \#1: A mi me gustó. Me gustó sobretodo el primer episodio, me gustó mucho el uso de la música. El segundo me gustó también pero no tanto, quizá no le sentí tanto el feeling como al primero

Participante \#2: A mí también me gustaron los dos pero también más el primero. Quizá porque el segundo era más como una pelea y me irritaba que si se odiaban tanto quería que terminaran. En el primero me gustó mucho el mensaje del final, me dejó pensando bastante

Participante \#3: Yo opino igual que ellos, me gustó mucho. Vería más episodios y me quedé con ganas de saber qué sigue, quién se topara con esta moneda. Y me gustó también mucho que siento que es algo que podría ver y consumir en distintas plataformas. Podría verlo en YouTube como serie pero también es algo que mis amigos o mi mamá podrían pasarme por Whatsapp y que también vería.

Participante \#4: Yo igual, me gustó bastante. Creo que vería más episodios y también me gustó más el primero por los juegos con la música. Me gustaron bastante las actuaciones.

Participante \#5: A mi también me gustó. A mi me gustó más el segundo. Le sentí mucha más adrenalina a esta pelea de la pareja y me sentí identificada y también sentí la cólera de la chica. Esa es mi opinión, es lo que me gustó más a mi. Y el final me dejó más atónita. 
Participante \#6: A mi también me gustó, me pareció una idea buena. Siendo honesto, yo no vería más episodios pero es porque yo no veo en general series. No me gusta. Pero creo que es algo personal.

Moderador: Gracias, me gustaría saber cómo percibieron la duración ¿les pareció muy largo? ¿es algo que consumirían en redes?

\section{Participantes: No}

Participante \#4: Yo creo que estaba bien, no era demasiado largo. Yo lo vería si lo encontrara en mi feed

Moderador: ¿Todos de acuerdo? ¿Quizá en el primero les pareció un poco largo algún momento?

\section{Participantes: No}

Moderador: Perfecto, ahora me gustaría saber si lo compartirían y en qué plataformas esperarían verlo. Excluyendo una vez más las cadenas de streaming

Participante \#1: Facebook o Instagram

Participante\# 2: También Facebook e Instagram

Participante \#3: Facebook e Instagram, pero Instagram en el feed, no las stories. Y también Youtube

Participante \#4: Facebook, Instagram y YouTube

Participante \#5: Facebook y YouTube

Participante \#6: Yo no lo vería por lo que comenté antes.

Moderador: Perfecto, chicos. Por último, me gustaría saber si les quedó claro el tránsito de la moneda o la figura de la moneda en general

Participante \#3: Me pareció un poco confuso, pero más por el hecho de que en el segundo episodio la perdí un poco de vista

Participante \#4: A mi también pero más por el hecho de que no comprendí que rol tenía dentro de la historia o la serie en general. Pero me imagino que es algo que quizá comprenda al ver los demás episodios. Quizá al final la moneda une a dos personajes o algo así.

Participante \#6: Claro, creo que es quizá intrigante más que confuso

Moderador: Pero, la moneda en sí ¿les parece un elemento atractivo o irrelevante?

Participantes: Sí, atractivo

Participante \#3: Siento que es atractivo, pero no imprescindible. O sea, funciona con él como sin él pero sí me llama la atención

Participante \#4: Sí, estoy de cauerdo con eso

Moderador: Perfecto, chicos. Muchas gracias por participar. 


\section{Segunda sesión}

Moderador: Antes de comenzar, quiero agradecer por su participación en este focus group. Yo soy Natalia. En una primera etapa introductoria, vamos a buscar conocer un poco sobre su consumo de ficciones en internet. Luego pasaremos a ver dos episodios de una nueva serie web y conversaremos para saber sus opiniones. La sesión está siendo grabada pero todos los comentarios y resultados de esta plática serán usados con fines académicos y privados. La sesión durará de 30 a 40 minutos, los resultados son anónimos, no hablaremos sobre asuntos personales o privados. Buscamos que cada uno de ustedes pueda dar a conocer su opinión libremente y que todos puedan participar. Es importante mantener un ambiente de respeto, por lo cual hay que esperar a que cada quien termine de hablar y no interrumpirlos, etc. ¿Alguna pregunta?

Moderador: Perfecto, para comenzar me gustaría saber sus nombres y apellidos y qué estudian o a qué se dedican en el caso de que trabajen.

Participante\#1: Yo soy Gabriella Villasis y tengo 22 años. Estudio Marketing

Participante \#2: Hola, Isabella y tengo 21. Estudio Ingeniería Industrial

Participante \#3: Yo soy Christian Castro, tengo 18 años y estudiaré Ingeniería Industrial porque ahora estoy en Estudios Generales

Participante \#4: Yo me llamo Renato Sandoval, tengo 19 y estudio Negocios

Participante \#5: Mi nombre es Daniel Trujillo. Tengo 23 años y soy de Ingeniería Industrial

Participante \#6: Hola, yo soy Janice Pérez, también de Ingeniería Industrial y tengo 21 años.

Participante \#7: Yo me llamo Alejandra Ponce y tengo 21 años. También estudio Ingeniería Industrial

Moderador: Gracias. Para comenzar, quisiera saber qué plataformas usan más en internet en el día a día

Participante \#1: Facebook, Instagram, Whatsapp, YouTube

Participante \#2: Instagram, Facebook, Whatsapp, Snapchat

Participante \#3: Facebook, Instagram t Whatsapp

Participante \#4: YouTube, Facebook, Instagram y Whatsapp

Participante \#5: Facebook, Whatsapp e Instagram

Participante \#6: Facebook, Instagram, Whatsapp, YouTube

Moderador: Perfecto, ahora me gustaría saber qué tipo de videos ven en esas redes sociales. Sin contar con plataformas de Streaming como Netflix 
Participante \#1: Yo veo videos graciosos que me aparecen, o también algunos que son de cosas útiles. También me gustan esos videos de "10 cosas que no sabías"

Participantes: Sí, yo también

Participante \#2: Yo también veo esos videos de "10 cosas que no sabías", videos de bromas y cosas por el estilo

Participante \#3: También veo esos videos, tutoriales o videos de comida en general

Participante \#4: Más o menos lo mismo que los chicos han mencionado

Participante \#5: Igual

Participante \#6: Yo veo esos videos. Los de "10 cosas que no sabías" me gustan bastante. También videos de curiosidades en general, de ciencia, historia, etc.

Participante \#7: También videos graciosos, tutoriales, etc.

Moderador: Perfecto, ¿y respecto a contenidos de ficción? Que contengan una historia

Participante \#1: Yo veo bastantes animes

Participantes: Yo también

Moderador: ¿Varios ven animes? Levanten la mano quienes sí, por favor (4 levantan la mano). Perfecto. Y, ¿otro tipo de contenido de ficción?

Participante \#4: Videos de comedia, ¿puede ser? Los que mencionamos antes

Moderador: Sí. Perfecto quisiera saber en qué plataformas los consumen y cuánto duran más o menos los videos de este tipo que suelen consumir.

Participante \#5: Yo creo que menos de 5 minutos

Participante \#3: Sí, yo también creo que más o menos eso

Participante \#2: Depende, ¿no? Porque si es un ánime como hablábamos antes puede durar más pero si es un video de Facebook efectivamente cinco minutos es suficiente

\section{Participantes: Sí}

Moderador: Perfecto, ahora vamos a ver los episodios que les comenté en un inicio.

(comienza la proyección)

Moderador: Perfecto, ahora cuéntenme un poco qué les pareció

Participante \#1: El segundo episodio me pareció increíble. El primero me pareció un poco largo por momentos. Como el inicial cuando los chicos se miraban y llegaba un momento en que era incómodo porque no se hablaban. Y en determinado momento me llegó a aburrir porque ya sabía cuál era la dinámica cuando escuchaba que eran canciones distintas. El segundo me pareció genial, no le cambiaría nada. La pelea me enganchó bastante y el final me dejó sorprendido

Participante \#3: Sí, a mi también me gustó bastante. Sobre todo el segundo. En el primero creo que, por ejemplo, cuando llegamos al penúltimo chico podría ser una escena 
mucho más rápida porque ya se entendió la mecánica y sabemos qué va a pasar. Que sea solo un instante como explicando "hubo un tercer chico" pero sin hacerle hincapié.

Participante \#6: Claro, a mí me gustaron también los dos episodios, pero me gustó más el segundo. Siento que lo viví más

Moderador: Cuéntenme como sintieron la duración, ¿lo verían en redes o es muy largo?

Participantes: Sí lo veríamos

Moderador: Y ahora, por favor, cuéntenme en qué redes buscarían o esperarían ver un contenido así

Participante \#1: YouTube, Facebook o Instagram

Participante \#2: YouTube, Facebook o Instagram

Participante \#3: Facebook o Instagram

Participante \#4: YouTube, Facebook o Instagram

Participante \#5: YouTube, Facebook

Participante \#6: YouTube, Facebook

Participante \#7: YouTube, Facebook o Instagram

Moderador: Perfecto. ¡Muchísimas gracias a todos! 


\section{Anexo 8: Transcripción de los resultados de la primera exhibición de los productos}

Moderador: Bueno, ahora en base a lo que hemos visto podemos empezar a comentar apreciaciones u opiniones que deseen compartir. ¿Alguien que desee comenzar?

Participante \#1: Bueno, a mi me gustó bastante. Sobre todo el primer episodio, en lo personal, porque me gustó el juego con la música y sentí que esta misma le daba un “feeling” especial y fue el episodio que más me dejó pensando

Moderador: Gracias

Participante \#2: A mi también me gustó bastante ese episodio. También el otro pero sentí que conecté más con ese y me gustó bastante el mensaje que dejaba la final

Moderador: Gracias, quizá alguien tenga una opinión distinta sobre ese episodio.

Participante \#3: A mi en lo particular no me agradó tanto, quizá porque yo soy músico entonces me pareció un tanto desordenado. Me confundía un poco y recién lo comprendí cuando llegué al final. En cambio, el segundo episodio me pareció genial, la idea de esta chica que de tanto quejarse de todo al final termina extrañando eso.

Moderador: Gracias.

Participante \#4: A mi no me pareció desordenado. Si bien en un principio no entendía bien qué pasaba también creo que entendía que esa era un poco la idea, que me preguntara qué estaba pasando hasta armar todo el sentido hasta el final

Moderador: Gracias, ¿alguien más que desee hacer algún comentario?

Participante \#4: A mí me gusta bastante, ambos episodios. Creo que ambos logran su objetivo de dejarte con un sentimiento bastante fuerte. El primero te impresiona bastante con ese final que es super triste y te deja un tanto frustrado cuando no se miran pero sabes que son perfectos para el otro pero ya ella ya se cansó. Igual con el segundo episodio, con esa relación donde todo estaba mal pero por alguna razón se extrañan. Y me gusta porque ambas cosas son super orgánicas, se sienten bastante ciertas, bastante humanas. Y en ese sentido, me gustaría seguir viendo esta serie de desamor.

Moderador: Gracias 
Participante \#5: Yo quería comentar que me parece una propuesta bien interesante pero sobre todo me parece importante en el sentido en el que se trata de un producto de final de carrera porque busca probar cosas nuevas, explorar formas nuevas de contar una historia que no son las convencionales. En el primer episodio usa la música, en el segundo esta serie de repeticiones de imágenes y de textos. Usa recursos creativos, ingeniosos y me deja con la intriga de saber qué recurso se aprovechará en los siguientes episodios, cómo se hará para seguir en esta línea innovadora que no es tan tradicional.

Moderador: Gracias

Participante \#6: Yo también quería hacer un comentario que es que creo que algo que hasta ahora no se ha mencionado es que ambos episodios tienen en común estos finales super fuertes, que son inesperados y te dejan reflexionando sobre los temas que tocan. Son finales muy circulares, que te cogen por sorpresa.

Moderador: Gracias 


\section{Anexo 9: Transcripción de los resultados de la segunda exhibición de los productos}

Directora: Bueno, ahora les pediríamos sus preguntas comentarios, apreciaciones o consultas

Participante \#1: Hola, la dirección de arte en el vestuario y peinados estaba muy cuidada en la combi, ¿estaba pensada así por algún motivo?

Directora: Sí, lo pensamos mucho con el director de arte. Usamos como referentes distintas subculturas para mostrar el tránsito del personaje en el viaje amoroso que realiza. Así el director de arte trabajó con muchísimo detalle en trabajar sobre referentes. De hecho, fue impresionante la semejanza que logró entre los referentes que tuvo y los looks finales que se hicieron para las escenas.

Participante \#2: Pero la idea de lo limpio, el que no haya arrugas, ¿esa estética prolija tiene un subtexto?

Directora: Claro, es que se trata de una estética que no busca aproximarse a un código realista o naturalista sino más bien al código de género juvenil. En general ese género suele ser así, vemos adolescentes prolijos con un aspecto perfectamente cuidado.

Participante \#3: Yo quería preguntarte sobre tus motivaciones. Ya que es una antología de desamor, es una forma particular de retratar el desamor, no es la clásica pelea o discusión de pareja regular, por así decirlo. Sino es algo más abstracto y hasta casi surrealista por momentos. Me gustaría saber qué te llevó a ti a llegar a esas dos ideas

Directora: Claro. Realmente yo quería contar historias pequeñas y cotidianas identificables para todo el mundo pero contarlas de una manera distinta utilizando distintos recursos que permitan aprovechar su corta duración o hacer la narrativa efectiva en esa corta duración.

Participante \#4: ¿Por qué optaste por no tener ningún texto? Así es más difícil aún mantener la atención sin tener diálogos

Directora: Justo cuando tuve esa idea quise realizarla basada plenamente en la música. Me interesó primero la idea de que dos personas podrían estar escuchando la misma música al mismo tiempo y eso me condujo a la construcción del resto de la historia usando netamente la música como representación de esta "asincronía". 
Participante \#4: Otro comentario, más que desamor yo quizá definiría la temática como desilusión o cansarse de estar en determinada situación. Porque la primera chica buscó y buscó tanto que cuando finalmente encontró a la persona con la que sincronizaba musicalmente ya no tuvo ganas de relacionarse. Y la segunda también, estuvo en círculo en su relación en el que todo la fastidiaba.

Directora: Gracias, ¡es un comentario muy valioso!

Participante \#5: Yo quería decir que la música elegida para la protagonista del primer episodio tiene una letra que justo enuncia "si soy un puente, crúzame". Creo que la lección de esa canción para ella que constantemente intenta hace funcionar sus relaciones y no lo consigue creo que va muy bien y justamente la letra calzaba con los momentos adecuados. Quería saber cómo elegiste esa canción

Directora: Claro, para comenzar toda la música con la que se realizó ese episodio son canciones de amigos míos y sus bandas. Parte de la razón por la cuál quise contar esa historia es que quería jugar y mostrar la música increíble que hacen bastantes amigos míos. La canción que me comentas se llama Puente de André Urban y salió poco tiempo antes de que escribiese los episodios. Cuando la oí justo estaba en proceso de escritura y me pareció que era perfecta, que la letra y la melodía eran ideales para expresar lo que esta muchacha buscaba, su estado emocional y su manera de concebir una relación. Mi cerebro hizo "click” mientras la oía y terminé así de escribir el episodio. 